INSTITUTO DE PESQUISAS ENERGÉTICAS E NUCLEARES

Autarquia associada à Universidade de São Paulo

\title{
PROJETO E IMPLANTAÇÃO DE MELHORIAS NA BLINDAGEM BIOLÓGICA DA INSTALAÇÃO PARA ESTUDOS EM BCNT
}

GREGÓRIO SOARES DE SOUZA

Dissertação apresentada como parte dos requisitos para obtenção do Grau de Mestre em Ciências na Área de Tecnologia Nuclear- Reatores.

Orientador:

Prof. Dr. Paulo Rogério Pinto Coelho 
"Have no fear for atomic energy cause, none of them can stop the time" Robert Nesta Marley 
Dedico este trabalho ao meu pai Carlos Augusto e à minha mãe Paula Lusa com todo meu amor e carinho. 


\section{AGRADECIMENTOS}

Agradeço a Deus.

Agradeço aos meus pais e a minha família por sempre estarem do meu lado. Em especial, a minha avó Graça e avó Irene por serem exemplos de vida.

A vida de uma pessoa pode ser comparada a uma escalada em uma montanha qualquer. Existe o objetivo final e para se alcançar esses objetivos existem as etapas fundamentais. Agradeço ao professor Dr. Paulo Rogério por ter me ajudado nesta etapa da minha escalada sendo um orientador extraordinário. Valeu Paulo !

Agradeço aos prof. Dr. Paulo de Tarso Dalledone Siqueira e ao prof. Dr. Hélio Yoriyaz pelos muitos conselhos e por servirem de exemplos de profissionais competentes e éticos.

Agradeço ao IPEN e todos seus funcionários pelo suporte na realização deste trabalho. Em especial o Sr. Sabino da oficina, o Dr. Ulysses do reator IPEN-MB 01 e a equipe de radioproteção do reator IEA-R1.

Agradeço ao Tio Saulão e a minha tia Gina pelo apoio desde o primeiro ano da física.

Agradeço a Tia Xani por ser a tia mais peralta! E a tia De por ser a tia mais séria !

Agradeço a Mestra Kahn por já ser uma mestra. Valeu pelos conselhos e conversas.

Agradeço a Srta. Antunes por me tirar do sério e me acalmar ao mesmo tempo. Por ser uma pessoa incrível e inspiradora e por estar do lado não importa o que aconteça.

Agradeço ao Cesinha por ser o Cesinha e ao Dr. Thiago Barroso.

Agradeço ao Leitão e todos da toca do Leitão por fazer de um lugar simples um lugar fenomenal. Agradeço a Banda Carniça e os Abutres, Leo, Cone, Slow e Brunão vocês são os caras.

Agradeço aos colegas bolsistas do CEN, Douglas, Thiago, Pedrão, Pedro Japa, Rafael Muniz, Rafael Cabelo, Talita, Leo, Mireia, Ariane, Felipe Cintra, Felipe Massicano, Milena, Rodrigo, Vinicius, Giuliana, Tassio e a todos bolsistas que passaram pelo CEN durante esse trabalho.

E finalmente, agradeço a CNPQ pela bolsa durante o desenvolvimento do trabalho. 


\title{
PROJETO E IMPLANTAÇÃO DE MELHORIAS NA BLINDAGEM BIOLÓGICA DA INSTALAÇÃO PARA ESTUDOS EM BNCT
}

\author{
Gregório Soares de Souza
}

RESUMO

\begin{abstract}
A técnica de captura de nêutrons em Boro é uma técnica promissora de tratamento de câncer, ela usa do alto LET das partículas provenientes da reação ${ }^{10} \mathrm{~B}(n, \alpha)^{7} \mathrm{Li}$ para destruir as células cancerígenas. O desenvolvimento desta técnica começou em meados da década de $50 \mathrm{e}$ até hoje ela é alvo de estudos e pesquisas em diversos centros espalhados pelo mundo, no Brasil construiu-se uma instalação que tem como objetivo realizar pesquisas em BNCT, esta instalação está localizada junto ao canal de irradiação número três do reator nuclear de pesquisa IEA-R1 e possui uma blindagem biológica projetada para atender as normas de radioproteção. Esta blindagem biológica foi desenvolvida para permitir que se realizem experimentos com o reator ligado a potência máxima, fazendo com que não seja necessário ligar e desligar o reator para se irradiar amostras. Entretanto quando se abre o canal de irradiação o background do salão de experimentos do salão de experimentos aumenta e esta variação de background inviabiliza a realização das medidas do grupo de pesquisa em difração de nêutrons que utiliza o canal de irradiação número seis. Este trabalho tem como objetivo acrescentar melhorias na blindagem a fim de reduzir ao máximo essa variação de background fazendo com que seja possível realizar medidas na instalação de pesquisas em BNCT sem interferir nas medidas do grupo de pesquisa do canal de irradiação seis. Para isto, utilizou o código MCNP5, dosímetros termoluminescentes e detectores de ativação tipo folha para planejar melhorias na blindagem biológica. Calculou-se com o auxílio do código uma melhoria que consegue reduzir em média o fluxo térmico em $71,2 \pm$ $13 \%$ e verificou-se experimentalmente uma redução média de $70 \pm 9 \%$ na dose devido aos nêutrons térmicos.
\end{abstract}




\title{
IMPROVEMENTS AT THE BIOLOGICAL SHIELDING OF BNCT RESEARCH FACILITY IN THE IEA-R1 REACTOR
}

\author{
Gregório Soares de Souza
}

\begin{abstract}
The technique of neutron capture in boron is a promising technique in cancer treatment, it uses the high LET particles from the reaction $10 B(n, \alpha) 7$ Li to destroy cancer cells. The development of this technique began in the mid-'50s and even today it is the object of study and research in various centers around the world, Brazil has built a facility that aims to conduct research in BNCT, this facility is located next to irradiation channel number three at the research nuclear reactor IEA-R1 and has a biological shielding designed to meet the radiation protection standards. This biological shielding was developed to allow them to conduct experiments with the reactor at maximum power, so it is not necessary to turn on and off the reactor to irradiate samples. However, when the channel is opened for experiments the background radiation in the experiments salon increases and this background variation makes it impossible to perform measurements in a neutron diffraction research that utilizes the irradiation channel number six. This study aims to further improve the shielding in order to minimize the variation of background making it possible to perform the research facility in BNCT without interfering with the action of the research group of the irradiation channel number six. To reach this purpose, the code MCNP5, dosimeters and activation detectors were used to plan improvements in the biological shielding. It was calculated with the help of the code an improvement that can reduce the average heat flow in $71.2 \% \pm 13$ and verified experimentally a mean reduce of $70 \pm 9 \%$ in dose due to thermal neutrons.
\end{abstract}


LISTA DE FIGURAS ___ viii

LISTA DE TABELAS $\mathbf{x}$

1 - INTRODUÇÃO __ _ 1

1.1. - A Terapia por Captura de Nêutron em Boro

1.1.1. - A Reação $10 B(n, \alpha)^{7}$ Li da BNCT e sua radiobiologia____ 2

1.1.2. - Histórico da BNCT e status atual ___ 3

1.1.3. - Reatores Nucleares como fonte de nêutrons para a BNCT

1.1.4. - BNCT no Instituto de Pesquisas Energéticas e Nucleares (IPEN/CNEN-SP) e no Brasil ___ 6

1.2. - Justificativa das melhorias na blindagem biológica da instalação de BCNT _ 7

1.3. - Objetivos Gerais _ 9

1.3.1. - Objetivos Específicos — 10

2 - FUNDAMENTOS TEÓRICOS ___ 11

2.1.- Dosimetria e Radioproteção ___ 11

2.1.1. - Radioatividade _ 12

2.1.2. - Atividade 13

2.1.3. - Fluência e fluxo

2.1.4. - Fluência de Energia, Fluco de Energia e Espectro de Energia __ 15

2.1.5. - Kerma 17

2.1.6. - Dose absorvida e dose equivalente___ 19

2.2. - Radioproteção —_ 19

2.3.- Interação da radiação com a matéria ___ 20

2.3.1. - Fótons__ 21

2.3.1.1. - Espalhamento incoerente (Compton) __ 22

2.3.1.2. - Efeito Fotoelétrico __ 24

2.3.1.3. - Produção de pares — 25

2.3.1.4. - Atenuação de Fótons - Lei da atenuação exponencial ___ 25

2.4.- Neûtrons _ 26

2.4.1 - Nêutrons Térmicos _ 26

2.4.2 - Interações do nêutron com a matéria __ 27

2.4 .3 - Moderação de nêutrons__ 28

2.5. - Detectores de ativação tipo folha de Au__ 30 
2.6. - Dosímetros Termoluminescentes (TLD) 34

2.7.- O método Monte Carlo 36

2.7.1 - O código MCNP5 37

2.7.1.1. - Interações de nêutrons 38

2.7.1.2. - Interações de fótons 39

3 - MATERIAIS E MÉTODOS 40

3.1. - A instalação de pesquisa em BNCT e sua blindagem biológica 40

3.2. - Dosímetros termoluminescentes 42

3.2.1. - Dosimetria de nêutrons térmicos em campos mistos 43

3.2.2. - Dosimetria de radiação gama 45

3.2.3. - Leitura dos TLD's e tratamento térmico 45

3.3. - Detectores de ativação tipo folha de ouro 48

3.4. - Simulações com o MCNP5 49

3.5. - Materiais para blindagem de nêutrons 55

4 - RESULTADOS E DISCUSSÕES 57

4.1. - Blindagens Iniciais e IdentiFINDER 58

4.2. - Simulações das melhorias definitivas com o MCNP5 63

4.3. - Medidas experimentais utilizando TLD's e detectores de ativação tipo folha 96

5 - CONCLUSÕES E SUGESTÕES DE ATIVIDADES FUTURAS 74 


\section{1 - INTRODUÇÃO}

\section{1 - A Terapia por Captura de Nêutron em Boro}

Câncer é o nome dado a um conglomerado de mais de 100 doenças que possuem a característica básica de possuir células defeituosas (cancerosas) que crescem desordenadamente e invadem/espalham-se por tecidos e órgãos do corpo humano; quando este crescimento é acelerado e agressivo, o conjunto de células cancerosas é denominado neoplasia maligna (câncer maligno). Se esse conjunto de células cancerosas se multiplica devagar e é familiar ao tecido original, o câncer é denominado tumor benigno (INCA, 2010). Atualmente o câncer é uma das doenças que mais mata no mundo e sua incidência pode ser em diversos tipos de células com gravidades diferentes. Segundo o INCA (Instituto Nacional do Câncer) no Brasil em 2011 existirão 489.270 casos novos de câncer (Ministério da Saúde , 2009). Existem diversos tipos de tratamentos para esta doença tais como cirurgia, radioterapia e novas técnicas de tratamento estão em estudo pela comunidade científica.

Desde a descoberta dos raios-x por Wilhelm Conrad Roentgen em 1895 a comunidade científica tenta utilizar a física para propósitos medicinais. Muitas destas tentativas resultaram em técnicas de tratamento consagradas tais como a radioterapia e processos de obtenção de imagens para exames clínicos como a ressonância magnética e a tomografia computadorizada. A radioterapia utiliza feixes de elétrons e fótons para auxiliar médicos no tratamento de doenças como o câncer e estes feixes são bem consagrados na literatura e existem protocolos de tratamento específicos; isto não ocorre com os nêutrons. O possível uso dos nêutrons para auxiliar na medicina com fins terapêuticos foi proposto por Locher (Locher, 1936) poucos anos depois da descoberta do nêutron por Chadwick em 1932. Devido ao fato dos nêutrons interagirem apenas com o núcleo necessitou-se um avanço na área nuclear para que se pudessem entender melhor seus mecanismos de deposição de energia e interação com a matéria (Segre, 1980). À 
medida que a física nuclear avançava o papel do nêutron na medicina foi alvo de diversas pesquisas.

Uma das técnicas de tratamento de câncer em estudo que utiliza o nêutron é a terapia por captura de nêutron em boro, em inglês Boron Neutron Capture Therapy, comumente chamada pela comunidade científica de BNCT. Esta técnica foi proposta há 70 anos (Locker, 1936) e como qualquer outra técnica tem a preocupação de manter as células sadias e eliminar as células cancerosas e é nesse quesito que a BNCT é atraente por utilizar a reação ${ }^{10} \mathrm{~B}(\mathrm{n}, \alpha){ }^{7} \mathrm{Li}$ como fundamento. Esta reação por possuir alta seção de choque (3.838 barns) do ${ }^{10} \mathrm{~B}$ para captura de nêutrons térmicos $\left(E_{\text {máx }}<0,5 \mathrm{eV}\right.$ ) faz com que o nêutron seja muito absorvido e a emissão de partículas de curto de alcance destroem as células tumorais. A técnica é composta de dois procedimentos clínicos:

Primeira Etapa: Injetar no paciente um composto contendo ${ }^{10} \mathrm{~B}$ que seja preferencialmente absorvido pelas células cancerosas. O que se determina adequado para atingir o efeito de tratamento é $10^{9}$ átomos de ${ }^{10} \mathrm{~B}$ por célula cancerosa e 10 reações ${ }^{10} \mathrm{~B}(\mathrm{n}, \alpha)^{7}$ Li por célula (H.Soloway, Barth, Gahbauer, Blue, \& Goodman, 1997). O composto em si já é um campo de estudo da BNCT. Os compostos químicos BSH, sódio mercaptoundecahidro-cloro-dodecarbono - $\mathrm{Na}_{2} \mathrm{~B}_{12} \mathrm{H}_{11} \mathrm{SH}$ e BPA, boro-fenilanina conseguem atingir níveis de seletividade aceitáveis.

Segunda Etapa: Submeter a região tumoral do paciente a um feixe de nêutrons térmicos, porém estes nêutrons penetram poucos centímetros, caso seja necessário uma penetração maior utiliza-se feixes de nêutrons de energia epitérmica $(0,5 \mathrm{eV}-10 \mathrm{KeV})$ estes nêutrons são termalizados devido a espalhamentos com o material biológico do corpo do paciente provocando pouco efeito danoso e atingem uma profundidade maior com a energia na faixa térmica. Para efeitos de tratamento é necessária uma fluência de nêutrons térmicos de $10^{13} \mathrm{n} / \mathrm{cm}^{2}$ (Moss, et al., 1997) na região tumoral para que a irradiação tenha a duração em torno de uma hora completando o tratamento em dose única.

\subsection{1 - A Reação ${ }^{10} B(n, \alpha)^{7} L i$ da BNCT e sua radiobiologia}

A BNCT utiliza a reação ${ }^{10} \mathrm{~B}(\mathrm{n}, \alpha){ }^{7} \mathrm{Li}$ como principio de destruição das células cancerígenas através da deposição da energia liberada pelos produtos da reação. $\mathrm{O}^{7} \mathrm{Li}$ o 
${ }^{4} \mathrm{He}$ (partícula $\alpha$ ) são partículas pesadas e energéticas que depositam toda sua energia cinética nas dimensões de uma célula $(<10 \mu \mathrm{m})$ por possuírem um LET (Linear Energy Transfer) de $162 \mathrm{KeV} / \mu \mathrm{m}$ a $196 \mathrm{KeV} / \mu \mathrm{m}$ (H.Soloway, Barth, Gahbauer, Blue, \& Goodman, 1997). O esquema da reação é apresentado abaixo:

Em 6,3\% das reações a energia cinética $(2,79 \mathrm{MeV})$ das partículas ( $7 \mathrm{Li}$ e $\alpha)$ é transferida totalmente para a célula e em 93,7\% das reações a energia cinética transferida é um pouco menor (2,31 MeV) porque acompanha um raio gama de $478 \mathrm{KeV}$ da desexcitação do núcleo de ${ }^{7}$ Li. Nos dois casos estas partículas pesadas e energéticas quando colidem com o núcleo da célula cancerosa tornam a mesma inativa e esta pratica - que se chama de apoptosis (suicídio celular) (Coderre \& Morris, 1999), independentemente se a célula se encontra em mitose (processo de divisão celular) ou não.

A dose total dada na BNCT é um combinação complexa (Campos, 2000) composta de 4 componentes:

i. Dose devida aos nêutrons térmicos no nitrogênio do material biológico: ${ }^{14} \mathrm{~N}(\mathrm{n}, \mathrm{p}){ }^{14} \mathrm{C}$

ii. Dose devida ao Boro-10, reação fundamental da BNCT: ${ }^{10} \mathrm{~B}(\mathrm{n}, \alpha)^{7} \mathrm{Li}$;

iii. Dose devida aos nêutrons rápidos e epitérmicos sendo espalhados no material biológico: $\mathrm{H}\left(n, n^{\prime}\right) \mathrm{H} ; \mathrm{O}\left(n, n^{\prime}\right) \mathrm{O}$ e $\mathrm{C}\left(n, n^{\prime}\right) \mathrm{C}$

iv. Dose devida aos raios gama das interações dos nêutrons através de captura radioativa. Caso a fonte de nêutrons do tratamento seja um reator nuclear existe uma dose de raios gama que são provenientes do núcleo do reator. Estes itens exceto o ii são considerados contaminação no planejamento de um tratamento de BNCT e devem ser eliminados o máximo possível. 


\subsection{2 - Histórico da BCNT e status atual}

A história da BNCT começa em 1936, 4 anos após a descoberta do nêutron, quando o biofísico Gordon L. Locker propôs o principio da BNCT em um dos seus trabalhos publicados (Locker, 1936). Em 1951 W.H. Sweet estudou a concentração do composto químico BORAX em células de tumores (Slatkin, 1991).

Nesse contexto científico começaram estudos clínicos na década de 50 no Hospital Geral de Massachusetts e também no Laboratório Nacional de Brookhaven (BNL), utilizando o reator BGRR (Brookhaven Graphite Research Reactor) e o então recente reator BMRR (Brookhaven Medical Research Reactor) como fontes de nêutrons, para se tratar o glioblastoma multiforme (GBM), um tipo de câncer que ataca as células gliais ${ }^{1}$ que dão suporte aos neurônios do cérebro humano (Martinez \& Mould, 1990).

O GBM é considerado um tumor infiltrante e incontrolável aonde as técnicas de tratamento convencionais surtem pouco efeito; este fato tornou o GBM principal alvo de estudos em BNCT. Na época tratou-se 63 pacientes com diversos níveis de GBM, sendo 18 pacientes no Instituto Tecnológico de Massachusetts (MIT) que utilizou como fonte de nêutrons o reator MITR (Massachusetts Institute of Tecnology Reactor).

Apesar dos diversos estudos com compostos carregadores de boro estas dificuldades iniciais fez com que a BNCT fosse associada a uma redução de sobrevida porque infelizmente a radiobiologia da reação $\left.{ }^{10} \mathrm{~B}(\mathrm{n}, \alpha)\right)^{7} \mathrm{Li}$ e a biodistribuição do boro eram desconhecidos na época e o BORAX atingia a relação tumor:cérebro em um valor de 3 a 28 mas somente durante um curto intervalo de tempo (Sweet, 1997), ou seja, não se atingia uma seletividade suficiente no tumor no momento da irradiação e a alta concentração de ${ }^{10} \mathrm{~B}$ no sangue ocasionou a destruição do endotélio capilar que provocou inchaço e falha do sistema vascular no cérebro, essa concentração de ${ }^{10} \mathrm{~B}$ no sangue não podia ser medida durante o exato momento do tratamento porque ainda não existia uma técnica disponível (Slatkin, 1991). Nos tratamentos no BNL com feixe térmicos, pouco penetrantes, a dose na superfície da pele era alta provocando necrose em muitos pacientes.

Este insucesso da BNCT devido ao fato do composto não conseguir manter a relação da concentração de boro tumor/cérebro alta durante um intervalo de tempo suficiente e

\footnotetext{
${ }^{1}$ Células gliais: são células não neuronais do sistema nervoso central que proporcionam suporte e nutrição aos neurônios.
} 
o feixe de nêutrons não possuir a energia necessária para irradiações mais profundas fez com que testes clínicos no EUA se encerrassem em 1961, porém manteve-se um vasta pesquisa com novos compostos carregadores de ${ }^{10} \mathrm{~B}$ a fim de se manter a relação tumor:cérebro alta durante um intervalo de tempo suficiente para que fosse possível realizar o tratamento; neste grupo de pesquisa estava o professor Dr. Hiroshi Hatanaka que regressou do EUA e começou sua pesquisa com BNCT e GBM (Hatanaka, 1986) no Japão, utilizando como fonte de nêutrons o reator HTR (Hitachi Training Reactor), o reator KURR (Kyoto University Research Reactor) e o MulTR (Musashi Institute of Tecnology Reactor) este último utilizado depois do fechamento do reator HTR.

Hatanaka e seu grupo de pesquisa em colaboração com o grupo do BNL conseguiu sintetizar um novo composto carregador de ${ }^{10} \mathrm{~B}, \mathrm{o} \mathrm{Na}{ }_{2} \mathrm{~B}_{12} \mathrm{H}_{11} \mathrm{SH}$ (BSH) (Sweet, 1997) e seu método clinico diferenciou-se pelo fato de se realizar uma craniotomia antes da irradiação, os pacientes eram irradiados com nêutrons térmicos, às vezes, se utilizava uma bola de ping-pong para impedir que o leito do tumor se colapsasse e fechasse a cavidade do tumor.

A penetração dos nêutrons térmicos aumentava devido ao vazio da esfera e se espalhava com mais uniformidade pelo tecido (Sweet, 1997). A utilização de um composto carregador de ${ }^{10} \mathrm{~B}$ mais seletivo e essas novas técnicas clínicas obteve um sucesso relativo e a BNCT voltava a ser tornar promissora (Statkin, 1991). Por exemplo, alguns pacientes com GBM grau III/IV tratados no Japão por Hatanaka obtiveram uma sobrevida de 60\% após 5 anos, e após 10 anos uma taxa de sobrevida de 10\% (Ujeno, 1992), sendo que esta taxa de sobrevida após 10 anos para o tratamento com fótons é de $2 \%$.

O resultado do trabalho de Hatanaka repercutiu no mundo e em 1988, o New England Medical Center/Harvard junto com o MIT desenvolveu um programa em conjunto para novas pesquisas em BNCT (Zamenhof, Solares, \& Kiger III, 1997) utilizando o composto carregador de ${ }^{10} \mathrm{~B}$, a Borofenilalanina (BPA) um aminoácido contendo um átomo de boro e um feixe epitérmico de $0,5 \mathrm{eV}-20 \mathrm{keV}$. Os estudos se concentraram em melanomas e GBM e este novo composto carregador de boro atingiu uma concentração tumor-sangue de 3.5 a 4.0 (Slatkin, 1991). Estes avanços alcançados tanto no Japão com o professor Hatanaka quanto no trabalho em conjunto do New England Medical Center/Harvard e o MIT, fez com que o se recomeçasse os estudos em BNCT também no 
BNL com o uso de um feixe epitérmico em pacientes com GBM e melanomas em fase de metástase.

Nesse recomeço do MIT e BNL, mais de 60 pacientes foram tratados até 1999, e em paralelo a este recomeço nos EUA, ocorreu em Petten (Holanda) no HFR (High Flux Reactor) pesquisas em BNCT sob a supervisão da European Colaboration on BNCT (junção de 16 países europeus e mais de 40 centros de pesquisas) (Moss, et al., 1997), utilizando o composto BSH e feixes epitérmicos de nêutrons, sendo que alguns pacientes com GBM de grau avançado já foram tratados (Campos, 2000).

Em 1998, um grupo de pesquisa começou os estudos em BNCT na Finlândia, realizando tratamento com pacientes em diversos estados de GBM utilizando o composto BPA e feixes epitérmicos. Novos programas de BNCT na República Tcheca, Suécia, China e Argentina (International Atomic Energy Agency, 2001) utilizando o composto BPA e feixes epitérmicos estão em progresso e atualmente um tratamento para GBM utilizando BNCT já pode ser comercializado na Finlândia (Boneca Medical Company, 2010). Atualmente, a BNCT está mundialmente ampliada, no Japão novas instalações e novas técnicas (Fujii, Tanaka, Maruhashi, Ono, \& Sakurai, 2010) estão sendo planejadas para ampliar o programa de BNCT; na Itália pesquisadores estão desenvolvendo técnicas de dosimetria (Bortolussi, et al., 2010) e métodos de irradiação extracorpórea para tratar câncer de fígado utilizando BNCT.

\subsection{3 - Reatores Nucleares como fonte de nêutrons para a BNCT}

A BNCT necessita de um campo de nêutrons térmicos intenso para que um número maior de reações ${ }^{10} \mathrm{~B}(\mathrm{n}, \alpha)^{7} \mathrm{Li}$ aconteçam no interior da célula cancerosa e assim provocar sua destruição. O histórico da BNCT comprova que o uso de um feixe térmico não consegue penetrar muito e este é indicado para tratar lesões superficiais como o câncer de pele, já para tratar lesões mais profundas como a GBM, chegou-se a conclusão (Fairchild, 1989) que o mais indicado é a utilização de feixes epitérmicos porque este feixe se termaliza basicamente por espalhamentos elásticos com o hidrogênio do material orgânico. O objetivo para se desenvolver um feixe de nêutrons para a BNCT é proporcionar um campo de nêutrons térmicos máximo com a mínima contaminação 
possível de fótons e neutrons rápidos na região da lesão minimizando a dose em regiões sadias

Produzir o feixe ideal para realizar tratamentos ou pesquisas em BNCT não é uma tarefa fácil quando a fonte de nêutrons é um reator nuclear. Um feixe é considerado aceitável para tratamentos quando possui características em torno destes parâmetros (Moss, et al., 1997):

i. Fluxo epitérmico de aproximadamente $10^{9}$ nêutrons $/ \mathrm{cm}^{2} . s$.

ii. Energia dos nêutrons entre $1 \mathrm{eV}$ a $10 \mathrm{keV}$.

iii. Taxa máxima de dose devida a radiação gama em torno de $1 \mathrm{~Gy} / \mathrm{h}$.

iv. Taxa máxima de dose devida a nêutrons rápidos em torno de 0,5 Gy/h.

v. Razão entre corrente (J) e fluxo ( ) maior ou igual a 0,8 .

O último item serve como um medidor de direcionamento do feixe, sendo 0,5 para feixe totalmente isotrópico e 1 para feixe totalmente paralelo. Para se alcançar os parâmetros acima, o feixe de nêutrons que escapa do núcleo do reator deve sofrer algumas modificações.

Os componentes indesejados como a radiação gama e a parcela de nêutrons rápidos devem ser filtrados/atenuados, utilizando as características nucleares de certos materiais denominados filtros e moderadores. Através de uma série de interações com estes materiais o nêutron pode ter sua energia diminuída ou sua direção modificada através de espalhamentos elásticos ou inelásticos, pode ser capturado ou pode simplesmente fluir pelo material através de "janelas" de seções de choque características dos materiais para determinadas energias (Moss, et al., 1997). Existe uma variedade de materiais que diminuem a energia dos nêutrons, por exemplo: $\mathrm{Al}_{1} \mathrm{Al}_{2} \mathrm{O}_{3}, \mathrm{D} 2 \mathrm{O}, \mathrm{Fe}, \mathrm{BeO}, \mathrm{Ti}$ e $\mathrm{PbF}_{2}$, existem materiais que atenuam a radiação gama, estes costumam ser materiais pesados como $\mathrm{Bi}$ e $\mathrm{Pb}$; existem também materiais que eliminam nêutrons térmicos tais como ${ }^{10} \mathrm{~B}, \mathrm{Cd}$ e ${ }^{6} \mathrm{Li}$. Alcançar o feixe ideal é impossível, assim o que se faz é um balanço entre as características do feixe para se atingir o melhor possível tendo em vista o tipo de tratamento necessário e a quantidade de irradiações que serão feitas. O cálculo para se desenvolver o melhor conjunto de filtros e moderadores para cada situação é feito através de códigos computacionais que utilizam métodos estocásticos tais como o MCNP (Briesmeister, 2001) ou métodos determinísticos, por exemplo, o DOT 3.5 (Oak Ridge National Laboratory, 1975). 


\subsection{4 - BNCT no Instituto de Pesquisas Energéticas e Nucleares (IPEN/CNEN-SP) e no Brasil}

No Instituto de Pesquisas Energéticas e Nucleares (IPEN) pesquisadores do centro de engenharia nuclear (CEN) começaram um projeto na década de 90 para construir uma instalação para pesquisas em BNCT (Coelho, et al., 1996) utilizando o canal de irradiação número três do reator nuclear de pesquisa IEA-R1; o projeto foi sendo modificado visando atender os quesitos de segurança do IEA-R1 e limites de radioproteção, chegando a sua configuração final em 2003 quando foi construída a blindagem biológica ao redor do canal de irradiação e colocado o conjunto de filtros e moderadores no canal de irradiação. A instalação visa realizar pesquisas na área de BNCT possibilitando irradiações de amostra "in vivo" e "in vitro", estudos com simuladores antropomórficos (Muniz, Coelho, Silva, Siqueira, \& Souza, 2010), efeitos da radiação em DNA, desenvolvimento de novos dosímetros e irradiações em animais de pequeno porte já foram realizadas (Flores, Coelho, Muniz, Souza, Arruda-Neto, \& Maria, 2010) para se estudar a aplicação da BNCT no combate ao câncer de pele. Uma descrição mais detalhada da instalação é dada na seção 3 deste trabalho.

Em geral a BNCT é uma terapia cara por necessitar estar acoplada a uma fonte de nêutrons, partícula que só pode ser gerada através de reações nucleares, na maioria dos casos se utiliza reatores nucleares de pesquisa como fonte, mas existe também a possibilidade de se utilizar aceleradores, estes funcionam com o choque de prótons acelerados contra núcleos pesados através da reação $X(p, n) Y$ liberando nêutrons. Esta é uma alternativa mais barata do que a construção de um reator, por exemplo, porém o fluxo de nêutrons de forma geral costuma ser menor. E também há necessidade de materiais moderadores devido ao fato que a reação acima libera predominantemente nêutrons rápidos.

No Brasil a BNCT está ainda em fase inicial, porém este grupo de pesquisa do CEN e alguns pesquisadores do instituto de física da UNICAMP e do Instituto Butantã estão juntando forças para poder alavancar a técnica, tendo em vista o progresso da BNCT nos 
últimos anos. Já se estudou a possibilidade de se utilizar fontes de nêutrons $\left({ }^{241} \mathrm{AmBe} e\right.$ ${ }^{252} \mathrm{Cf}$ ) acopladas a técnica de BNCT, através de braquiterapia ${ }^{2}$ (Campos \& Andrade, 2000).

\section{2 - Justificativa das melhorias na blindagem biológica da instalação de BNCT}

O IEA-R1 é um reator nuclear de pesquisa do IPEN-CNEN/SP que em seus canais de irradiações realizam-se pesquisas na área de física nuclear, física das radiações e também em BNCT, além de servir para produção de radioisótopos em medicina nuclear. O IEA-R1 é um reator do tipo piscina e foi construído na década de 50 , sua potência máxima é de 5 $\mathrm{MW}$, porém atualmente a potência de operação é de 3,5 MW, na seção 3 deste trabalho o IEA-R1 é descrito de forma mais completa.

O salão de experimentos do reator fica no subsolo do prédio, no mesmo nível do núcleo que fica imerso perto do fundo da piscina com $9 \mathrm{~m}$ de profundidade. É neste salão que estão as saídas dos canais de irradiação do IEA-R1 e as instalações com os equipamentos dos grupos de pesquisa que utilizam o IEA-R1. Atualmente três canais estão sendo utilizados:

i. Canal de irradiação $n$ o 3: Instalação para pesquisa em BNCT

ii. Canal de irradiação n 6: Instalação para pesquisa em difração de nêutrons

iii. Canal de irradiação no 8: Instalação para pesquisa em neutrongrafia

Todos os canais de irradiação são tubos ocos feitos de alumínio que chegam à face do núcleo do IEA-R1 e no interior dos mesmos podem ser colocadas amostras para serem irradiadas, isto ocorre no caso da instalação para pesquisas em BNCT, nas demais instalações utiliza-se o feixe de nêutrons fora dos canais de irradiação. Um desenho esquemático da planta do IEA-R1 e do uso dos canais de irradiação pode ser visto na figura 1.1, no lado esquerdo da figura está um esquema geral do IEA-R1 e no lado direito estão os canais de irradiações com suas respectivas utilizações.

\footnotetext{
${ }^{2}$ Braquiterapia: É uma forma de radioterapia em que materiais radioativos são implantados nas proximidades do tumor.
} 


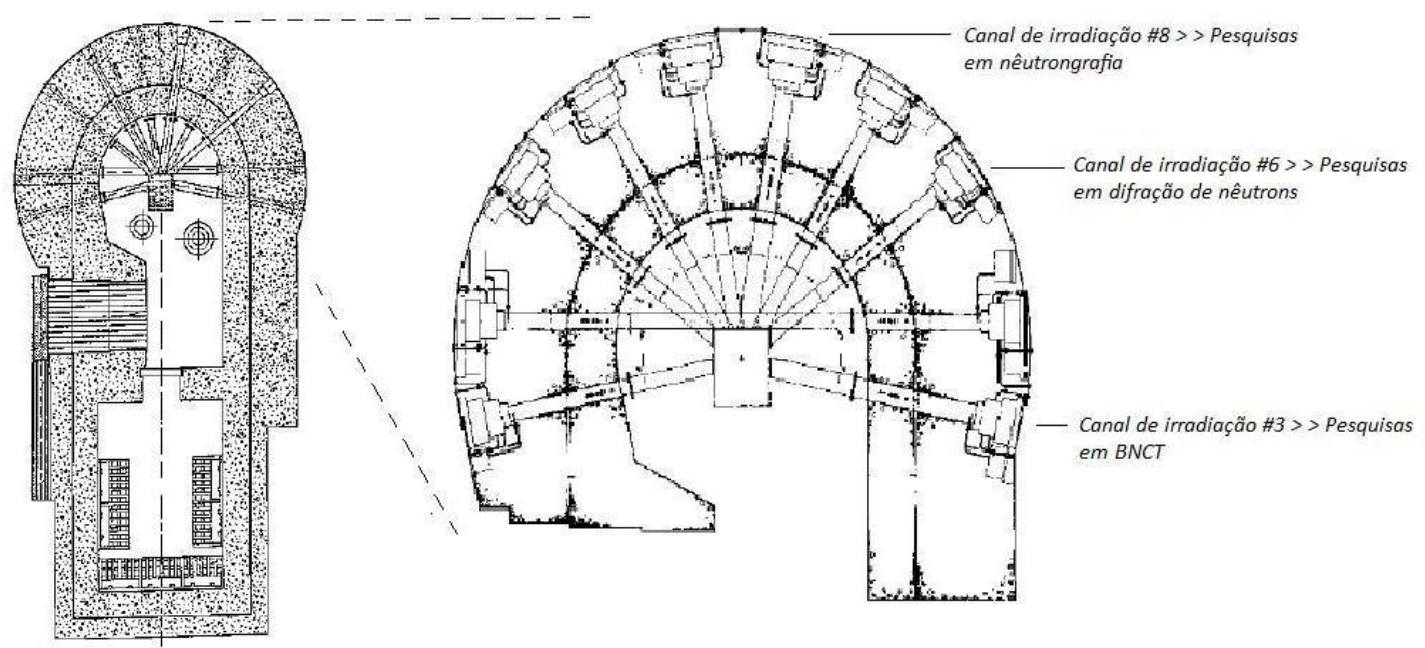

Figura 1: Desenho esquemático do IEA-R1 e seus canais de irradiação.

O IEA-R1 opera de segunda-feira a quarta-feira normalmente com a potência de 3,5 MW, e todos os grupos de pesquisa o utilizam durante esse período. Os grupos de pesquisa estão com suas operações dentro dos limites de radioproteção (Comissão Nacional de Energia Nuclear, 1988) e o salão de experimentos é monitorado constantemente pelo grupo de radioproteção do IEA-R1, inclusive a utilização de cada canal de irradiação deve ser notificada à equipe de radioproteção e à sala de controle do IEA-R1.

Devido ao fato do reator ser utilizado para pesquisa e também para produção de radioisótopos, desligá-lo para que se troquem amostras na instalação para pesquisas em BNCT e depois ligá-lo para irradiá-las, inviabilizaria o reator para alguns de seus outros fins. Portanto a instalação de pesquisas em BNCT foi desenvolvida para que fosse possível realizar trocas de amostras mesmo com o reator ligado a sua potência máxima de $5 \mathrm{MW}$.

Para que isso fosse possível a blindagem biológica da instalação deveria ser adequada para conter o feixe de nêutrons e gamas proveniente do núcleo do reator. Com o auxilio dos códigos DOT 3.5 e MCNP a blindagem biológica foi calculada (Silva, Coelho, \& Siqueira, 2002) para que a dose fora da BB ficasse dentro dos níveis de dose para trabalhadores ocupacionalmente expostos. A blindagem é constituída de parafina e concreto, somando mais de 35 toneladas de material. Uma descrição mais detalhada da blindagem biológica é dada na seção 3 deste trabalho. É de se esperar que ao abrir o canal de irradiação da instalação de BNCT para se realizar medidas, o nível de dose ao 
redor da BB aumente; este aumento de fato ocorre e é em nível de radiação de fundo (background) para nêutrons e para gamas.

As medidas realizadas pelo grupo de pesquisa em difração de nêutrons no canal de irradiação seis são sensíveis a esse aumento de background quando ela ocorre para nêutrons térmicos e essas medidas são feitas na forma de contagens em diversos ângulos e posições do feixe espalhado, necessitando assim tempo para se atingir um número suficiente de contagens que garanta uma incerteza baixa, isso é feito para cada ângulo ou posição diferente de medida e essa variação de background acaba aumentando essas contagens. Esse aumento nas contagens não pode ser discriminado no sistema de detecção, logo não é possível perceber quais contagens são devidas à medida de fato e quais contagens são devidas à interferência. Esse aumento nas contagens também ocorre quando o canal de irradiação número oito (pesquisas em nêutrongrafia) é utilizado. Melhorias específicas para nêutrons térmicos na BB da instalação para BNCT podem reduzir essa variação de background a um nível que talvez viabilize a realização simultânea das duas pesquisas.

\section{3 - Objetivos Gerais}

Atualmente o uso, na maioria dos casos, do canal de irradiação três é realizado na segunda feira através de um acordo com o grupo responsável pelo o uso do canal de irradiação seis. Esse acordo visa atender as necessidades de cada grupo e existe certa maleabilidade para que se possam atender as necessidades de cada grupo já que os experimentos realizados no canal de irradiação seis são de longa duração e a instalação para BNCT possui diversos usuários com necessidade de irradiações diferentes e normalmente de curta duração e como regime de operação do IEA-R1 é de aproximadamente 64 horas por semana, e isto faz com que o uso do reator seja concorrido.

O principal objetivo desse trabalho é aumentar o horário de uso da instalação para pesquisa em BNCT, através de adições de blindagens especificas para nêutrons térmicos, fazendo com que o aumento de background durante a troca de amostras atinja um nível que viabilize a realização de medidas simultâneas no canal de irradiação três e seis. 


\subsection{1 - Objetivos Específicos}

- Desenvolver um conjunto inicial de melhorias na blindagem para viabilizar o uso da instalação nos três dias de operação do reator IEA-R1.

- Familiarizar-se com os procedimentos experimentais que envolvem dosimetria e caracterização do feixe de nêutrons existentes no grupo de pesquisa; e desenvolver em conjunto com o grupo de pesquisa em BNCT uma metodologia de selecionamento de dosímetros termoluminescentes para nêutrons.

- Modelar a geometria da blindagem biológica da instalação de BNCT no MCNP com todas as melhorias de blindagem.

- Desenvolver com MCNP uma fonte de nêutrons que melhor caracterize o campo de nêutrons e gamas do canal de irradiação três.

- Instalar as melhorias na BB de forma definitiva. 


\section{2 - FUNDAMENTOS TEÓRICOS}

Nesta seção do trabalho são apresentados os conceitos físicos básicos envolvendo fótons e nêutrons utilizados neste trabalho, a teoria física da dosimetria termoluminescente e dos detectores por ativação e por último o método estatístico utilizados pelo código de transporte MCNP. Estes conceitos foram divididos em tópicos:

- Dosimetria das radiações e radioproteção.

- Interação da radiação com a matéria.

- Detectores tipo folha e dosímetros termoluminescentes.

- Método Monte Carlo (MMC).

\section{1- Dosimetria e Radioproteção}

A dosimetria das radiações tem seu início em 1895 junto com a descoberta do raio X por Roentgen, da radioatividade por Becquerel em 1896 e do elemento rádio pelo casal Curie em 1898, e em um curto intervalo de tempo estas descobertas já serviam como ferramentas uteis na medicina, tendo em vista que a primeira radiografia por raio-x é uma imagem da mão de Roentgen (Segre, 1980). O que se define por dosimetria é o conjunto dos estudos que envolvem as medidas da dose absorvida resultante das interações das radiações ionizantes e indiretamente ionizantes (Attix, 2004).

A ICRU (International Commission on Radiation Units and Measurements) determina que a radiação seja dividida em radiação diretamente ionizante e indiretamente ionizante (International Comission on Radiation Units and Measurements, 1971):

- Radiação diretamente ionizante: Partículas carregadas que depositam sua energia na matéria através de várias pequenas interações colombianas. 
- Radiação indiretamente ionizante: Partículas sem carga que depositam sua energia em partículas carregadas da matéria e estas por serem diretamente ionizante depositam a energia recebida. As interações da radiação indiretamente ionizante não são tão volumosas devido ao fato destas interagirem com o núcleo e com a eletrosfera podendo passar sua energia total em apenas uma interação.

Os efeitos do depósito de energia da radiação podem ser de diversos tipos o que se costuma fazer é estudar os efeitos ou subprodutos destas interações. Por exemplo, medindo a carga elétrica dos elétrons ou íons produzidos na ionização, a luminescência, a energia transferida ou absorvida, a alteração da condutividade, o calor produzido, o defeito cristalino ou alteração química que essas interações podem proporcionar. Com o auxílio de conceitos chamados de grandezas radiológicas consegue-se associar valores para caracterizar o campo de radiação e também à quantidade de radiação absorvida por um determinado material, esses conceitos servem para quantificar a radiação, seus efeitos e subprodutos.

Estes conceitos surgiram com a possibilidade das radiações serem utilizadas para fins terapêuticos e de diagnósticos, pois as radiações ionizantes podem induzir detrimentos à saúde humana, logo definir grandezas para medição e caracterização da radiação é necessário para que se obtenha o uso saudável e correto das radiações. Elaborar estes conceitos não é uma tarefa fácil porque os detectores de radiação, por exemplo, não possuem seus valores de resposta na mesma unidade das grandezas envolvidas e escolhidas. Ou seja, a resposta de um dosímetro termoluminescente, por exemplo, não pode ser diretamente associada a um efeito biológico, mas sim a uma quantidade de dose absorvida em determinado material sob determinadas condições (Knoll, 1979). A seguir um resumo dos conceitos envolvidos é esboçado.

\subsection{1 - Radioatividade}

Em 1896, o físico francês Antoine Henri Becquerel (1852-1908) constatou que sais de urânio emitiam radiações que eram capazes de produzir sombras de objetos metálicos sobre chapas fotográficas (Segre, 1980). Becquerel trabalhou com uma grande quantidade desse sal para provar que a radiação era proveniente do próprio sal, posteriormente Becquerel descobriu que essa radiação era proporcional a concentração 
de urânio no sal, e que essa radiação permanecia constante quando se variava temperatura, ou se aplicava campos elétricos ou magnéticos, se modificava a pressão e até o estado químico. Essa descoberta chamou atenção do famoso casal de cientistas Pierre e Marie Curie, eles investigaram outro tipo de minério chamado pechblenda, este composto emitia mais radiação do que o urânio puro, o que levou o casal a desconfiar que deveria existir um composto no minério com um maior poder de emissão de radiação do que o urânio. Desse minério extraíram e separaram em 1898, uma pequena quantidade desse material que foi batizado de radium. Nascia o termo radioatividade dado pela própria Marie Curie (Segre, 1980), o fenômeno da radioatividade ocorre quando o núcleo precisa se organizar e aperfeiçoar sua estrutura, quando o mesmo se encontra instável. Para se organizar o núcleo emite um ou mais tipos de radiação, transmutando em outro elemento até que o núcleo atinja uma configuração estável, hoje se sabe que estas emissões são governadas por probabilidades estatísticas.

\subsection{2 - Atividade}

Quando um nuclídeo está instável ele emite radiações para atingir um estado estável. Nesse contexto é estabelecido um conceito denominado atividade do radionuclídeo, definido pela taxa com que este radionuclídeo (nuclídeo instável) emite essas radiações em um determinado intervalo tempo. Supondo uma quantidade de nuclídeos instáveis em uma determinada amostra, é definida uma constante $\lambda$ denominada constante de decaimento radioativo total (total radioactive decay constant) (Attix, 2004) com unidade de $\mathrm{s}^{-1}$. A quantidade esperada de radionuclídeos que irão se desintegrar em um intervalo de tempo é dado por, este valor é a atividade dessa amostra. Se nessa amostra não se adicionar mais radionuclídeos, a taxa com que o valor de decai é igual à atividade:

Integrando de $t=0$ (quando $N=N_{0}$ ) a t e resolvendo as integrais obtém-se: 
É possível escrever a equação 2.2 em termos da atividade do material radioativo multiplicando $N$ e $N_{0}$ por $\lambda$ :

Se o radionuclídeo possui mais que um modo de decaimento para estados mais estáveis a constante de decaimento total pode ser escrita como a soma das constantes de decaimento parciais (Attix, 2004):

E a atividade total é

A unidade para atividade utilizada até o ano de 1977 era a Curie (Ci), definida como o número de desintegrações por segundo que ocorre em $1 \mathrm{~g}$ de ${ }^{226} \mathrm{Ra}\left(3,7 \times 10^{10}\right.$ desintegrações), hoje é recomendado que se utilize a unidade Becquerel (Bq) (International Comission on Radiation Units and Measurements, 1971) que corresponde a 1 desintegração por segundo.

O conceito de atividade de um material é importante para se definir o que se chama de meia-vida . O tempo de meia vida de um material radioativo é o intervalo de tempo necessário para que metade dos nuclídeos de uma amostra decaia (Attix, 2004). 0 é calculado com o auxilio da equação 2.2 . 
Neste trabalho, os conceitos de atividade e meia vida foram utilizados quando se trabalhou com detectores por ativação tipo folha de Au para se medir o fluxo de nêutrons térmicos e epitérmicos, em experimentos na blindagem biológica da instalação para pesquisa em BNCT.

\subsection{3 - Fluência e Fluxo}

As radiações provenientes de reações nucleares e decaimentos radioativos são de origem estocástica, e a quantidade de radiação que chega a um determinado ponto $\mathrm{P}$, por unidade de área e intervalo de tempo segue uma distribuição de Poisson ${ }^{3}$, que para uma grande quantidade de eventos essa distribuição se aproxima de uma distribuição normal (Attix, 2004). Considerando esse ponto $P$ incluso em uma esfera finita e o número $d N$ de partículas que irão atravessar essa esfera por uma unidade de área e atingir $P$ em um determinado intervalo de tempo arbitrário, pode definir-se uma grandeza denominada fluência $\Phi(T a u h a t a$, Salati, \& Prinzio, 2003) como:

A $\Phi$ é expressa em unidades de $\mathrm{m}^{-2}$ ou $\mathrm{cm}^{-2}$ e pode ser definido para um intervalo

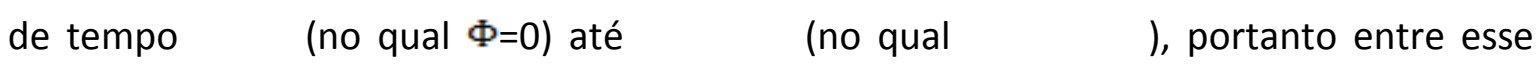
intervalo de tempo máximo pode se definir em um determinado instante a grandeza denominada fluxo como sendo:

\footnotetext{
${ }^{3}$ A distribuição de Poisson representa um modelo probabilístico adequado para o estudo de um grande número de fenômenos observáveis e um destes fenômenos é a emissão de partículas por uma fonte radioativa.
} 
Onde é o incremento da fluência em um intervalo de tempo infinitesimal , o fluxo tem sua unidade expressa em $\mathrm{m}^{-2} \cdot \mathrm{s}^{-1}$ ou $\mathrm{cm}^{-2} \cdot \mathrm{s}^{-1}$, e já que o é expresso em função de $\Phi$ pode se integrar a função e expressar a $\Phi$ pela seguinte integral:

Tanto a $\Phi$ quanto o são grandezas expressas para qualquer radiação (fótons, nêutrons e etc.), qualquer direção e qualquer energia da radiação em questão. Não é possível descrever completamente um campo de radiação somente com esses conceitos, são necessários informações sobre a direção e energia das partículas que compõem o campo em questão.

\subsection{4 - Fluência de Energia, Fluxo de Energia e Espectro de energia}

Considerando o mesmo ponto $\mathrm{P}$ ainda incluso na esfera finita, com a soma de todas as energias carregadas pelas partículas de uma radiação qualquer através de uma área infinitesimal , pode se definir uma grandeza definida como fluência de energia (Attix, 2004), dada por:

A é expressa em unidades de $J \cdot \mathrm{m}^{-2}$ ou eV. $\mathrm{cm}^{-2}$, e pode ser definido para um intervalo de tempo (no qual $=0$ ) até (no qual ), portanto entre esse intervalo de tempo máximo pode se definir em um determinado instante a grandeza denominada fluxo de energia como sendo:

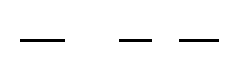

Onde é o incremento da fluência de energia em um intervalo de tempo infinitesimal , o tem sua unidade expressa em J.m ${ }^{-2} \cdot \mathrm{s}^{-1}$ ou eV.cm $\mathrm{cm}^{-2} \cdot \mathrm{s}^{-1}$, e já que o é expresso em função de pode se integrar a função e expressar a pela seguinte integral: 
Os conceitos de fluxo, fluência, fluência de energia e fluxo de energia são importantes para definir o que se chama de espectro energético de um determinado campo de radiação. Considerando os ângulos polares de direção e e a energia $E$ de um campo de radiação ao redor do ponto $\mathrm{P}$ consegue definir o que se chama de fluxo diferencial dado por:

E é expresso mais comumente nas unidades de $\mathrm{sr}^{-1} \cdot \mathrm{eV}^{-1} \cdot \mathrm{cm}^{-2} \cdot \mathrm{s}^{-1}$ e integrando esse fluxo diferencial para todo o ângulo sólido ${ }^{4}$ em coordenadas polares e mantendo o em função da energia, obtém-se o que se chama de espectro energético dado por:

O espectro energético de um determinado campo de radiação pode ser mostrado em um gráfico $x$ como sendo a área sob a curva e pode ser dado em função da intensidade, por exemplo, ou das contagens de um determinado detector. Essa é uma grandeza fundamental para a caracterização do campo de radiação e pode ser definida para qualquer tipo de radiação sejam nêutrons, fótons ou elétrons (Attix, 2004). Neste trabalho o conceito de espectro energético é utilizado quando é caracterizado pelo código MCNP ou quando é medido experimentalmente utilizando detectores por ativação.

\subsection{5 - Kerma}

As definições de fluxo, de fluência e espectro energético servem para caracterizar qualquer campo de radiação e essas definições são totalmente independentes do tipo de interação que a radiação irá ter com a matéria. Quando é necessário quantificar essas interações e seus efeitos em relação ao depósito de energia novos conceitos devem ser

\footnotetext{
${ }^{4} \mathrm{Em}$ coordenadas polares o infinitesimal de ângulo sólido é dado por $d \Omega=\operatorname{sen} \theta d \theta d \beta$
} 
definidos. Neste trabalho apenas radiações indiretamente ionizantes (nêutrons e fótons) são utilizadas e para esse tipo de radiação define-se uma grandeza denominada kerma $\mathrm{K}$ para quantificar o depósito de energia em determinado material. O kerma (Kinect Energy Released per unit of MAss) (Tauhata, Salati, Prinzio, \& Prinzio, 2003) é definido como sendo:

Onde é o infinitesimal da energia transferida pela radiação incidente para a energia cinética das partículas carregadas em . O é calculada da seguinte forma (Attix, 2004):

Onde é a quantidade de energia das partículas sem carga entrando em , é a quantidade saindo, exceto a conversão de energia cinética de partícula carregada para energia de partícula não carregada, como por exemplo, o que acontece em radiação de bremsstrahlung ${ }^{5}$ e é a soma das energias correspondentes as transformações envolvendo energia de repouso ( é um valor positivo e é um valor positivo). O é expresso em unidades de erg/g ou em J/Kg, quando o kerma é definido para nêutrons as partículas secundárias que recebem são núcleo de recuo, prótons que recebem a energia devido a espalhamentos elásticos e partículas oriundas de reações nucleares, e se o kerma é definido para fótons, as partículas secundárias são elétrons ou pósitrons oriundos dos efeitos fotoelétrico, Compton e produção de pares. Essas partículas secundárias podem ser originadas de duas formas basicamente, o que se costuma fazer, é dividir o em dois tipos (Tauhata, Salati, Prinzio, \& Prinzio, 2003) o kerma de colisão, onde a energia é transmitida devido a colisões com os elétrons e os núcleos do meio, e o kerma de radiação aonde a energia incidente é transmitida e transformada em radiação eletromagnética, sendo que + . Geralmente os meios no qual o kerma é definido são o ar e a água, neste trabalho utilizou-se o conceito de Kerma no ar para os fótons do ${ }^{60} \mathrm{Co}$ na calibração dos dosímetros termoluminescentes

\footnotetext{
${ }^{5}$ Fótons produzidos quando elétrons acelerados são freados bruscamente contra um alvo.
} 
sensíveis principalmente à fótons feitos pelo grupo de pesquisa em BNCT. O kerma dos fótons do ${ }^{60} \mathrm{Co}$ para o ar em um determinado ponto $\mathrm{P}$ ao redor da fonte foi calculado utilizando a seguinte expressão (Attix, 2004):

Onde é um valor tabelado (Evans, 1968) para cada meio denominado como coeficiente linear de transferência de energia no meio, é a densidade do meio e $\Psi$ é a fluência de energia. Se os fótons não são monoenergéticos o é definido pela integral:

As equações 2.18 e 2.19 podem ser aplicadas para nêutrons, mas é comum definir um campo de nêutrons em função do fluxo ao invés de fluência de energia como é feita para fótons, logo para nêutrons monoenergéticos o kerma é dado por:

Onde é um valor tabelado (Casswell, J.J., \& Randolph, 1980) para um determinado material com número atômico $Z$ e $\Phi$ é a fluência. Para um campo de nêutrons polienergético, o é dado por:

Para os dosímetros termoluminescentes sensíveis a nêutrons térmicos, no selecionamento e na calibração feito pelo grupo de pesquisa de BNCT, utilizou-se os conceitos de kerma para nêutrons no ar. 


\subsection{6. - Dose absorvida e dose equivalente}

A dose absorvida é definida em termos da energia fornecida pelas partículas carregadas e não carregadas dentro de um volume $V$ de massa , que é definida da seguinte maneira (Attix, 2004):

Onde os parâmetros envolvidos são os mesmos definidos para a equação 2.17 , mas adicionam-se as partículas sem carga na formulação da equação 2.22; é a energia da partícula descarregada entrando no volume $V$ e é a energia da partícula sem carga saindo do volume V. A energia absorvida é energia fornecida num intervalo de tempo no volume $V$ de massa e é dada por:

A dose absorvida tem a unidade de $\mathrm{J}_{\mathrm{Kg}}{ }^{-1}$ que é definida como Gray (Gy), porém essa definição de dose absorvida é para todos tipos de radiação que transferem energia no volume de interesse. A definição de dose absorvida pode ser escrita em função do seu efeito biológico, e este efeito é diferente para cada tipo de radiação, para um mesmo efeito biológico é definido o conceito de dose equivalente que é dado por (Attix, 2004):

A dose equivalente é dada nas mesmas grandezas da dose absorvida, porém é definida como Sievert (sV) e o fator é o fator de qualidade para cada tipo de radiação, o ICRU 66 traz os valores para os fatores de qualidade para determinados intervalos de energia do nêutron. Os valores de dose ao redor da blindagem biológica são medidos pelo serviço de radioproteção em função da dose equivalente, isto tanto para nêutrons quanto para fótons. 


\section{2 - Radioproteção}

A utilização das radiações ionizantes ou indiretamente ionizantes pela sociedade requer uma atenção constante visto que seus efeitos podem ser hereditários devido a possíveis danos genéticos que a radiação possa vir a causar. A radioproteção tem como objetivo prevenir ou diminuir os efeitos somáticos causados pela radiação (Tauhata, Salati, Prinzio, \& Prinzio, 2003), ela usa de vários fundamentos e os limites de dose equivalente para o trabalhador exposto ocupacionalmente e para o público são mostrados na tabela 1. O fator $W_{t}$ é um fator de peso para o cálculo de dose para cada órgão especifico do corpo tendo em vista que cada órgão/tecido tem uma resistência diferente à radiação.

Tabela 1 - Limites de dose anuais (mSv) (Comissão Nacional de Energia Nuclear, 1988)

\begin{tabular}{lcc}
\hline \multicolumn{1}{c}{ Quantidade } & Trabalhador & Público \\
\hline Dose equivalente efetiva & 50 & 1 \\
Dose equivalente para órgão/tecido & 500 & $1 / \mathrm{W}_{\mathrm{t}}$ \\
Dose equivalente para a pele & 500 & 50 \\
Equivalente de dose para o olho & 150 & 50 \\
Extremidades (mãos, antebraços, pés e & 500 & 50 \\
tornozelos) & & \\
\hline
\end{tabular}

Estes valores de limite de dose foram utilizados para o cálculo de desenvolvimento da blindagem biológica da instalação de BNCT para que fosse possível realizar experimentos e trocar amostras com o reator ligado e também para monitorar o nível de dose ao redor da blindagem biológica. 


\section{3 - Interação da radiação com a matéria}

Em 1887 Heinrich Hertz realizou experimentos que comprovava que a radiação eletromagnética apresenta um comportamento ondulatório quando se propaga comprovando a teoria de Maxwell sobre a propagação da luz, o que Hertz não desconfiava era que ele também estava verificando um efeito que mais tarde Einstein utilizaria para contradizer alguns aspectos da teoria clássica eletromagnética de Maxwell (Segre, 1980). O que Hertz observava era que a luz ultravioleta ao incidir sobre um par de eletrodos fazia com que existisse uma descarga elétrica entre eles. O que Hertz estava visualizando era o que se chama de efeito fotoelétrico, efeito que só pode ser explicado atribuindo a radiação eletromagnética um caráter corpuscular.

Em 14 de Dezembro de 1900 em seu artigo intitulado como "Sobre a teoria da lei de distribuição de energia do espectro normal" o físico alemão Max Planck tentou explicar a radiação do corpo negro considerando que a radiação deveria estar quantizada em valores discretos em função de um constante $h$ que o próprio Planck em uma carta a um amigo chamou de "ato de desespero". Einstein era um jovem físico muito interessado no trabalho de Planck e em 1905 comprovou que o efeito fotoelétrico só podia ser explicado se a radiação eletromagnética fosse desvencilhada dos conceitos ondulatórios e o que se chama de dualidade da radiação eletromagnética é o fato desta se comportar como onda quando se propaga e como partícula quando interage com a matéria.

$\mathrm{Na}$ interação dos fótons destacam-se três processos principais de deposição de energia: efeito fotoelétrico, efeito Compton e produção de pares. A probabilidade de ocorrer cada processo é uma função da energia do fóton, da densidade do meio e do seu número atômico. Já os nêutrons como não possuem carga elétrica, mas possuem massa, interagem através de reações nucleares e têm suas probabilidades de ocorrer em função da energia do nêutron e das características nucleares do meio.

\subsection{1- Fótons}

Os fótons podem interagir com a matéria das seguintes formas:

i. Espalhamento incoerente (Compton)

ii. Efeito Fotoelétrico

iii. Produção de pares 
iv. Espalhamento coerente (Rayleigh)

v. Interações fotonucleares

Os três primeiros itens sãos os mais relevantes quando se trata de deposição de energia, já que no espalhamento coerente o fóton é espalhado em um ângulo pequeno e praticamente não ocorre perda de energia e para que ocorram interações fotonucleares os fótons precisam ter energias suficientemente altas (MeV) para excitar os núcleos do alvo e assim provocar reações do tipo ( $\gamma, n$ ou p). O gráfico da figura 2 mostra a região de predominância das três principais formas de interação do fóton com a matéria em função da energia do mesmo e do número atômico do material.

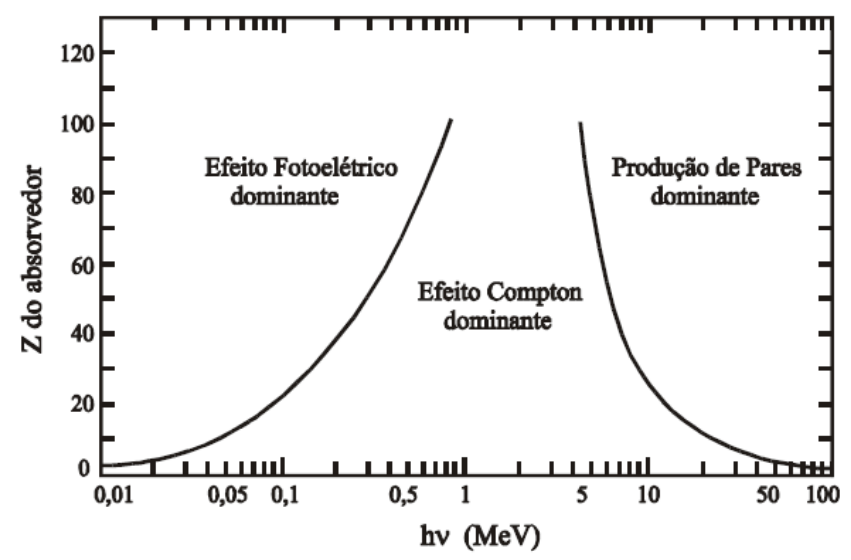

Figura 2 - Interações predominantes em função da energia do fóton incidente e do número atômico do material (Tauhata, Salati, Prinzio, \& Prinzio, 2003).

Para se trabalhar com problemas que envolvem blindagem de radiação o que se utiliza é um material com alto numero atômico, com alta densidade para que se obtenha um alto coeficiente de atenuação linear dos fótons e que também possua uma alta probabilidade de absorção fotoelétrica.

Geralmente, o material escolhido é o chumbo por apresentar um número atômico alto (82), uma densidade alta $\left(11,35 \mathrm{~g}_{\mathrm{cm}} \mathrm{cm}^{-3}\right)$, ser relativamente barato e apresentar boa ductibilidade. Utiliza-se também ligas de tungstênio que apresentam também um número atômico alto (74), densidade alta $\left(17 \mathrm{~g} . \mathrm{cm}^{-3}\right)$ e também são bastante maleáveis, porém são mais caras e se mostram mais eficientes para blindar fótons de energias superiores a $500 \mathrm{KeV}$ justamente por possuir uma densidade maior do que a do chumbo. 


\subsubsection{1- Espalhamento incoerente (Compton)}

O espalhamento incoerente ou efeito Compton, em homenagem à A. H. Compton que em 1927 por estudar este efeito recebeu o prêmio Nobel, é o choque entre um fóton incidente com uma determinada energia (hv) e um elétron livre, que se encontra em repouso no material, o elétron recebe uma energia cinética $\left(E_{e}\right)$ no choque e é espalhado em um ângulo $\theta$ e a resto da energia (hv') fica no fóton que é espalhado em um ângulo $\varnothing$. Um esquema simplificado do choque entre o fóton incidente e o elétron é demonstrado na figura 3.

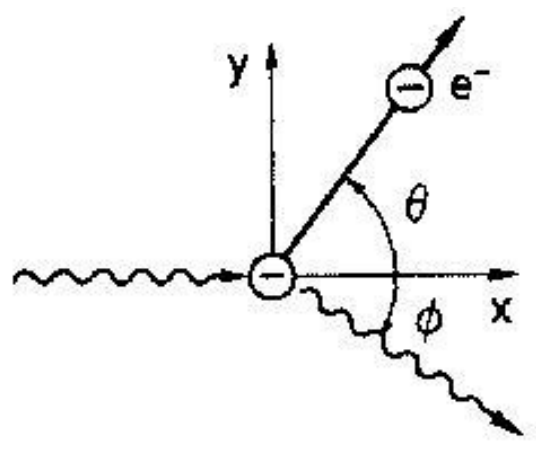

Figura 3 - Esquema simplificado do efeito Compton.

As conservações de energia e momento são expressas da seguinte forma:

$$
\begin{gathered}
h v+m_{e} c^{2}=h v^{\prime}+E_{e} \\
\frac{h v^{\prime}}{c} \operatorname{sen} \theta=p_{e} \operatorname{sen} \phi \\
h v=p_{e} \cos \phi+\frac{h v^{\prime}}{c} \cos \theta
\end{gathered}
$$

Onde $E_{e}$ e $p_{e}$ são a energia total e o momento linear do elétron após o choque. Acrescentando a relação entre energia e momento para o elétron relativístico $\left(E_{e}=p_{e} c+m_{e} c^{2}\right)$ e algumas manipulações matemáticas (Attix, 2004), chega-se as equações para energia do fóton espalhado, para a energia do elétron espalhado e a relação entre $\theta$ e $\varnothing$. 


$$
\begin{gathered}
h v^{\prime}=\frac{h v}{1+\left(h v / m_{0} c^{2}\right)(1-\cos \phi)} \\
E e=h v-h v^{\prime} \\
\cot \theta=\left(1+\frac{h v}{m_{0} c^{2}}\right) \tan \left(\frac{\phi}{2}\right)
\end{gathered}
$$

Os valores das seções de choque para os diversos ângulos e energias possíveis do efeito Compton são dadas pela equação de Klein-Nishina, que em 1928 aplicaram a teoria relativística de Dirac para o elétron do efeito Comptom, porém, a dedução matemática dessa equação foge do escopo desse trabalho.

\subsubsection{2- Efeito Fotoelétrico}

O efeito fotoelétrico tem sua história de descobrimento dividida entre $\mathrm{H}$. Hertz por primeiro evidenciar o efeito, Einstein por explicar o efeito através da teoria do fóton a partir de idéias de quantização de Planck e Millikan por verificar experimentalmente em 1915 a teoria de Einstein. Sendo que Einstein ganhou o Nobel em 1921 por sua contribuição à física teórica e pela descoberta da lei do efeito fotoelétrico e em 1923 Millikan também ganhou o Nobel por seus trabalhos sobre a carga elementar e também sobre o efeito fotoelétrico.

O efeito acontece da seguinte maneira: o fóton transfere toda sua energia para um elétron do átomo alvo e este escapa da eletrosfera com certa energia cinética. Um esquema simplificado do efeito fotoelétrico é mostrado na figura 4.

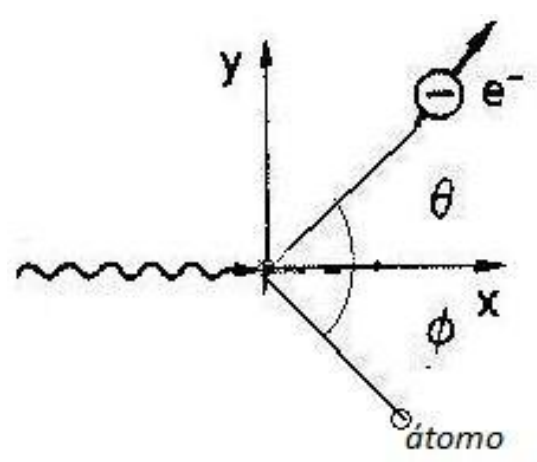

Figura 4 - Esquema simplificado do efeito fotoelétrico. 
As conservações de energia e momento são expressas da seguinte forma:

Onde , e são respectivamente a energia de ligação necessária para desligar o elétron do átomo, a energia cinética do elétron e a energia cinética do átomo, geralmente se despreza devido ao fato da massa do átomo ser muito maior do que a massa do elétron, mas o momento do átomo é essencial para o equacionamento (Attix, 2004). Ao contrário do que acontece com o efeito Compton não existe uma equação que define as probabilidades de ocorrer o efeito fotoelétrico porque é difícil incluir a energia de ligação na solução da equação, o que se faz é obter resultados experimentais e extrapolá-los para regiões restritas de energia. Este efeito junto com a produção de pares são os que mais contribuem em cálculos de blindagens justamente por serem processos de absorção de fótons.

\subsubsection{3 - Produção de pares}

O terceiro processo principal na qual o fóton perde sua energia é a produção de pares, este efeito foi evidenciado pela primeira vez na câmara de bolhas de Patrick Blacket e por este experimento ele ganhou o prêmio Nobel em 1948. A produção de pares consiste na transformação da energia de um fóton em massa de repouso de duas partículas carregadas, no caso, o elétron e o pósitron. Este processo predomina quando a energia do fóton é alta e a interação do fóton é com o núcleo do átomo alvo. A figura 5 mostra um esquema simplificado da produção de pares.

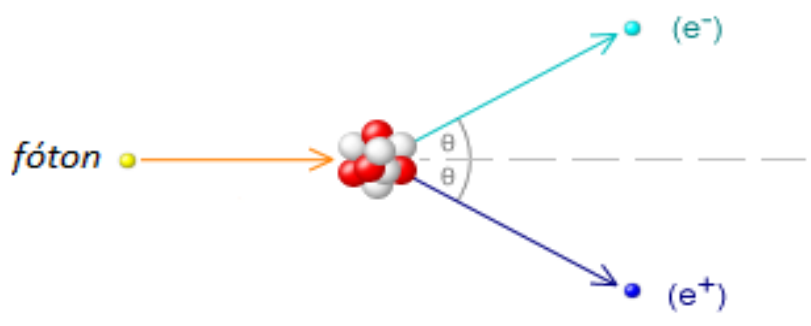

Figura 5 - Esquema simplificado da produção de pares. 
As conservações de energia são expressas da seguinte forma:

A explicação deste fenômeno é feita com o auxilio da mecânica quântica relativística e não existem equações simples para as probabilidades relacionadas aos parâmetros envolvidos.

\subsubsection{4 - Atenuação de Fótons - Lei da atenuação exponencial}

Quando um feixe de fótons atravessa um material de espessura , a quantidade de fótons que consegue atravessar o material possui um comportamento exponencial que é dado pela equação abaixo:

Onde é a intensidade final e é a intensidade inicial; esta intensidade pode ser dada em função da fluência ou do fluxo, e é o coeficiente de atenuação total que é seção de choque total de interação do fóton por qualquer um dos processos descritos acima.

\section{4- Nêutrons}

A descoberta do nêutron trata-se de uma história dramática, ao contrário de muitas descobertas na física que aconteceram quase que instantaneamente, a descoberta do nêutron levou alguns anos para ser concluída. Walter Bothe e seu aluno H. Becker foram os pioneiros na história da descoberta dos nêutrons quando em 1928 bombardearam berílio com partículas alfas de polônio, com o objetivo de confirmar as desintegrações observadas por Rutherford acompanhadas de emissões gamas de alta energia, mas ao invés descobriram uma "radiação penetrante" que eles interpretaram como raios gama (Segre, 1980).

Em 1931, Irene Curie e Frederic Joliot utilizaram uma amostra forte de polônio para estudar essa "radiação penetrante" e evidenciaram que essa radiação conseguia 
ejetar prótons de uma camada de parafina, tentaram explicar o fenômeno como uma forma análoga ao efeito Compton, mas as seções de choque e a energia dessa radiação deveriam ser altíssimas. Chadwik em 1932, no laboratório Cavendish repetiu as experiências do casal Joliot e conseguiu provar que essa radiação penetrante continha um componente neutro com a massa aproximadamente igual ao do próton, a razão de Chadwik perceber o nêutron foi que ele estava mentalmente preparado para sua existência, isto devido a trabalhos e conversas com Rutherford (Segre, 1980).

\subsection{1 - Nêutrons Térmicos}

Os nêutrons podem entrar em equilíbrio com o meio que estão interagindo, isto ocorre quando a probabilidade dele ganhar ou perder energia fica igual em um grande número de colisões, nesta condição o nêutron é definido como térmico, e diz-se que ele está em equilíbrio térmico com os átomos ou moléculas do meio, e são nêutrons nesse estado energético que causam a interferência nos experimentos do canal de irradiação seis do IEA-R1.

Neste estado energético o comportamento do nêutron é semelhante a um átomo de um gás e pode ser descrito pela teoria cinética dos gases e sua distribuição de velocidades é maxwelliana, eles possuem uma velocidade média de $2200 \mathrm{~m} / \mathrm{s}$ e energia cinética média de $0,025 \mathrm{eV}$. Neste trabalho foi considerado nêutrons térmicos aqueles com energia inferior a $0,5 \mathrm{eV}$, nêutrons epitérmicos aqueles com energia entre $0,5 \mathrm{eV}$ e $10 \mathrm{KeV}$ e rápidos os nêutrons com energia superior a $10 \mathrm{KeV}$.

\subsection{2- Interações do nêutron com a matéria}

Devido ao fato do nêutron não ter carga e não interagir com a matéria utilizando a força coulombiana, ele apenas interage com os núcleos alvos do material. Basicamente o nêutron pode ser espalhado elasticamente, inelasticamente ou ser absorvido em uma reação nuclear (Yoshimura, 2009). Os nêutrons têm suas probabilidades de interações definidas em unidades $\left(1 \mathrm{~b}=10^{-24} \mathrm{~cm}^{2}\right)$ de seção de choque $(\sigma)$. As seis principais interações que o nêutron sofre são definidas brevemente a seguir. 
i. Espalhamento elástico: O nêutron é espalhado e a energia do sistema nêutron + núcleo alvo se conserva.

ii. Espalhamento inelástico: O nêutron é espalhado, a energia do sistema nêutron + núcleo não se conserva e o núcleo alvo é atinge estados excitados.

iii. Captura: O nêutron é absorvido e o núcleo emite uma partícula carregada pesada de alto LET e pequeno alcance (ex: partículas $\alpha$ ou prótons).

iv. Captura radioativa: O nêutron é absorvido o núcleo alvo se transmuta em um novo isótopo e raios gamas de decaimentos são emitidos.

v. Emissão de nêutrons: O nêutron é absorvido e o núcleo alvo libera um ou mais nêutrons.

vi. Fissão: O nêutron provoca a fissão do núcleo alvo e ocorre liberação de dois ou três nêutrons.

As seções de choque para estas interações mudam conforme a energia do nêutron incidente, mas em geral diminuem com o aumento da energia do nêutron, no entanto existem fenômenos específicos e regiões onde existem picos de ressonância que fazem com que não exista uma forma simples para descrever as curvas de seção de choque em função da energia do nêutron incidente.

Quando se calcula blindagens priorizam-se as interações de captura, porém estas interações prevalecem quando o nêutron já possui uma energia baixa, o que se costuma fazer é colocar material moderador, ou seja, um material aonde as seções de choque para que ocorram espalhamentos sejam altas e o nêutron depois de alguns espalhamentos elásticos ou inelásticos possa atingir uma energia menor e consequentemente ser absorvido por captura.

\subsection{3- Moderação de nêutron}

A moderação de nêutrons é o processo no qual nêutrons rápidos são convertidos em nêutrons térmicos através principalmente de espalhamentos elásticos e inelásticos. Considerando que o processo de moderação que predomina para alvos leves é através de espalhamento elástico, a seguir na figura 6 é demonstrado no sistema de laboratório e no sistema de centro de massa este tipo de espalhamento. 


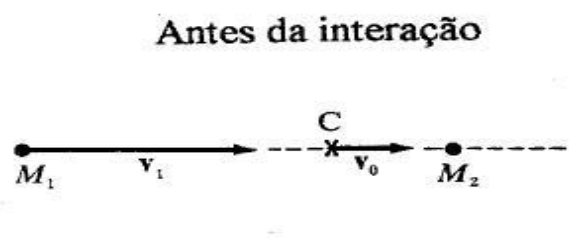

a) Sistema lab.
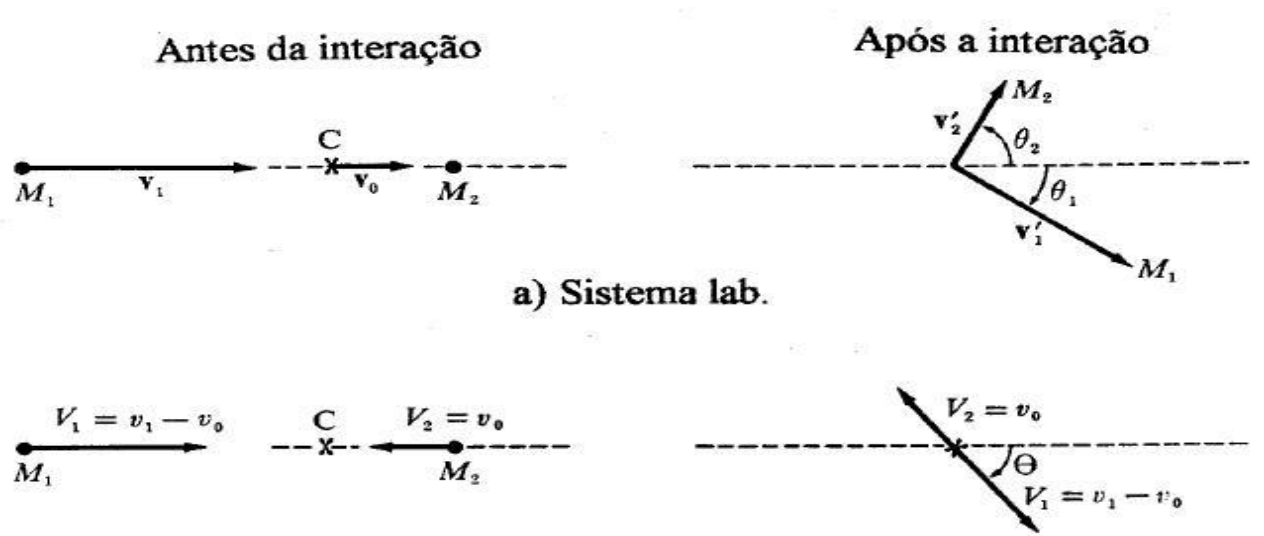

b) Sistema c. m.

c) Sistema lab.

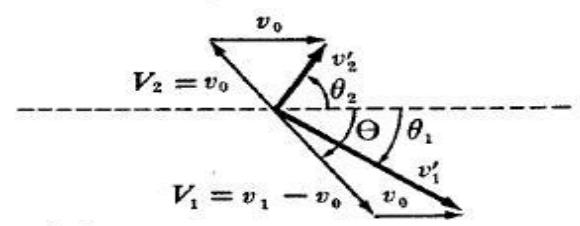

Figura 6 - Esquema do espalhamento elástico entre um nêutron de massa M1 e um núcleo atômico de massa M2 no sistema de laboratório (a), no sistema de centro de massa (b) e de volta ao sistema de laboratório (c); figura obtida da apostila do curso TNR-5764 - Fundamentos de Tecnologia Nuclear - Reatores.

$O$ nêutron se choca com massa $M_{1}$ e velocidade $V_{1}$ com um núcleo alvo de massa $M_{2}$, após a interação o nêutron e o núcleo alvo se movimenta com velocidades $v_{1}{ }^{\prime}$ e $v_{2}{ }^{\prime}$ e ângulos $\theta_{1}$ e $\theta_{2}$ respectivamente, e o centro de massa se move com velocidade igual a:

E na mesma direção de , ao subtrair de todas as velocidades obtém-se o referencial de centro de massa, item $b$ da figura 6 , aplicando a conservação de momento implica dizer que o nêutron e o núcleo alvo têm vetores iguais e opostos e a conservação energia cinética só é mantida no sistema de centro de massa se a velocidade do nêutron e núcleo alvo não se modificarem (Lamarsh, 1972). Quando se retorna ao sistema de laboratório (item c. da figura 6) adiciona-se novamente às velocidades e o valor de $v_{1}{ }^{\prime}$ pela lei dos cosenos é: 
E a energia cinética depois da interação do nêutron é dada por e assume um valor máximo quando $\theta$ vale $0^{\circ}$ e valor mínimo quando vale $180^{\circ}$, escrevendo a razão entre e (energia cinética antes da interação) para um valor de ângulo entre o máximo e o mínimo e adotando a razão igual a $A$, obtém-se com algumas simplificações:

A razão pode ser considerada como o valor da massa do núcleo já que vale um e é conveniente (Lamarsh, 1972) escrever a equação acima utilizando um parâmetro $\alpha$ dado por:

E a equação 2.34 fica da seguinte forma:

Percebe-se então que se vale zero é igual a e se vale 180 é igual a , logo quando o núcleo alvo é o hidrogênio o valor de $\alpha$ na equação 2.35 é zero. Isto faz com que o nêutron possa perder toda sua energia com apenas uma interação com o núcleo de hidrogênio, principal razão que materiais hidrogenados são escolhidos para blindagens de nêutrons. Neste trabalho utilizou placas de polietileno (carbono e hidrogênio) com $5 \%$ de ${ }^{10} B$ que possui uma alta seção de choque de captura através da reação ${ }^{10} B(n, \alpha){ }^{7}$ Li para nêutrons térmicos, logo a placa funciona como moderadora para nêutrons com energia acima da térmica e também como absorvedora de nêutrons térmicos. Utilizou-se também polietileno puro coberto com cádmio, o cádmio por ser um excelente absorvedor de nêutrons térmicos elimina os nêutrons que foram moderados no polietileno puro. 


\section{5 - Detectores de ativação tipo folha de Au}

Justamente pelo fato do nêutron não possuir carga sua detecção é feita de modo indireto, e uma delas é pela indução de radioatividade nos núcleos alvos dos átomos do meio, esta radioatividade é proporcional a intensidade do feixe e é medida através de espectroscopia gama, técnica consagrada e bastante utilizada nos laboratórios do IPEN (Bittelli, 1988).

Utilizou se folhas de ouro ( $\mathrm{Au}$ ) com $1 \mathrm{~mm}$ de espessura e com alto grau de pureza. $\mathrm{A}$ reação utilizada é a captura radioativa do $\left({ }^{197} A u(n, y) A u^{198}\right)$ e esta reação possui um valor de seção de choque alto para a região térmica e um valor menor para a região epitérmica, tornando possível também medir o fluxo epitérmico utilizando folha de Au. Ao se irradiar um par de folhas de Au idênticas sob mesmas condições de irradiação consegue-se discriminar o fluxo térmico e epitérmico através do uso da razão de cádmio. Experimentalmente se envolve uma das folhas em um estojo de cádmio, este por ser excelente absorvedor de nêutrons na região térmica acaba blindando a folha do estojo e deixando esta exposta principalmente a nêutrons epitérmicos já que a seção de choque de absorção é baixa para a região rápida e decai com o aumento da energia do nêutron incidente.

A seguir são feitas as deduções necessárias para o cálculo do fluxo térmico e epitérmico de acordo com a referência utilizada (Bittelli, 1988). Quando as folhas de Au são submetidas a um campo de nêutrons a taxa com que se formam os átomos de $\mathrm{Au}^{198}$ é dado pela seguinte equação:

Onde é o número de átomos radiativos em um tempo , é o número inicial de átomos não radioativos, é a seção de choque de captura radioativa média, é a seção de choque de absorção média, é o fluxo total de neutrons em todas as energias e

é a constante de decaimento do átomo radioativo que é formado. O fluxo total de nêutrons é dado pela integral do fluxo em todas as energias: 
As seções de choque médias envolvidas são calculadas através da seguinte forma:

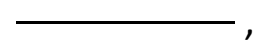

onde é a seção de choque em função da energia. A taxa de consumo dos átomos de ${ }^{197}$ Au é dado por:

onde é a seção de choque total. Resolvendo a equação acima obtém-se:

onde é o número de átomos inicial; substituindo a equação acima na equação 2.37 obtêm-se:

Resolvendo a equação acima pela técnica do fator integrante

obtêm-se:

e obtêm-se:

Integrando a equação acima mas considerando que

$\mathrm{e}$

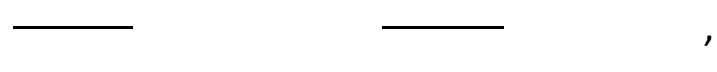

onde é a densidade de átomos do material, é o volume do material irradiado, é a atividade no final da irradiação e é a seção de choque macroscópica média de ativação. A atividade ao final da irradiação da folha de Au é dada por: 
Define-se atividade de saturação que é valor de ativação que a folha de $\mathrm{Au}$ atingiria se ela fosse irradiada por um tempo infinito, e observa-se que para tendendo ao infinito a equação 2.45 é dada por . Utilizando-se a definição de atividade de saturação na equação acima, obtem-se:

e substituindo essa expressão na equação 2.46 chega-se no fluxo que é dado por:

O tempo de irradiação da folha de $A u$, o tempo de espera até a espectroscopia gama e o tempo da espectroscopia gama (contagem) deve ser cronometrado, pois são essenciais para os cálculos de fluxo térmico e epitérmico. A figura 7 (Bittelli, 1988) mostra o comportamento da atividade da folha nos momentos de irradiação, de espera até a contagem e da contagem.

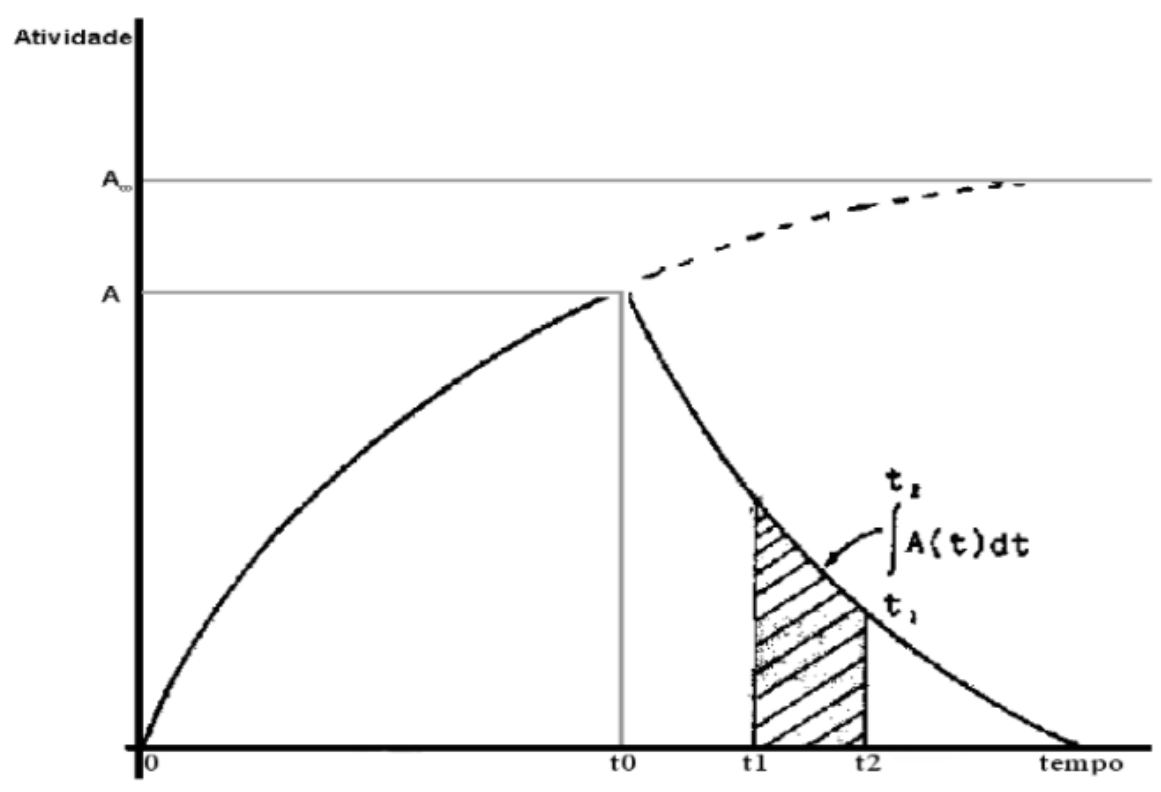

Figura 7 - Comportamento da atividade da folha de Au ao longo do processo (Bittelii, 1988).

A folha acumula entre os instantes $t_{1}$ e $t_{2}$ uma contagem na espectrometria gama que é dada por: 
Resolvendo a equação acima se obtêm a atividade da folha ao final da irradiação:

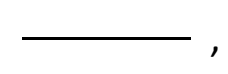

onde é a contagem obtida na espectrometria gama, é o tempo de espera até a contagem, é a eficiência do sistema de detecção, é a probabilidade de emissão do gama contado e é o tempo de contagem. Utilizando a atividade calculada na equação 2.49 na equação 2.46 obtém-se o valor da atividade de saturação.

Para se calcular os valores de fluxo térmico e epitérmico, é necessário determinar o número de núcleos alvos da folha de $\mathrm{Au}$, que é dado por:

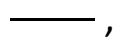

onde é o número de avogrado, é massa da folha de Au, é a fração isotópica e é o peso atômico do núcleo alvo.

A folha de Au que não está no estojo de cádmio tem sua atividade de saturação devido ao fluxo térmico e ao fluxo epitérmico, ou seja:

Define-se como razão de cádmio a razão entre as atividades da folha de Au fora do estojo de cádmio e a da folha de Au dentro do estojo:

O cádmio não é um absorvedor ideal apenas de nêutrons térmicos e acaba absorvendo cerca de $10 \%$ dos nêutrons epitérmicos, logo a atividade de saturação da folha dentro do estojo de cádmio deve ser corrigida pelo fator de cádmio : 
Manipulando as equações $2.51,2.52$ e 2.53 , obtêm-se as atividades de saturação devido aos nêutrons térmicos e epitérmicos que são dadas por:

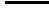

Substituindo a equação 2.54 na equação 2.47 , considerando 2.55 e lembrando que determina-se o fluxo térmico:

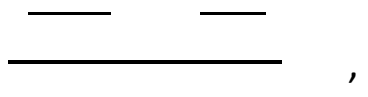

onde é a seção de choque microscópica média (98b) do Au na região de absorção do cádmio (até $0,5 \mathrm{eV}$ ), este valor de seção de choque microscópica média em trabalhos futuros deve ser corrigido com a correto espectro energético do fluxo de nêutrons no ponto onde se realiza a medida, e é perturbação que a folha de Au causa no fluxo térmico devido sua alta seção de choque de absorção. Como na região epitérmica o fluxo varia com o inverso da energia do nêutron incidente e a região epitérmica vai de $0,5 \mathrm{eV}$ ( ) até $10 \mathrm{KeV}($ ) é necessário introduzir a variável letargia que é dada por

Substituindo a equação 2.55 na equação 2.47 determina-se o fluxo epitérmico:

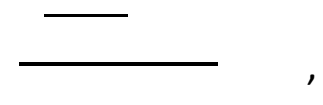

onde é a integral de ressonância do Au para nêutrons epitérmicos e é a perturbação que a folha de Au causa no fluxo epitérmico devido a sua seção de choque de absorção. 
As equações 2.57 e 2.56 deduzidas da referência (Bittelli, 1988) são utilizadas para se calcular os fluxos térmicos e epitérmicos dentro do canal de irradiação (Muniz, Coelho, Silva, Siqueira, \& Souza, 2010) e também nos experimentos envolvendo a blindagem biológica da instalação de pesquisas em BNCT. O procedimento experimental de obtenção da eficiência do detector está descrito em um trabalho anterior do grupo de pesquisa em BNCT (Muniz R. O., 2010).

\section{6 - Dosímetros Termoluminescentes (TLD)}

Os dosímetros termoluminescentes (TLD) são pequenos cristais de material dielétrico que possuem defeitos na sua rede cristalina que são causados propositalmente quando se adiciona em pequenas quantidades um material ativador que os torna possível de realizar medidas de dose de radiação ionizante. Este material ativador cria dois tipos de imperfeições na rede cristalina (Attix, 2004):

i. Armadilhas entre a banda de valência e a banda de condução que aprisionam os elétrons.

ii. Centros de luminescências que permitem que o elétron armadilhado possa perder sua energia através de emissão de fótons.

A incidência da radiação ionizante no cristal do dosímetro termoluminescente (TLD) faz com que o elétron saia da camada de valência e vá para a camada de condução, ao retornar ele é armadilhado em vacâncias da rede cristalina causadas pela ausência de um íon com carga negativa. Num processo posterior, o TLD é aquecido para que o elétron ganhe energia e possa escapar do poço de energia potencial da armadilha e assim voltar para camada de condução e posteriormente à camada de valência, neste processo o elétron entra em outra armadilha denominada centro de luminescência que permite que o elétron se recombine com a rede e por fim emita o fóton correspondente a energia do poço potencial da armadilha. A figura 8 mostra um esquema simplificado do processo de termoluminescência do TLD. 

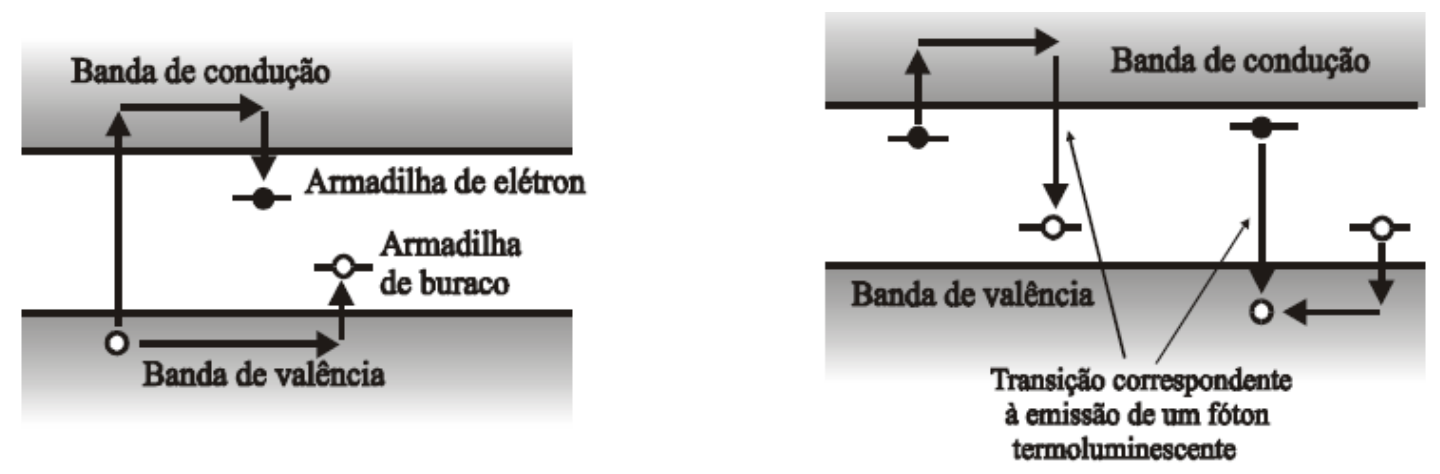

Figura 8 - Processo de termoluminescência em um TLD (Tauhata, et al., 2003).

A quantidade de fótons emitida no processo da termoluminescência é proporcional a quantidade de elétrons armadilhados que por sua vez é proporcional a radiação ionizante a qual o TLD foi exposto. A teoria por trás do armadilhamento/desarmadilhamento do elétron é mais complexa do que a apresentada neste trabalho, sendo que a primeira teoria proposta foi a de Randall e Wilkins em 1945 (Attix, 2004), que determina a probabilidade de escape do elétron a uma determinada temperatura, e é dada por:

Onde é a probabilidade de escape por unidade de tempo, é a vida média na armadilha, o fator freqüência da armadilha, é a energia da armadilha, é temperatura de aquecimento e é a constante de Boltzmann. À medida que a temperatura aumenta a probabilidade de desarmadilhamento se modifica dando origem ao que se chama de curva TL do TLD, que é a quantidade de fótons emitida em função da temperatura . Cada TLD tem sua curva TL característica com seus picos dosimétricos aonde a probabilidade de desarmadilhamento é maior. A figura 9 mostra um exemplo de um curva TL e os picos dosimétricos para um dosímetro termoluminescente genérico. 


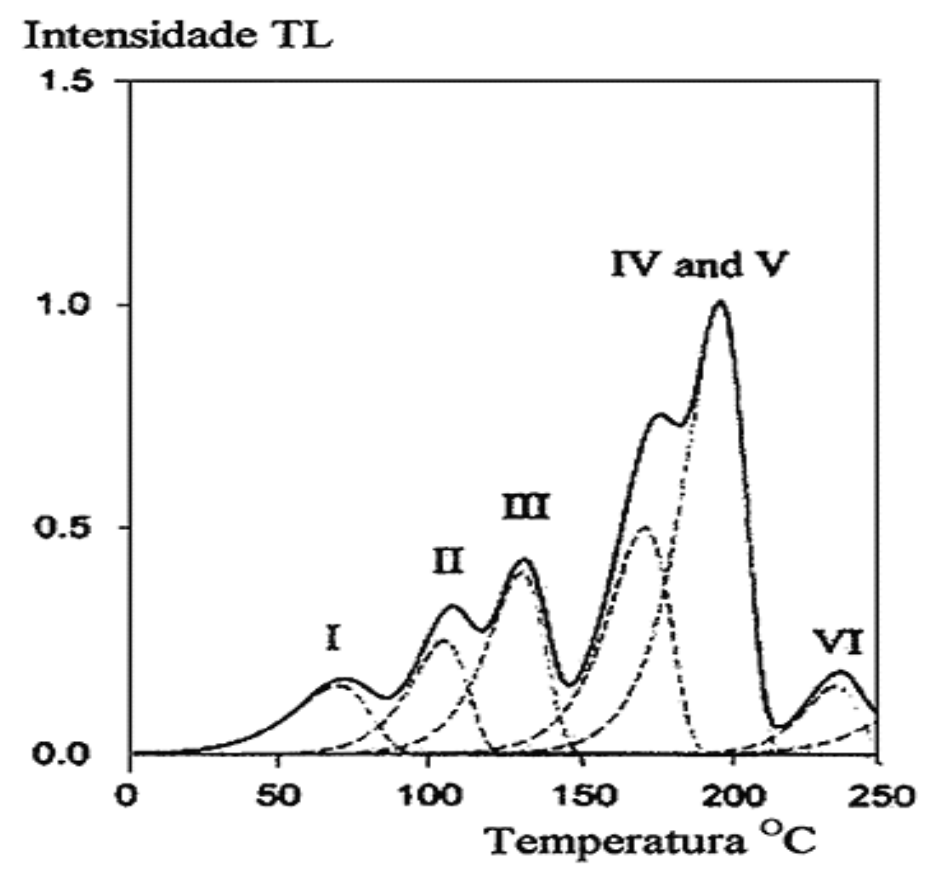

Figura 9 - Curva TL para um dosímetro termolumincescente genérico (Campos L. L., 1998).

Um TLD pode servir como um dosímetro se apresentar num sistema de leitura uniforme reprodutibilidade a um campo de irradiação constante. E a partir de uma leitora de TLD, que nada mais é do que um equipamento capaz de quantificar os fótons emitidos é possível medir essa luz emitida e gerar a curva TL. Posteriormente o TLD pode ser reutilizado, necessitando um tratamento térmico específico para cada TLD a fim de desocupar todas as armadilhas existentes no cristal do TLD. Neste trabalho utilizou-se TLD's sensíveis a nêutrons térmicos e radiação gama que foram lidos e tratados termicamente conforme descrito na seção material e métodos.

\section{7- O método Monte Carlo}

O método de monte Carlo ( $M M C)$ é um método estatístico para se obter aproximações numéricas de funções complexas, seu nome (em homenagem ao famoso cassino da cidade de Monte Carlo) vem do projeto Manhattan aonde cientistas o utilizaram para construir armas nucleares, mas a técnica em si é mais antiga.

O MMC utiliza uma sequencia de números aleatórios para realizar a simulação de um fenômeno físico que possa ser descrito por funções de densidades de probabilidade (fdp's). A simulação é feita através de amostragens aleatórias dessas funções, estas 
amostragens são acumuladas para produzir o resultado estatístico final. Portanto o MMC não resolve uma equação analiticamente dando um valor exato, o MMC utiliza de várias amostragens de uma função para produzir um resultado e a sua ferramenta principal são as técnicas de amostragem das fdp's utilizadas.

\subsection{1 - O código MCNP5}

O código MCNP5 é um software consagrado desenvolvido no laboratório nacional de Los Alamos (EUA), mesmo laboratório que desenvolveu o projeto Manhattan, nomeou o método estatístico de Monte Carlo e expandiu o MMC para a física de modo geral.

O MCNP5 utiliza o MMC para a equação de transporte de nêutrons, fótons e elétrons. O software permite criar modelos geométricos próximos do real e gerar partículas de uma fonte determinada pelo usuário que irão interagir com o modelo geométrico.

Cada partícula é simulada desde a fonte radioativa que é descrita pelo usuário até a sua "morte" (absorção, escape etc.), sendo que em cada instante, os eventos da história da partícula e os parâmetros envolvidos são definidos através de amostragens, utilizando números aleatórios, das funções de probabilidade que representam os fenômenos físicos que fazem parte do toda a história partícula. Os valores dessas funções de probabilidade são definidos pelas seções de choque de cada elemento utilizado na simulação, estas seções de choque se encontram em bibliotecas que são acessadas pelo código e definem a probabilidade para cada tipo de evento que a partícula irá sofrer e seus parâmetros.

Os valores de interesse, que são os resultados fornecidos no arquivo de saída (output) ao usuário, são determinados por cartões no arquivo de entrada (input) denominado tallies e determina o tipo de cálculo que o código irá realizar. O software utiliza a trajetória da partícula entre cada colisão para realizar esses cálculos.

Supondo uma partícula emitida de uma fonte qualquer incidindo em uma célula (objetos volumétricos da modelagem geométrica do problema) ou superfície do problema, a probabilidade para a primeira colisão entre e ao longo da trajetória é dada por (Briesmeister, 2001): 
Onde é a seção de choque macroscópica total, utilizando um número aleatório (0 até 1 ) para amostrar a função através da técnica de amostragem método direto obtém-se:

Resolvendo a equação, obtém-se:

Entretanto também tem origem aleatória e pode ser substituída por apenas, logo a obtenção do livre caminho médio, distância média que a partícula percorre no meio até a próxima colisão, pelo MMC é dado por:

Assim no MMC a história completa da partícula é feita de colisão em colisão independentes do espaço e tempo do sistema, e é por isso que o MMC normalmente é confundido por resolver a equação de transporte que na sua forma integral não tem termos envolvendo derivadas de espaço e tempo.

Para cada tipo de partícula o código tem uma abordagem diferente de descrever a colisão e assim a continuação ou não da história da partícula. Neste trabalho apenas foi utilizado o transporte de nêutrons e fótons, entretanto a descrição matemática completa foge do objetivo e ela é apresentada no manual do código (Briesmeister, 2001), a seguir são mostradas as etapas utilizadas no código para as interações de nêutrons e fótons.

\subsubsection{1 - Interações de nêutrons}

O código MCNP5 utiliza as seguintes etapas para uma interação de nêutron com o núcleo do material (Briesmeister, 2001):

i. O núclideo do material é escolhido. 
ii. O código busca pelo cartão do núclideo que traz informações sobre a sua movimentação térmica, sua ligação química e estrutura cristalina. Caso não exista o código continua segundo modelos próprios.

iii. Fótons são gerados para serem opcionalmente transportados.

iv. A absorção (em qualquer caso possível) do nêutron é simulada, caso o nêutron não seja absorvido sua história continua.

v. A não ser que o cartão exista para o núclideo, o nêutron é simulado sendo espalhado elasticamente ou inelasticamente e a nova energia e direção do vôo são determinados

vi. Se o cartão é apresentado e o nêutron tem energia na região térmica $(<4 \mathrm{eV})$ é simulado em equilíbrio térmico com os núcleos alvos e a etapa acima (v.) é dispensada.

A colisão do nêutron é afetada pelo movimento térmico do átomo e também pela presença dos átomos vizinhos, o código leva em conta esse movimento térmico na modelagem das colisões, porém o usuário dispõem de um cartão específico que leva em conta as ligações químicas das moléculas e sua estrutura cristalina.

O cartão é uma opção que o usuário dispõe para simular corretamente o espalhamento de nêutrons térmicos por moléculas e estruturas cristalinas, este tratamento dado pela utilização do cartão segundo o manual é fundamental para uma correta simulação quando ocorre a termalização do nêutron, isto é disponível para algumas substâncias e temperaturas apenas, e neste trabalho foi utilizado quando disponível.

\subsubsection{2 - Interações de fótons}

As etapas que o código MCNP5 utiliza em relação a escolha do núclideo, sua absorção e geração de partículas secundárias (no caso elétrons) são as mesmas utilizadas para nêutrons porém a física da colisão é totalmente diferente. O código tem dois modelos de interações (Briesmeister, 2001):

i. Simples: O código ignora o espalhamento coerente e os fótons de fluorescência devidos à absorção fotoelétrica. 
ii. Detalhado: O código inclui o que foi ignorado no modelo simples.

O modelo detalhado é automático (default) para fótons até $100 \mathrm{MeV}$, logo é usado na maioria dos casos, e neste trabalho foi utilizado este modelo. O transporte de elétrons gerados a partir de fótons pode ser escolhido pelo usuário e não foi escolhido neste trabalho por esta partícula não ter importância no desenvolvimento das melhorias 


\section{3 - MATERIAIS E MÉTODOS}

Esta seção do trabalho é destinada à descrição das ferramentas envolvidas na elaboração do trabalho. Estas ferramentas podem ser divididas em cinco itens:

- Instalação de pesquisa em BNCT e sua blindagem biológica.

- Dosímetros termoluminescentes.

- Detectores de ativação.

- Simulações com o MCNP5.

- Materiais para blindagem de nêutrons.

\section{1 - A instalação de pesquisa em BNCT e sua blindagem biológica}

A instalação de pesquisa em BNCT baseia-se em um acesso (canal de irradiação) na face do núcleo do reator IEA-R1, onde existente um alto fluxo de nêutrons que fogem das reações em cadeia que ocorrem dentro do material combustível do núcleo do reator.

O reator nuclear IEA-R1 é um reator do tipo piscina aberto, projetado pela empresa norte americana Babcock \& Wilcox Co na década de 50. E desde então, vem sendo utilizado para produção de radioisótopos e experimentos em física nuclear nos seus canais de irradiação, com água leve atuando como moderador e refrigerante; na década de 90 o IEA-R1 foi remodelado para funcionar até $5 \mathrm{MW}$.

A instalação para pesquisa em BNCT é composta de um conjunto de filtros e moderadores seguido de uma posição reservada para a irradiação de amostras e uma blindagem interna de chumbo. Fora da parede da piscina está uma mesa de apoio contendo um mecanismo de trilhos, que retira e insere automaticamente a blindagem interna, fechando e abrindo o canal de irradiação para realização de irradiações. A figura 10 mostra um esquema simplificado da instalação para pesquisa em BNCT no canal de irradiação três do reator IEA-R1. 


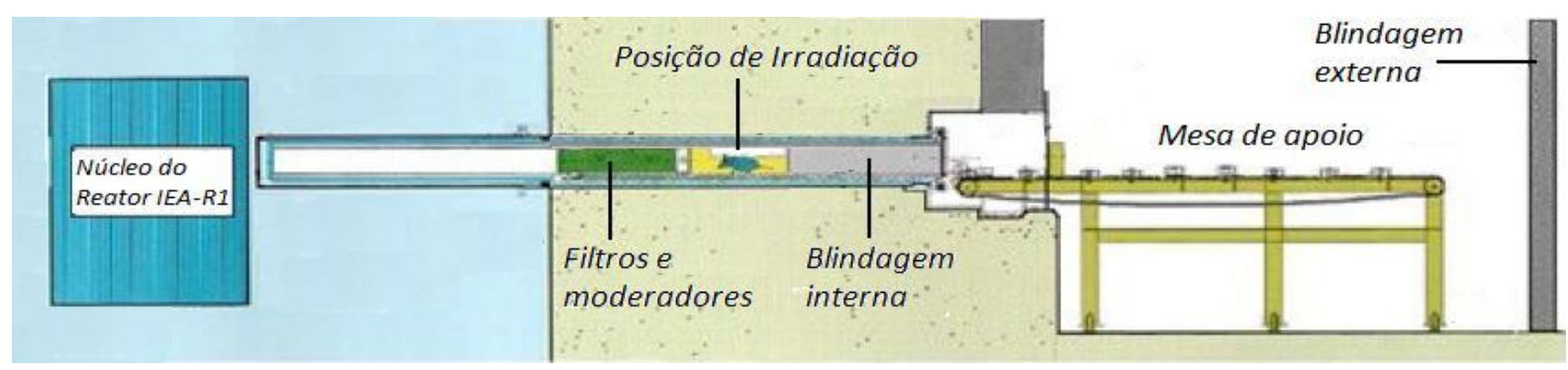

Figura 10 - Esquema simplificado da instalação para pesquisa em BNCT no Reator IEA-R1.

A instalação de pesquisa em BNCT na posição de irradiação fornece os seguintes valores de dose e fluxo medidos utilizando TLD's e folhas de Au respectivamente:

Tabela 2: Valores de fluxo e dose na posição de irradiação (Muniz R. O., 2010)

\begin{tabular}{lcccc}
\hline POSIÇÃO DE & $\left(\mathrm{n} / \mathrm{cm}^{2} \cdot \mathrm{s}\right)$ & $\left(\mathrm{n} / \mathrm{cm}^{2} \cdot \mathrm{s}\right)$ & $(\mathrm{Gy} / \mathrm{h})$ & $(\mathrm{Gy} / \mathrm{h})$ \\
\cline { 2 - 5 } IRRADIAÇÃO & & & \\
\cline { 2 - 5 } & $(2,52 \pm 0,06) \cdot 10^{8}$ & $(6,17 \pm 0,26) \cdot 10^{7}$ & $4,2 \pm 1,8$ & $10,1 \pm 1,3$ \\
\hline
\end{tabular}

Onde é o valor da dose devido a gama, é a dose devido a nêutrons térmicos, é o fluxo térmico e o é o fluxo epitérmico. Estes valores foram medidos em meados de 2010 e o reator encontrava-se operando à potência de 3,5 MW; uma mudança de configuração do núcleo, na potência de operação ou uma alteração na posição das barras de controle modifica estes valores que foram medidos na posição de irradiação, entretanto neste trabalho os valores de fluxo e dose medidos são menores porque os locais medidos são fora do canal de irradiação e ao redor da blindagem biológica.

A blindagem biológica (BB) da instalação no reator IEA-R1 para pesquisa em BNCT é constituída de dois módulos principais e pode ser dividida seguinte forma:

i. Blindagem interna móvel constituída de chumbo.

ii. Blindagem externa fixa constituída de parafina e concreto e um beam catcher.

Um esquema da BB com a blindagem interna inserida (canal de irradiação fechado) é mostrado na figura 11. 


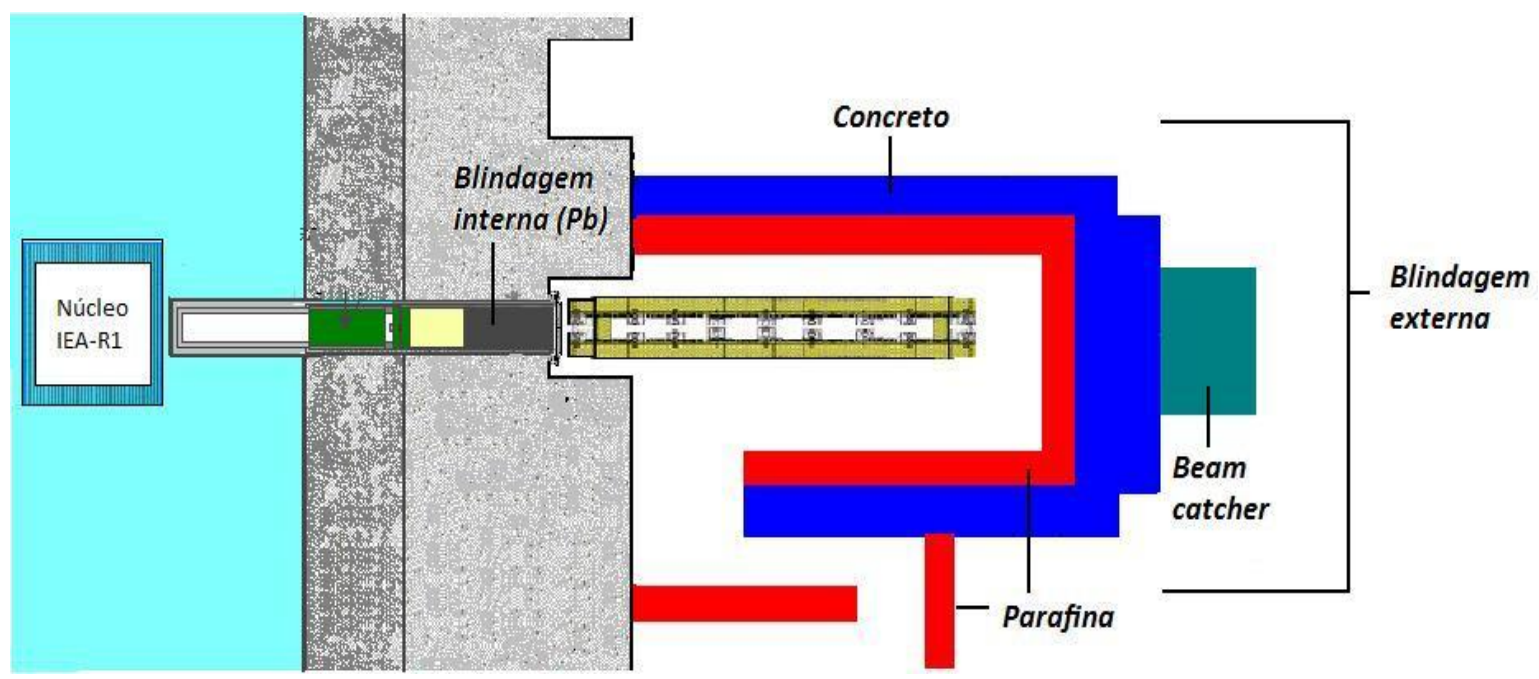

Figura 11 - Esquema da blindagem biológica; em vermelho está representado a parafina, em azul está representado o concreto, em preto está representado o chumbo e em verde está representado o beam catcher.

A blindagem biológica da instalação para pesquisa em BNCT foi desenvolvida utilizando os códigos DOT 3.5 e o MCNP-4B (Silva, Coelho, \& Siqueira, 2002). As condições fundamentais para o desenvolvimento da blindagem biológica era que ela estivesse dentro do orçamento disponível e que fosse eficiente para conter o forte campo de nêutrons e gamas. Isto levou ao uso de blocos de parafina e concreto com $25 \mathrm{~kg}$ e $34 \mathrm{~kg}$ respectivamente. As paredes laterais e o teto são constituídos de uma camada de $30 \mathrm{~cm}$ de parafina seguido de uma camada de $38 \mathrm{~cm}$ de concreto, com exceção da parede frontal que possui uma camada mais espessa de concreto $(76 \mathrm{~cm})$; na direção do canal de irradiação por fora da blindagem externa está posicionado um beam catcher que é constituído de uma caixa de chumbo revestido internamente com parafina. Os fatores de atenuação da parede frontal para nêutrons, gamas (oriundos do núcleo) e nêutrons gama (oriundos das interações dos nêutrons) são 15300, 600 e 3000 respectivamente, e para o teto e paredes laterais são 5100, 350 e 1600. A figura 12 mostra uma foto da blindagem externa da BB. 


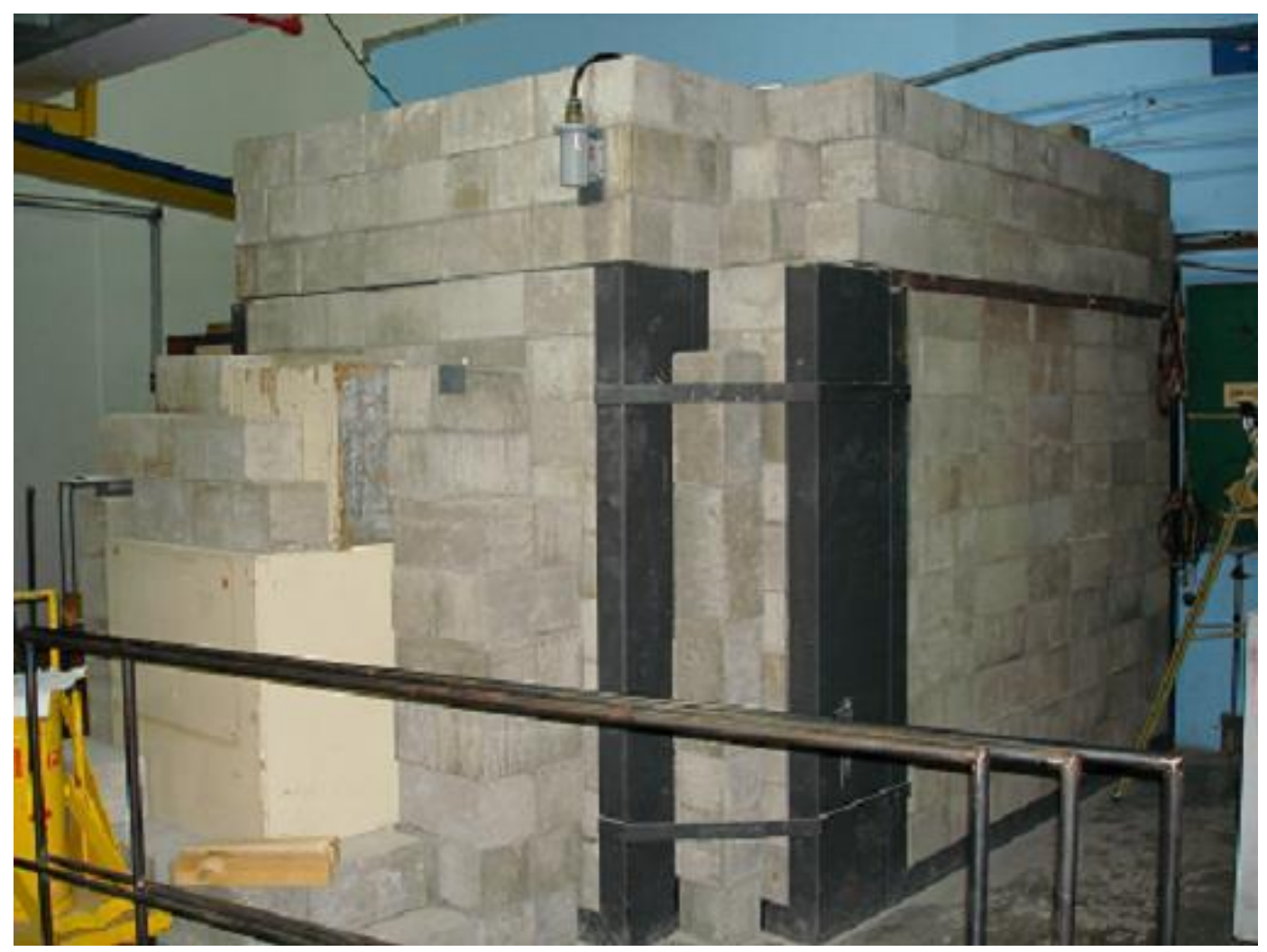

Figura 12 - Foto da blindagem externa e o beam catcher no centro.

\section{2 - Dosímetros termoluminescentes}

Os dosímetros termoluminescentes (TLD's) utilizados neste trabalho são fabricados pela empresa ThermoScientific e possuem as seguintes dimensões: $3,2 \times 3,2 \times 0,38 \mathrm{~mm}^{3}$. Para dosimetria de nêutrons térmicos utilizou-se o TLD 600 em conjunto com o TLD 700 e para dosimetria de radiação gama utilizou-se o TLD 400. A tabela 3 mostra a seguir as especificações de cada TLD, estas informações estão disponíveis no endereço eletrônico da ThermoScientific (ThermoScientific, 2011). 
Tabela 3: Principais características dos TLD’s

\begin{tabular}{|c|c|c|c|c|}
\hline & Dopante & Composição & $\begin{array}{l}\text { Espectro de } \\
\text { Emissão (Å) }\end{array}$ & Intervalo de uso \\
\hline TLD & $\mathrm{Mn}$ & $\mathrm{CaF}_{2}$ & $4400-6000$ & $0,1 \rho G y-100 \mathrm{~Gy}$ \\
\hline \multicolumn{5}{|l|}{400} \\
\hline TLD & $\mathrm{Mg}, \mathrm{Ti}$ & $\operatorname{LiF}\left(95,62 \%\right.$ de ${ }^{6} \mathrm{Li} \mathrm{e} 4,38 \%$ de $\left.{ }^{7} \mathrm{Li}\right)$ & $3500-6000$ & $10 \rho G y-10 G y$ \\
\hline \multicolumn{5}{|l|}{600} \\
\hline TLD & $\mathrm{Mg}, \mathrm{Ti}$ & $\operatorname{LiF}\left(99,993 \%\right.$ de ${ }^{7} \mathrm{Li} \mathrm{e} 0,007 \%$ de $\left.{ }^{6} \mathrm{Li}\right)$ & $3500-6000$ & $10 \rho G y-10 G y$ \\
\hline 700 & & & & \\
\hline
\end{tabular}

\subsection{1 - Dosimetria de nêutrons térmicos em campos mistos.}

O uso em conjunto do TLD 600 e TLD 700 é utilizado neste trabalho para dosimetria de campo misto (nêutrons e gamas). Este tipo de dosimetria é complicado justamente por se tratar de dois tipos de radiação totalmente diferente que compõem um mesmo campo. A alta seção de choque do ${ }^{6} \mathrm{Li}(940$ b) para a reação $(n, \alpha)$ na região térmica faz com que o TLD 600 seja um bom detector de nêutrons térmicos, porém existem certas ressalvas para seu uso (Piesch, Burgkhardt, \& Sayed, 1978), principalmente em campos de alta fluência de nêutrons. Tanto o TLD 600 e o TLD 700 apresentam respostas para radiação gama, entretanto devido à mudança na fração isotópica o TLD 700 é muito menos sensível a nêutrons térmicos, a figura 11 mostra o comportamento da seção de choque total de absorção para os dois núclideos que compõem a maior parte dos TLD’s 600 e 700. 


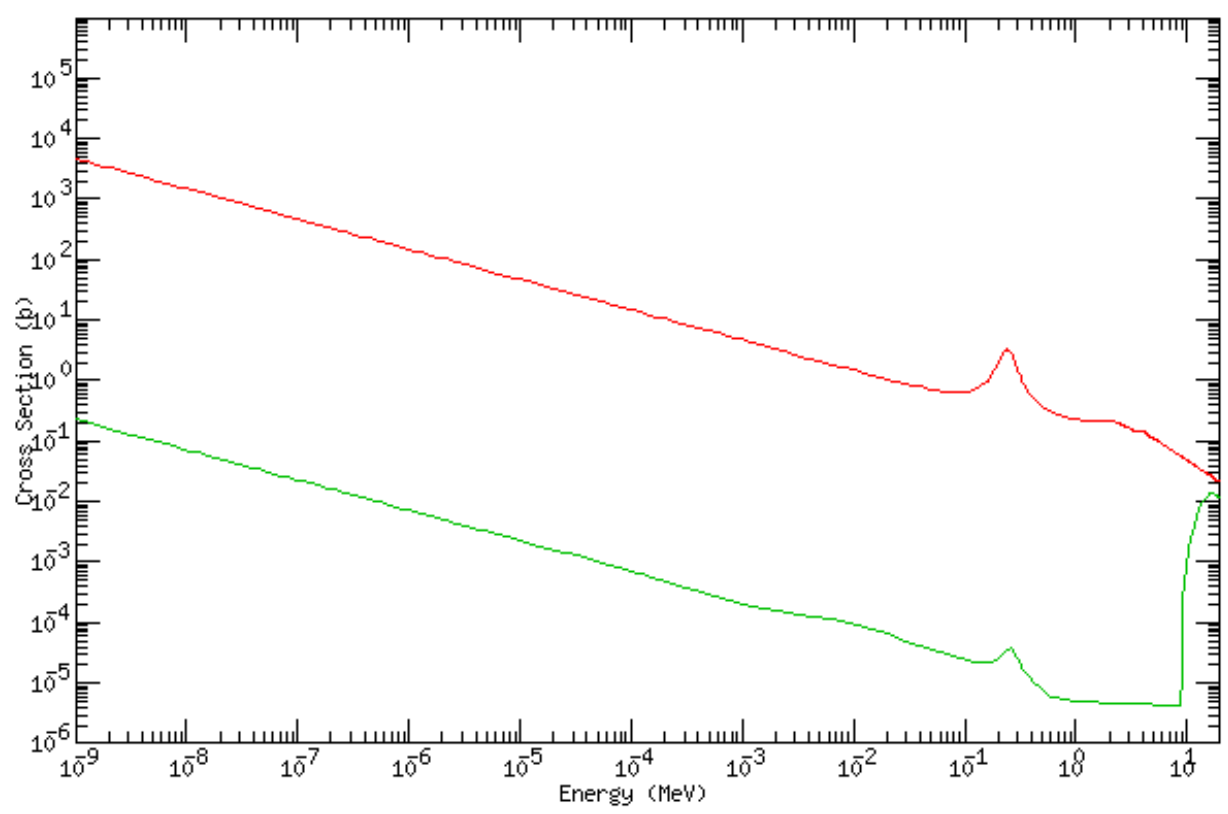

Figura 13 - Seções de choque totais para $0^{6}$ Li (vermelho) e para $0^{7}$ Li (verde) (Korea Atomic Energy Research Institute).

É evidente que a seção de choque para as reações de absorção do ${ }^{7}$ Li são muito menores do que para o ${ }^{6} \mathrm{Li}$, porém os dois TLD's são sensíveis a radiação gama devido ao fato de serem isótopos com a mesma configuração de eletrosfera, espaço do átomo das principais interações com fótons. Os TLD's 600 e 700 não possuem a mesma sensibilidade a radiação gama, mas possuem a mesma curva TL quando irradiados só com gamas; um estudo da sensibilidade dos TLD's 600 e 700 para a radiação gama foram feitos em conjunto com o grupo de pesquisa em BNCT e isto possibilita descontar a resposta gama com mais confiança.

A dosimetria de campo misto com o par TLD 600 e 700, segundo a literatura existente (A. Delgado, 2007), é realizada da seguinte maneira:

A dose devida a nêutrons térmicos ( é feita subtraindo a resposta do TLD 700 ( ) da resposta do TLD 600 ( ), porém existe uma cautela no uso desta técnica 
devido ao fato de que o TLD 700 também tem uma sensibilidade a nêutrons térmicos (Carrillo, Uribe, Woodruff, \& Stoebe, 1987) e apresenta alguns picos na sua curva TL devido aos nêutrons térmicos (Triolo, Brai, Marrale, Gennaro, \& Bartolotta, 2007), mas isto apenas em altas temperaturas da curva TL e sempre menores do que o TLD 600. Esta metodologia de dosimetria de nêutrons foi adotada pelo grupo de pesquisa em BNCT principalmente porque já havia uma experiência com dosimetria termoluminescente e também uma nova leitora de TLD's foi adquirida pelo grupo e além do custo dos TLD's 600 e 700 serem relativamente baratos perto de outros dosímetros.

Os TLD's 700 foram selecionados em um trabalho anterior do grupo de pesquisa (Junior, 2008), já os TLD’s 600 foram selecionados juntamente com o grupo de pesquisa em um trabalho mais recente, e a metodologia utilizada está descrito no anexo $A$ junto com o estudo da sensibilidade gama do TLD 600 e 700. Este selecionamento do TLD 600 e o estudo da sensibilidade gama introduziram dois novos fatores na equação 3.3:

Onde é o fator do selecionamento utilizado e é o fator gama, estes dois fatores estão descritos no anexo $A$ e foram obtidos juntamente com o grupo de pesquisa de BNCT.

Neste trabalho não se utilizou dosimetria absoluta, uma vez que os valores de dose ao redor da blindagem já se encontram dentro dos limites de radioproteção e porque o principal objetivo é observar o efeito relativo de cada blindagem adicionada, porém a curva de calibração do TLD 600 foi feita (Muniz R. O., 2010) bem como a do TLD 700 para medir os valores de dose em Gy dentro da posição de irradiação, onde os níveis de dose são elevados.

\subsection{2 - Dosimetria de radiação gama}

Para quantificar o campo de gamas utilizou-se o TLD 400 que é um bom dosímetro para radiação gama e possui uma alta sensibilidade e um intervalo de uso amplo, sendo utilizado sem restrições devido ao seu uso já consagrado. O selecionamento do TLD 400 e sua calibração também foram realizados em trabalhos anteriores (Junior, 2008). 
Utilizou-se também a dosimetria relativa para a radiação gama a fim de monitorar o valor de dose devido a radiação gama, este valor poderia ocasionalmente aumentar demais devido a reações $(n, \gamma)$ nas melhorias da blindagem.

\subsection{3 - Leitura dos TLD’s e tratamento térmico}

A leitora de TLD utilizada neste trabalho é uma Victoreen modelo $2800 \mathrm{~m}$. A figura 12 mostra a leitora de TLD.

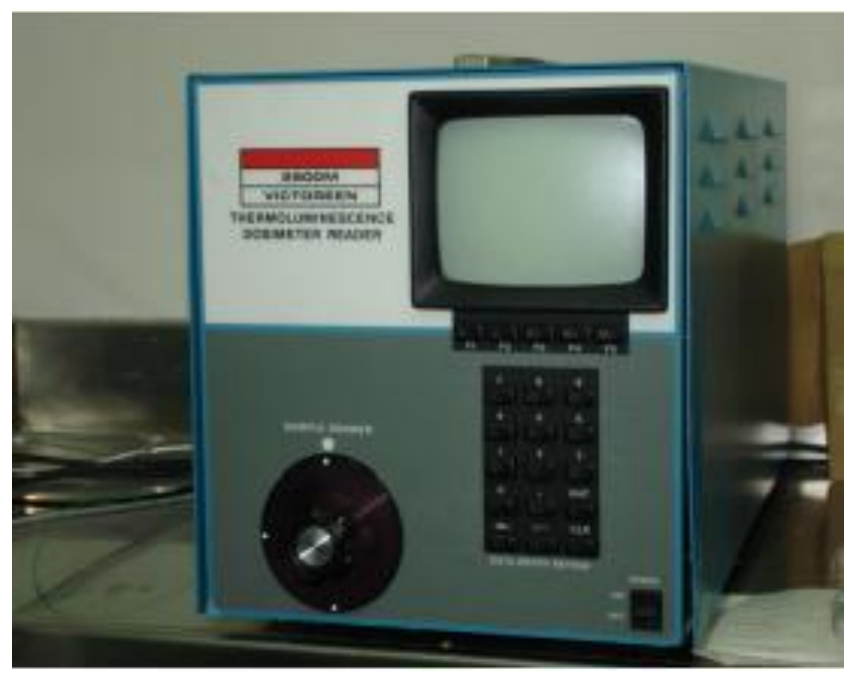

Figura 14 - Leitora de TLD Victoreen 2800 M.

O funcionamento de uma leitora de TLD consiste basicamente em aquecer o TLD que no processo de termoluminescência emitirá fótons de luz, os quais incidem em um fotocátodo e provocam a emissão de elétrons (efeito fotoelétrico).

Estes elétrons são multiplicados em um tubo por uma alta tensão aplicada entre o fotocátodo e o anodo. A figura 13 mostra um esquema simplificado de uma fotomultiplicadora.

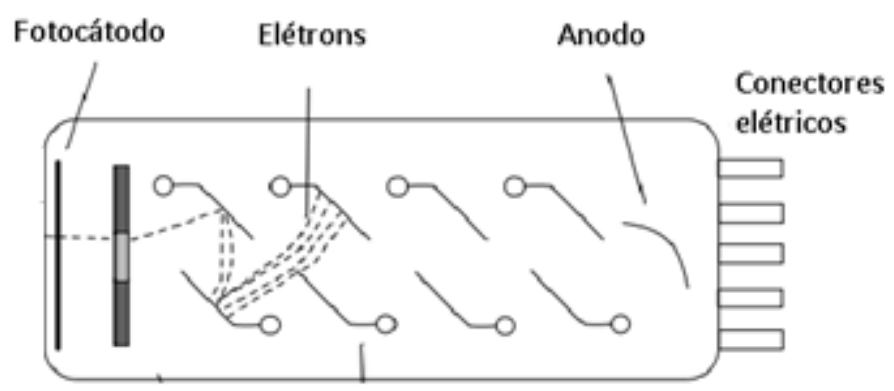

Figura 15 - Esquema simplificado de uma fotomultiplicadora. 
A tensão da fotomultiplicadora é uma ferramenta de ajuste da leitora de TLD para que ela possa ser suficientemente eficiente em casos aonde os fótons incidentes são poucos ou quando são em grande volume. Neste trabalho utilizou-se $500 \mathrm{~V}$ para as medidas utilizando TLD's no lado interno da blindagem e $1150 \mathrm{~V}$ para o lado externo.

Quando se compara os valores das medidas internas com as medidas externas é necessário corrigir com um fator de eficiência. Este fator é obtido através da luz de referência da leitora, esta luz de referência é uma fonte luminosa constante. Através de várias medidas da luz de referência consegue-se estabelecer uma relação entre as duas voltagens utilizadas. A tabela 4 mostra o valor da eficiência obtido.

Tabela 4: Eficiência entre as tensões de $500 \mathrm{~V}$ e $1150 \mathrm{~V}$

EFICIÊNCIA - RAZÃO ENTRE A MÉDIA DE RESPOSTAS DA LUZ DE REFERÊNCIA NA TENSÃO 1150 V E 500 V

\begin{tabular}{lcccc}
\hline Tensão (V) & Média & $\sigma$ Média & Razão & $\sigma$ Razão \\
$\mathbf{5 0 0}$ & 7,2 & 0,3 & & \\
$\mathbf{1 1 5 0}$ & 18264 & 111 & 2537 & 107 \\
\hline
\end{tabular}

Além do ajuste da tensão da fotomultiplicadora é necessário conhecer todos os parâmetros de leitura de cada TLD e sua curva TL. Isto se faz necessário para definir as regiões dosimétricas de interesse dentro da curva TL, e cada curva TL possui seus picos dosimétricos aonde a probabilidade de desarmadilhamento é maior. A figura 15 mostra as regiões de interesse para os TLD's.
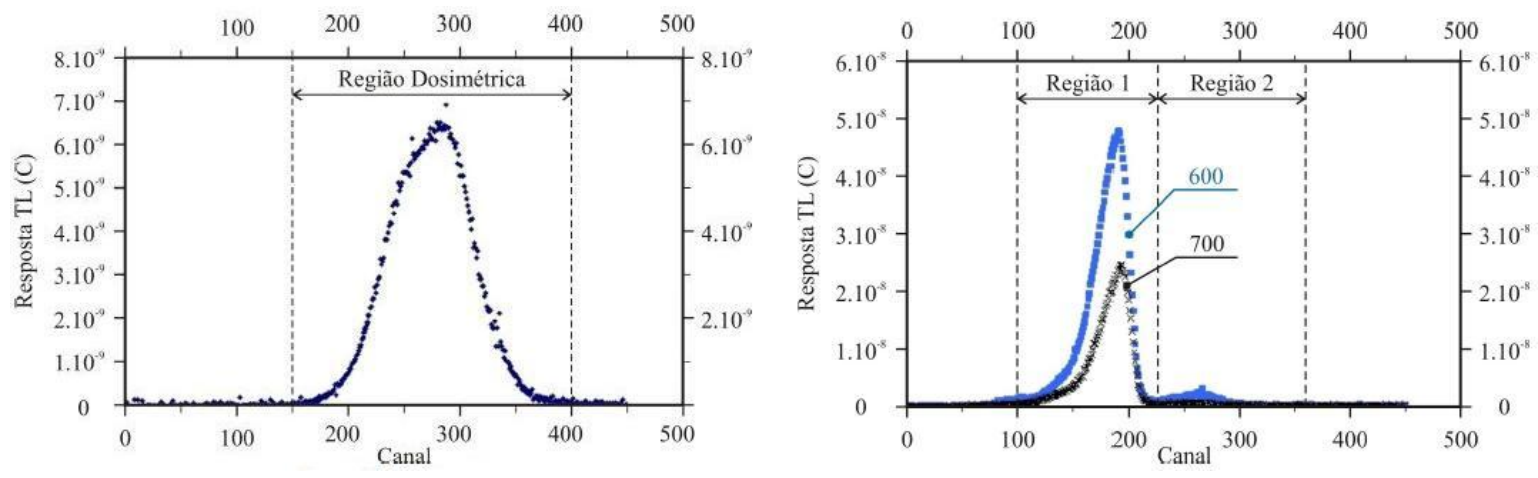

Figura 16 - Curva TL para os TLD's 400 (direita) e TLD's 600 e 700 (esquerda) (Muniz R. O., 2010). 
O TLD 400 possui uma região de interesse entre os canais 150 a 400 da leitora, e os TLD's 600 e 700 possuem duas regiões de interesse: a primeira entre os canais 100 a 220 e a segunda entre os canais 220 a 360, sendo que a primeira região de interesse é considerada o pico dosimétricos. A segunda região de interesse para os TLD's 600 e 700 também é motivo de pesquisa na literatura existente, devido ao fato que existe uma contribuição na curva TL que é devido aos nêutrons incidentes. Neste trabalho considerou-se apenas a primeira região como área dosimétrica mas o grupo de pesquisa em BNCT está estudando o uso do TLD 600 e 700 para entender melhor o funcionamento destes dosímetros em campos mistos.

Com as regiões de interesse das curvas TL identificadas é necessário definir os parâmetros de leitura, para os TLD's utilizados utilizou-se as recomendações do fabricante. A tabela 5 apresenta os parâmetros de leitura utilizados na Victoreen $2800 \mathrm{M}$.

Tabela 5: Parâmetros de leitura utilizados na Victoreen 2800 M

\begin{tabular}{ccccc}
\hline & $\begin{array}{c}\text { Taxa de } \\
\text { aquecimento } \\
\text { Victoreen } \\
\text { 2800M }\end{array}$ & $\begin{array}{c}\text { Temperatura } \\
\text { de pré } \\
\left({ }^{\circ} \mathrm{C} / \mathrm{s}\right)\end{array}$ & $\begin{array}{c}\text { Temperatura } \\
\text { aquecimento } \\
\left({ }^{\circ} \mathrm{C}\right)\end{array}$ & $\begin{array}{c}\text { Tempo de Ciclo } \\
(\mathbf{s})\end{array}$ \\
\cline { 2 - 5 } & 10 & 60 & 400 & 45 \\
\hline
\end{tabular}

Juntamente com o ajuste destes parâmetros a leitora deve estar conectada a uma fonte de nitrogênio (20L/h) para evitar a oxidação da prancheta que aquece o TLD. Após a leitura os TLD's podem ser reutilizados novamente, mas é necessário realizar um tratamento térmico a fim de zerar a resposta do TLD's novamente. Este procedimento é feito utilizando fornos tipo mufla e os parâmetros do tratamento térmico variam para cada tipo de TLD, a tabela 6 mostra os parâmetros do tratamento térmico recomendados pelo fabricante para os TLD's utilizados.

Tabela 6: Parâmetos do tratamento térmico 
Depois do tratamento térmico os TLD’s estão disponíveis para novas medidas e são acomodados em uma matriz aonde são preservadas suas identificações de linha e coluna, isto é feito para preservar sua calibração e também para que posteriormente se possa realizar um histórico de cada TLD e assim observar um eventual comportamento estranho do dosímetro.

\section{3 - Detectores de ativação tipo folha de ouro}

As folhas de ouro $(\mathrm{Au})$ utilizadas como detectores de ativação são pequenos discos de Au hiper puro com $10 \mathrm{~mm}$ de diâmetro e 0,13mm de espessura. Estas folhas de $\mathrm{Au}$ quando expostas a um fluxo de nêutrons ficam ativadas conforme descrito na seção 2.5, e em seguida as folhas de Au são submetidas a uma espectrometria gama utilizando um detector de Germânio Hiper Puro (HPGe) da ORTEC, localizado em laboratório do reator IPEN/MB-01. A figura 17 mostra o detector de espectrometria gama e a eletrônica associada.
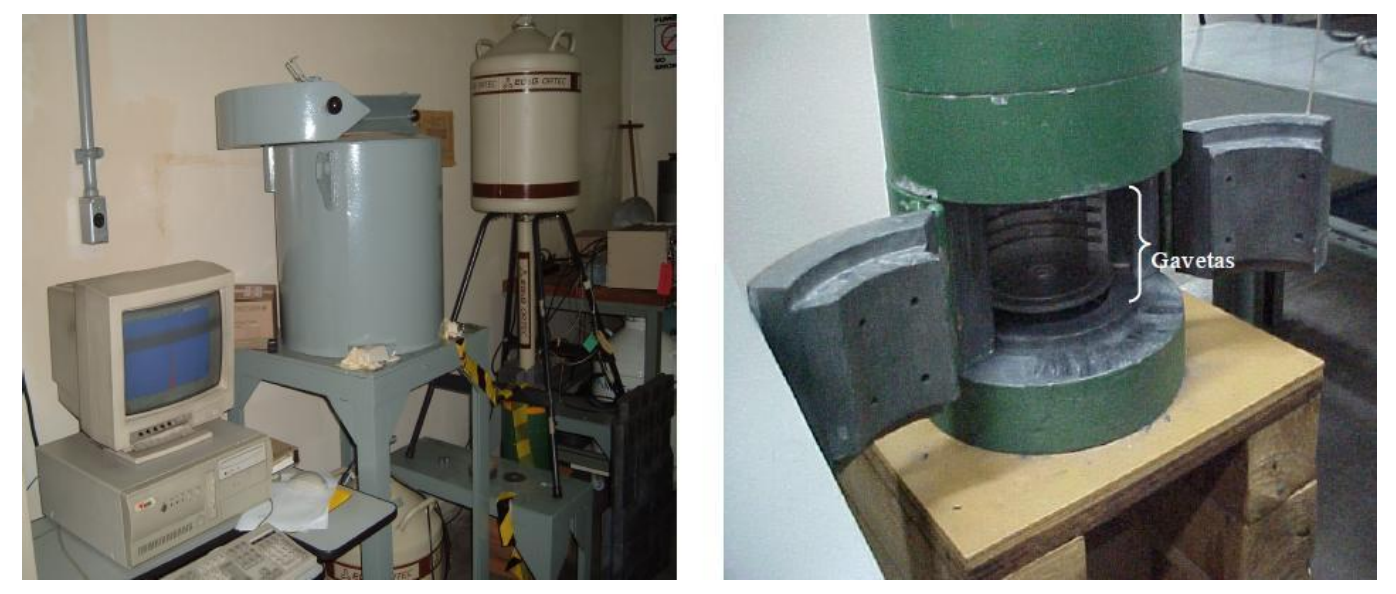

Figura 17 - Eletrônica associada (direita) e o detector HPGe (esquerda).

O HPGe é um detector semicondutor aonde as interações da radiação gama faz com que elétrons saltem da camada de valência para a camada de condução, aonde sujeitos a um campo elétrico podem ser coletados em um circuito externo. Porém o HPGe precisa ser mantido a baixas temperaturas para que apenas estes elétrons consigam atravessar a banda proibida e não os elétrons devido a agitações térmicas. A eletrônica associada ao HPGe é a padrão de instrumentação nuclear para espectrometria gama com o HPGe e consiste de: fonte de alta tensão, um pré - amplificador e amplificador, conversor de 
pulso analógico para digital, e estes associados a um discriminador integral e a um multicanal.

O multicanal registra cada contagem de uma determinada energia dos fótons incidentes em um determinado canal, e esta contagem é registrada e analisada pelo software Maestro 3.2 da ORTEC, que disponibiliza as contagens liquidas (contagens sem background) e o life time (tempo de contagem subtraído o tempo morto); neste trabalhou foram realizadas medidas utilizando um tempo morto de até $2 \%$. Utilizou-se a terceira gaveta (distante aproximadamente $4 \mathrm{~cm}$ do detector) do HPGe para realizar a espectrometria gama, esta gaveta teve sua eficiência determinada em conjunto com o grupo de pesquisa em BNCT e é a que se utiliza rotineiramente (Muniz R. O., 2010).

Além das contagens da espectrometria gama e os intervalos de tempo envolvidos (irradiação, espera e contagem) é necessário obter com precisão as massas das folhas de Au para o cálculo da quantidade de núcleos alvos, e para realizar tal medida foi utilizado uma balança Mettler H2O.

Com todos esses valores é possível medir, utilizando as equações demonstradas na seção 2.5, o fluxo térmico e epitérmico nos experimentos envolvendo a blindagem biológica da instalação de pesquisa para BNCT.

\section{4 - Simulações com o MCNP5}

As simulações utilizando o software MCNP5 foram realizadas em um computador do centro de engenharia nuclear com as seguintes configurações:

- Processador de quatro núcleos Intel ${ }^{\circledR}$ Core $^{\mathrm{TM}} 2$ Quad @2.83 GHz

- Memória RAM de 8062 MB

- Sistema operacional LINUX

O input da simulação é o arquivo de entrada que se deve fornecer ao software para que este realize a simulação desejada, e neste arquivo deve estar todos os parâmetros envolvidos na simulação. O input é constituído de três blocos: 
1) Primeiro bloco: Neste bloco são definidas as células que compõem a geometria da simulação, neste bloco também é definido o tipo de material e sua densidade também.

2) Segundo bloco: Neste bloco são definidas as superfícies que são utilizadas para definir as células do primeiro bloco.

3) Terceiro bloco: Neste bloco são definidos as composições dos materiais, as seções de choque, a fonte, os parâmetros de controle da simulação e os cartões de registro (tallies) utilizado para se obter os valores de interesse.

No primeiro bloco é descrito a geometria da simulação, e neste caso foi modelado a blindagem biológica (BB) de acordo com o seu projeto original, porém devido ao fato de que a BB não é chumbada na parede da piscina do reator, uma fresta de $1 \mathrm{~mm}$ foi colocada entre a parede do reator, este valor corresponde a uma média estimada. Como pode se perceber na figura 1 a parede do reator tem um formato cilíndrico, portanto esta fresta não é um valor fixo e possui um valor máximo de aproximadamente $4 \mathrm{~mm}$ na extremidade da BB e no centro da BB esta fresta é praticamente inexistente. A figura 18 mostra a modelagem da BB utilizada no software.
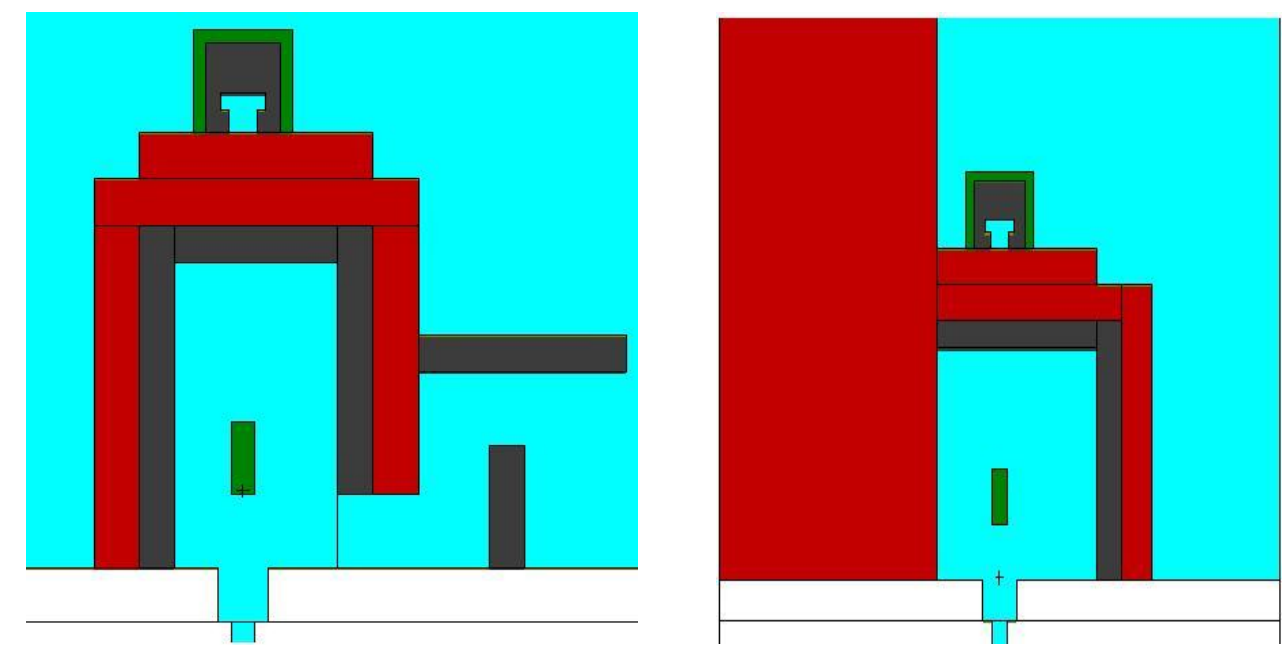

Figura 18 - Modelagem da blindagem biológica; plot superior (esquerda) e plot lateral (direita).

A cor verde do plot representa o chumbo, a cor vermelha representa o concreto normal, a cor branca representa o concreto da piscina (barita) do reator e a cor cinza representa a parafina. Neste plot a blindagem interna está retirada (canal de irradiação aberto) e a fresta entre a BB e a parede do reator não pode ser visualizada devido à 
escala do plot. A distância entre a superfície da parede do reator e a BB é apenas $1 \mathrm{~mm}$, e estão juntamente com todas as outras superfícies da simulação, no segundo bloco do input.

No terceiro bloco do input está definido a fonte e a composição dos materiais e as suas seções de choque. As composições dos materiais podem ser definidas em fração de massa ou em fração atômica, e a tabela 7 apresenta as composições dos materiais utilizados e as bibliotecas de seções de choque utilizadas.

Tabela 7: Composições e seções de choque dos materiais utilizados na modelagem da blindagem biológica

\begin{tabular}{|c|c|c|}
\hline Material & Composição & $\begin{array}{l}\text { Seção de } \\
\text { choque }\end{array}$ \\
\hline $\mathrm{Ar}$ & N (79\%); O (21\%) & ENDF - VI \\
\hline Barita & $\begin{array}{l}\mathrm{O}(58 \%) ; \mathrm{H}(22 \%) ; \mathrm{Al}(0,6 \%) ; \mathrm{Na}(0,1 \%) ; \mathrm{Mg}(0,2 \%) ; \\
\mathrm{Si}(1,7 \%) ; \mathrm{Fe}(0,4 \%) ; \mathrm{S}(8 \%) ; \quad \mathrm{Ba}(7 \%)\end{array}$ & ENDF/B-VI \\
\hline & $\mathrm{O}(58 \%) ; \mathrm{H}(10 \%) ; \mathrm{Al}(3 \%) ;$ & \\
\hline Concreto Comum & $\begin{array}{l}\text { Na }(2 \%) ; M g(0,1 \%) ; \text { Si }(21 \%) ; \mathrm{K}(0,9 \%) ; \mathrm{Ca}(4 \%) ; \\
\text { Fe }(0,4 \%)\end{array}$ & ENDF/B-VI \\
\hline Parafina * & $H(2) ; C(1)$ & ENDF/B-VI \\
\hline Chumbo & ${ }^{208} \mathrm{~Pb}(53 \%) ;{ }^{207} \mathrm{~Pb}(22 \%) ; \quad{ }^{206} \mathrm{~Pb}(25 \%)$ & ENDF/B-VI \\
\hline
\end{tabular}

* Fração atômica.

No terceiro bloco também é incluído as informações sobre a fonte radioativa a ser empregada na simulação, os parâmetros envolvidos na descrição da fonte são basicamente: tipo de fonte (superficial, volumétrica ou pontual), espectro energético, direção de vôo e tipo de partícula.

Os nêutrons que percorrem o canal de irradiação da instalação são provenientes das fissões nucleares que ocorrem dentro do material combustível do IEA-R1. Modelar o núcleo do reator IEA-R1 é uma tarefa complexa que está além do escopo deste trabalho e envolve diversos parâmetros de engenharia do combustível, posição das barras de controle, potência de operação etc. 
Neste trabalho, foram realizadas simulações para se obter um espectro energético que mais se assemelha ao real. A partir do espectro de fissão de Watt, a face do núcleo do IEA-R1 que está de frente ao canal de irradiação foi simulada.

O espectro de fissão de Watt é a distribuição de energia dos nêutrons produzidos no processo de fissão, existem outras formas de representar esse espectro, porém o de Watt é o espectro de fissão mais utilizado. A utilização deste espectro em uma face do núcleo é uma aproximação do real, já que ele é muito mais válido para as regiões centrais do núcleo. Entretanto, sua utilização não traz grandes erros porque existe material físsil sendo utilizado nas faces do núcleo do reator e os materiais refletores (berílio e grafita) também foram modelados. O espectro de fissão é modelado de acordo com equação (Briesmeister, 2001):

A equação 3.5 pode ser escolhida pelo usuário como função para o espectro energético da fonte e para a reação na região térmica com o ${ }^{235} \mathrm{U}$ os parâmetros e valem respectivamente 0,988 e 2,249, estes valores são fornecidos pelo código (Briesmeister, 2001). A figura 19 mostra a modelagem da face do núcleo do IEA-R1.

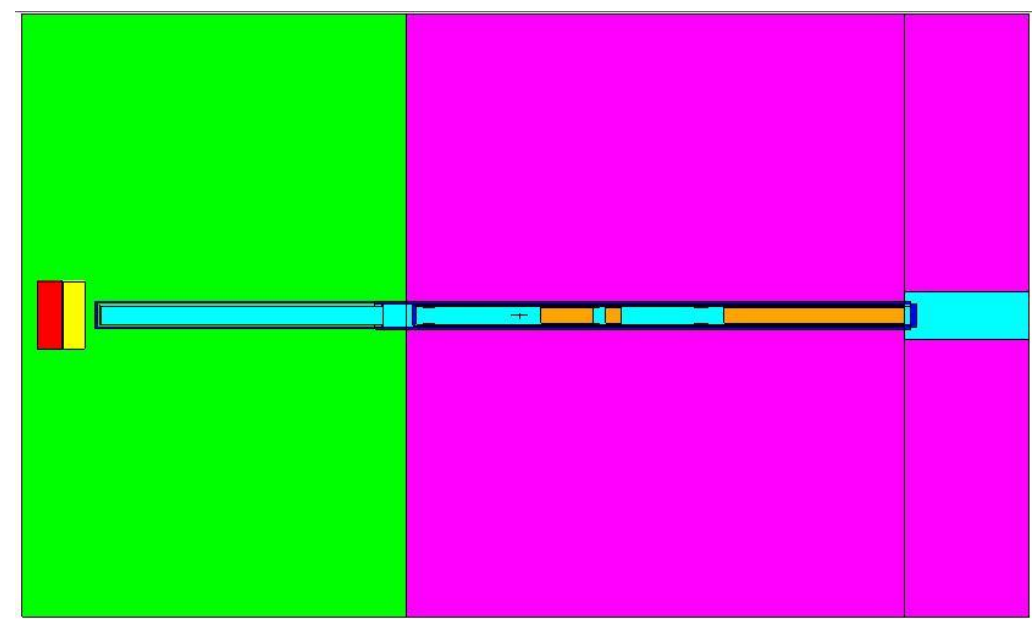

Figura 19 - Plot da modelagem da face do núcleo e do canal de irradiação.

A tabela 8 mostra as composições dos materiais, as seções de choque utilizadas e as cores identificadoras do plot. 
Tabela 8: Composições, seções de choque e cores identificadoras do plot

\begin{tabular}{|c|c|c|c|}
\hline Materiais & Composições & $\begin{array}{l}\text { Seções de } \\
\text { Choque }\end{array}$ & $\begin{array}{c}\text { Cor } \\
\text { identificadora }\end{array}$ \\
\hline Berílio & ${ }^{9} \mathrm{Be}$ & ENDF/B-VI* & Vermelha \\
\hline Grafita & ${ }^{12} \mathrm{C}$ & ENDF/B-VI* & Amarela \\
\hline Água & $\mathrm{H}(2) ; \mathrm{O}(1)$ & ENDF/B-VI* & Verde \\
\hline Aluminio & ${ }^{27} \mathrm{Al}$ & ENDF/B-VI* & Azul escuro \\
\hline Chumbo & $\begin{array}{c}{ }^{208} \mathrm{~Pb}(53 \%) ;{ }_{(25 \%)}^{207} \mathrm{~Pb}(22 \%) ;{ }^{206} \mathrm{~Pb} \\
\text { (25\%) }\end{array}$ & ENDF/B-VI & Laranja \\
\hline $\begin{array}{l}\text { Concreto } \\
\text { Barita }\end{array}$ & $\begin{array}{c}\mathrm{O}(58 \%) ; \mathrm{H}(22 \%) ; \mathrm{Al}(0,6 \%) ; \mathrm{Na} \\
(0,1 \%) ; \mathrm{Mg}(0,2 \%) ; \mathrm{Si}(1,7 \%) ; \mathrm{Fe} \\
(0,4 \%) ; \mathrm{S}(8 \%) ; \mathrm{Ba}(7 \%)\end{array}$ & ENDF/B-VI & Roxa \\
\hline Polietileno & H (15\%); C (85\%) & ENDF/B-VI* & Rosa \\
\hline $\mathrm{Ar}$ & N (79\%); O (21\%) & ENDF - VI & Azul claro \\
\hline
\end{tabular}

A modelagem da face do núcleo e do canal de irradiação até o seu fim foi feito de acordo com o projeto de construção do IEA-R1 e o projeto de construção do canal de irradiação. O canal de irradiação é constituído de alumínio e é divido da seguinte forma:

i. Beam hole externo

ii. Liner

iii. Cartola interna para suporte da calha com os filtros e blindagem interna, esta peça do canal de irradiação é importante para a segurança do reator IEA-R1 porque caso o beam hole for rompido a cartola não permite que a água da piscina saia pelo canal de irradiação.

A figura 20 mostra um plot axial da modelagem geométrica do canal de irradiação onde os itens acima podem ser visualizados. 


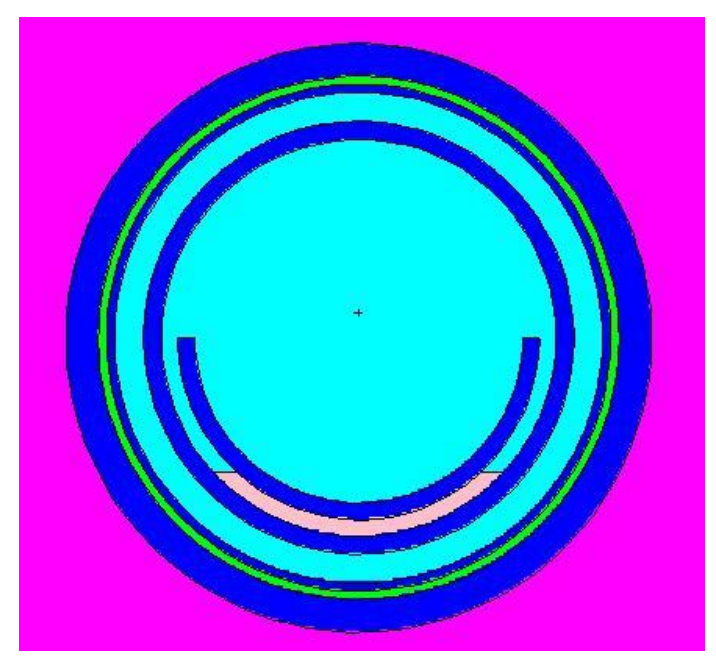

Figura 20 - Plot axial do canal de irradiação.

De fora para dentro está esquematizado o beam hole externo, o liner, a cartola e a calha para o suporte dos filtros e blindagem interna. Existe água entre o beam hole e 0 liner, esta água é proveniente do design original do canal de irradiação onde foi planejado inserir água para servir como blindagem para os pesquisadores. E entre a cartola e calha suporte existe uma peça feita de polietileno para facilitar o deslize da calha na cartola quando se retira a blindagem interna.

A partir dessa modelagem da face do núcleo uma fonte foi caracterizada junto a face interna da parede da piscina do reator, e a partir desta fonte a blindagem biológica da instalação foi simulada juntamente com as melhorias. O espectro energético desta fonte está descrito na figura 21. 


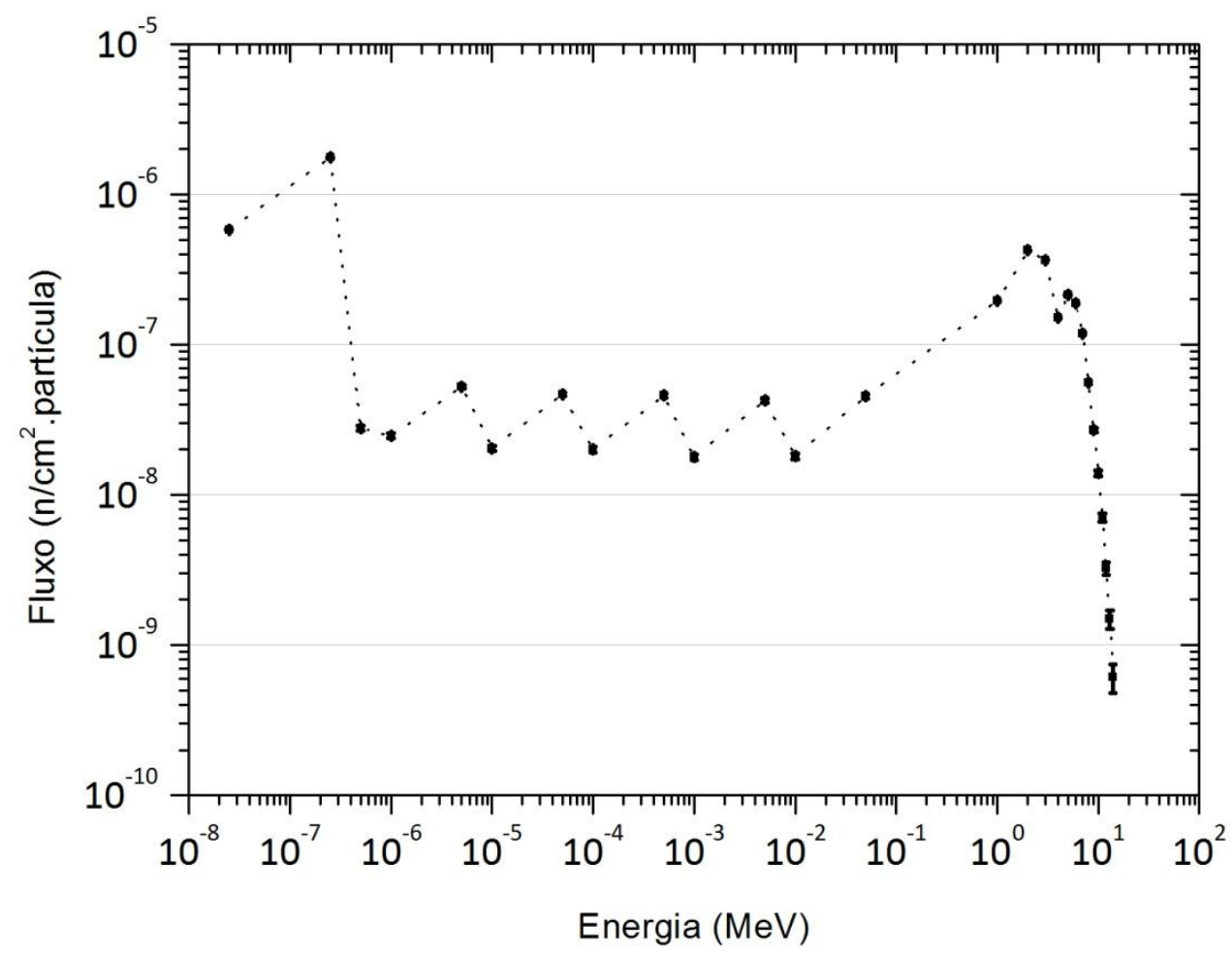

Figura 21 - Espectro energético do fluxo de nêutrons junto à face interna (piscina) da parede do reator IEA-R1.

O espectro obtido para esta fonte condiz com o que se esperava, existe um pico na região térmica que se sobrepõem as demais regiões do espectro, e na região epitérmica existem picos menores do que o pico térmico em uma ordem de grandeza, estes picos na região epitérmica devem ser atribuídos a regiões de ressonâncias. Existe também um pico na região rápida que se sobrepõem a região epitérmica, porém ainda é menor do que o pico na região térmica. Este espectro foi obtido em uma célula de ar junto à face interna (piscina) da parede do reator e na figura 22 é possível observar a célula de ar aonde esta fonte foi caracterizada.

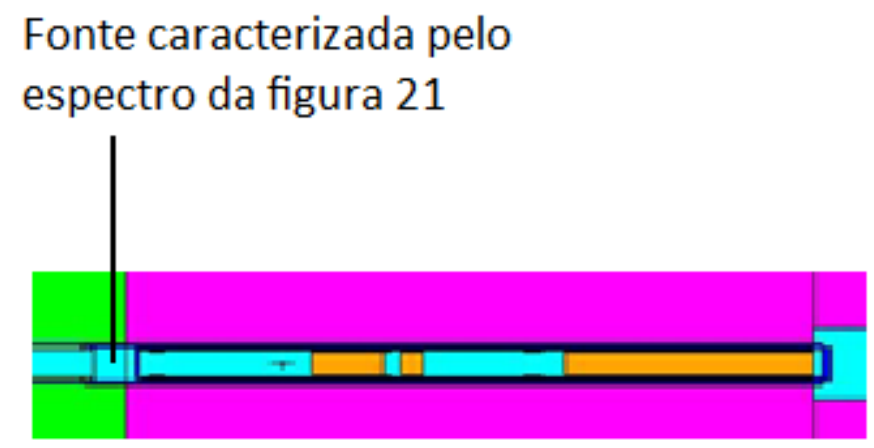

Figura 22 - Célula de ar aonde se caracterizou uma fonte a partir do espectro da figura 21. 
Para simplificar o cálculo e deixar o tempo de simulação menos expressivo essa fonte foi caracterizada a partir do espectro da figura 21 como sendo cilíndrica, homogênea e direcionada apenas para frente (sentido da parede). Essa simplificação, entretanto acarreta alguns erros porque toda a radiação que não entra necessariamente pelo canal de irradiação, ou seja os nêutrons que são espalhados na parede da piscina e mais a frente no canal apesar de virem a fazer parte do campo de irradiação não são levados em conta e também a informação sobre a distribuição radial do espectro energético é perdida quando se decidiu homogeneizar a fonte.

Porém essa fonte pode ser usada para as simulações das melhorias de blindagem porque se deseja apenas observar um comportamento relativo entre a situação sem melhoria nenhuma e com as situações futuras onde vão ser inseridas as melhorias da blindagem. Para um cálculo mais específico aonde se deseja realizar uma medida absoluta todas essas simplificações podem se tornar um empecilho para o cálculo. Além do fato de se necessitar dado mais específico sobre a queima do combustível e operação do reator e como já se afirmou anteriormente essa não é uma tarefa simples e foge totalmente do escopo desse trabalho.

\section{5 - Materiais para blindagem de nêutrons}

Para blindagem de nêutrons o que se usa normalmente é material hidrogenado devido ao fato do nêutron poder perder toda sua energia em apenas uma colisão. Existem infinitos tipos de materiais hidrogenados, e o polietileno é um deles e seu uso é atraente devido ao seu baixo custo.

Existe também a possibilidade do uso de placas de polietileno com certa quantia de

${ }^{10} \mathrm{~B}$ para absorver nêutrons térmicos, o uso de placas de polietileno borado é material consagrado (El-Khatib, Fawzy, \& Abou Taleb, 1996) (Abdel-Haleem, Zohny, \& Zaghloul, 1994) para blindagens de nêutrons. Porém, o custo de placas de polietileno borado é elevado, e uma opção mais em conta é cobrir o polietileno normal com $1 \mathrm{~mm}$ de cádmio. O cádmio é um excelente absorvedor de nêutrons térmicos e com $1 \mathrm{~mm}$ de espessura consegue-se um fator de atenuação de $10^{6}$ (Beckurtz \& Wirtz, 1964), a figura abaixo mostra a curva de seção de choque de absorção total para o cádmio. 


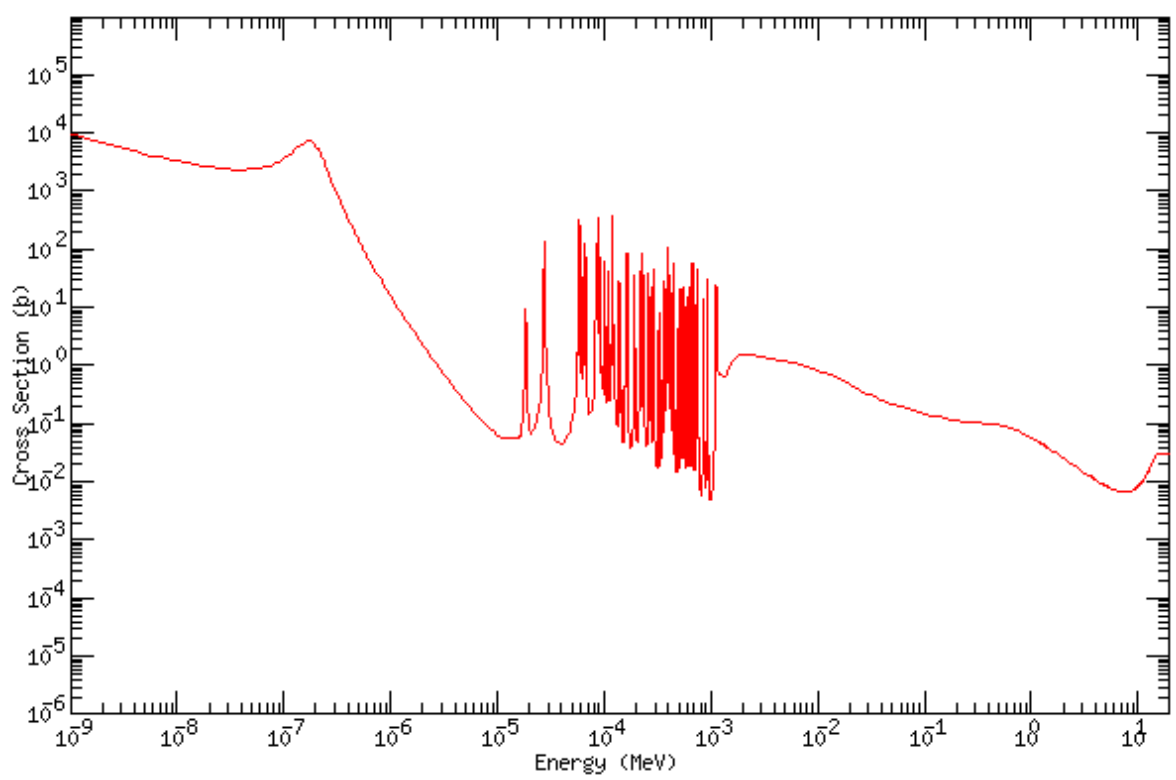

Figura 23 - Curva de seção de choque de absorção total para o cádmio (Korea Atomic Energy Research Institute).

Para a confecção das melhorias na blindagem foi utilizado placas de polietileno com 2,5 cm espessura e lâminas de cádmio de 0,5 $\mathrm{mm}$ de espessura. Também foi adquirida uma placa de polietileno borado (5\%) da empresa norte americana Direct Scientific e 150 kg de cádmio de alta pureza para cobrir parte da blindagem biológica no lado externo. Entretanto o cádmio disponível comercialmente é na forma de pequenos lingotes, necessita se realizar a fundição do material para posteriormente laminá-lo.

O cádmio por ser um material altamente tóxico deve ser fundido com cuidado e em laboratórios apropriados, entretanto para uma pequena quantidade é possível realizar a fundição no IPEN, já a laminação não poderia ser realizada no IPEN porque as laminadoras trabalham com a elaboração de material combustível e laminar cádmio contaminaria os rolos. Foram feitos orçamentos para laminação do cádmio fora do IPEN, porém os valores foram altíssimos, fazendo que não fosse possível laminar o cádmio para a conclusão deste trabalho.

Existem materiais de blindagem para nêutrons contendo hidrogênio e concentrações de boros na forma de material flexível ou tipo pasta como se fosse uma massa de vidraceiro. A regra geral é utilizar material hidrogenado e material com alta seção de choque para absorção de nêutrons. 


\section{4 - RESULTADOS E DISCUSSÃO}

Nesta seção do trabalho estão os principais resultados obtidos de medidas experimentais, simulações utilizando o código MCNP5 e as discussões sobre os resultados obtidos. Todas as blindagens desenvolvidas neste trabalho foram planejadas visando reduzir a dose devido a nêutrons térmicos ao redor da instalação, sem aumentar significativamente a dose gama nesta região e de modo a não interferir no funcionamento da instalação.

A instalação possui um sistema de garras que conduz as amostras até o suporte de irradiação e um sistema de câmeras que auxiliam neste procedimento. As blindagens adicionais foram sempre planejadas levando em conta não prejudicar o campo visual do sistema de câmeras, não comprometer o funcionamento do sistema de inserção de amostras. Muitas vezes, não prejudicar o campo visual das câmeras foi um fator limitante para o planejamento das blindagens adicionais sendo que existem três câmeras que monitoram o canal de irradiação. A figura 24 mostra uma foto da posição de irradiação quando a blindagem interna está retirada, onde é possível ver o trilho e uma das câmeras da instalação.

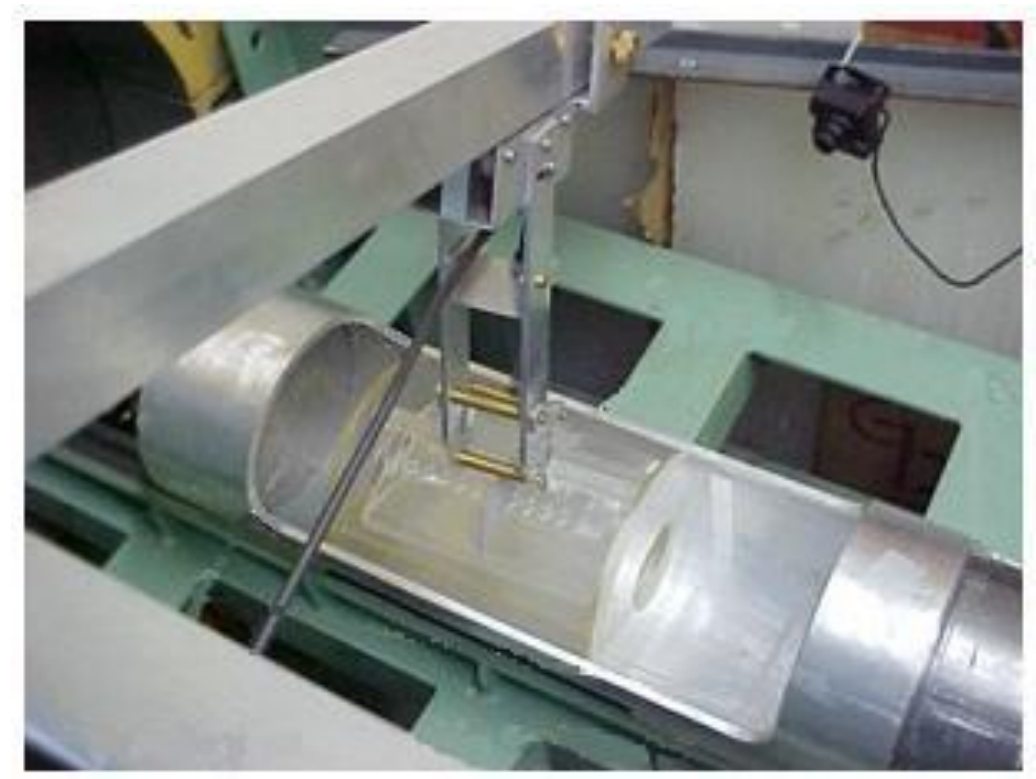

Figura 24 - Trilho para colocar amostras na cesta de irradiação e uma das câmeras da instalação. 
A estratégia adotada para a evolução do trabalho foi tentar diminuir o mais rápido possível a interferência para poder proporcionar um maior tempo disponível para o uso da instalação visto que na época existiam diversos usuários com diferentes necessidades. Por exemplo, o uso da instalação para experimentos envolvendo blindagens necessita de um intervalo de tempo alto para a coleta de dados necessários e sempre utilizando a blindagem interna removida. Já experimentos envolvendo a irradiação de amostras in vivo ou in vitro necessitam de apenas dezenas de minutos, e em alguns casos medidas de dose ao longo de um simulador antropomórfico necessitam de um intervalo de tempo um pouco maior.

Portanto, optou-se por tentar diminuir a interferência o mais rápido possível para que todos os experimentos fossem realizados, tendo em vista que uma boa parte dos usuários são estudantes de pós-graduação com suas respectivas datas limites para entrega de atividades.

Em seguida com auxilio de dosímetros termoluminescentes, detectores de ativação e o código MCNP, foram confeccionadas blindagens adicionais definitivas para incrementar a blindagem biológica da instalação.

\section{1 - Blindagens Iniciais e IdentiFINDER}

Utilizando um conjunto de materiais de blindagens já existentes de um laboratório do CEN/IPEN e alguns materiais emprestados de um laboratório do CRPq/IPEN, foi planejado um conjunto de blindagens de fácil e rápida montagem. Na época das medidas envolvendo estas blindagens, o grupo estava no início da elaboração de uma metodologia de dosimetria de nêutrons em campos mistos, e não havia a possibilidade de se utilizar TLD's para a medida, tendo em vista que diversos estudos (Muniz R. O., 2010) ainda precisavam ser realizados para utilizá-los.

Para rapidamente quantificar os efeitos das blindagens adicionadas foi utilizado o detector IdentiFINDER, fabricado pela ThermoScientific, disponibilizado pelo serviço de radioproteção do IEA-R1. Este aparelho possui um detector de $\mathrm{He}^{3}$ que é altamente sensível a nêutrons térmicos, 5530 barns para a reação ${ }^{3} \mathrm{He}(n, p)$ (Knoll, 1979).

Esta etapa do trabalho foi fundamental para guiar as futuras atividades e também conseguir quantificar a sensibilidade dos equipamentos instalados no canal de irradiação 
seis que sofrem a interferência em background durante a realização dos experimentos na área de BNCT. Os materiais disponíveis foram caixas com parafina cobertas com laminas de cádmio e placas de polietileno borado (5\%) de diversos tamanhos.

A primeira blindagem adicionada foi uma cortina de cádmio na janela do canal de irradiação para eliminar parte dos nêutrons térmicos e um conjunto de blocos de chumbo por trás para provocar espalhamentos no feixe e atenuar o campo de gamas. A figura 25 mostra a janela do canal de irradiação antes e depois da adição desta blindagem
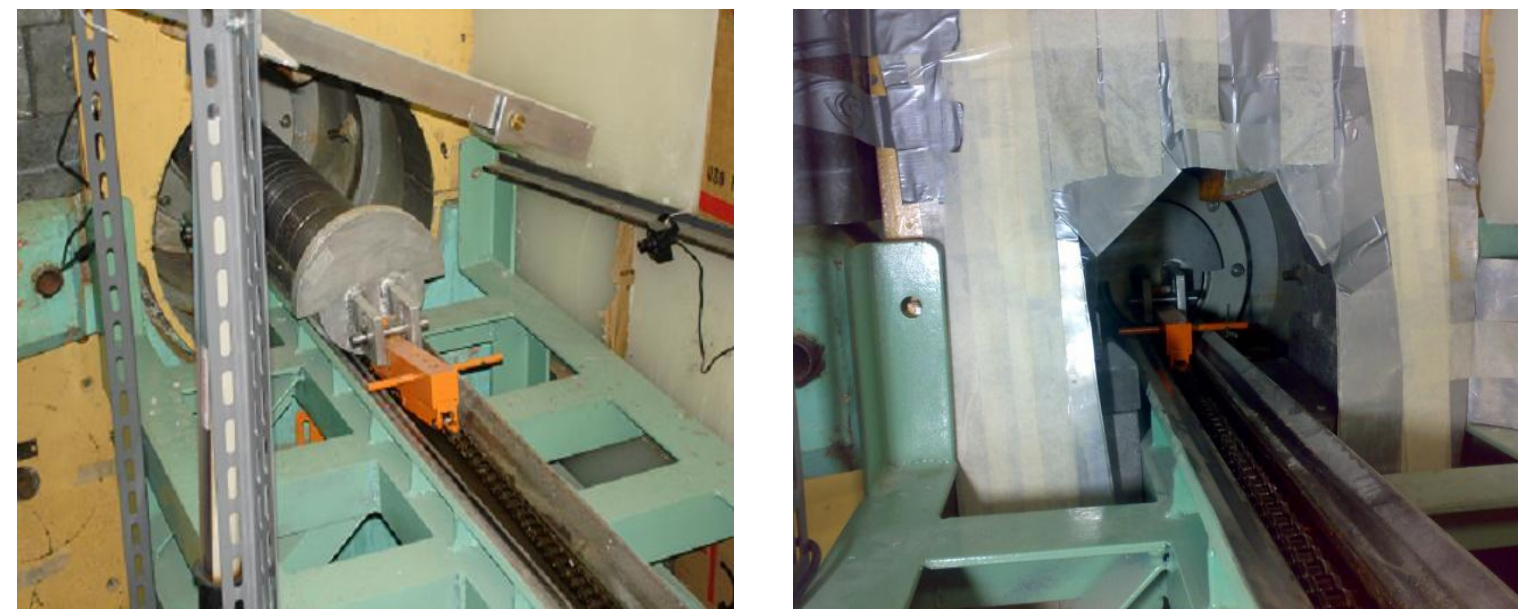

Figura 25 - Janela do canal de irradiação antes e depois da adição da blindagem.

Logo em seguida, foi colocado um conjunto de caixas de parafina cobertas com cádmio em cima da mesa de apoio, de maneira a fazer uma cobertura desde a parede do reator até o fim do trilho que retira a blindagem interna. Utilizaram-se as caixas de parafina por serem feitas de material hidrogenado que atenua a energia dos nêutrons $\mathrm{e}$ as lâminas de cádmio de $1 \mathrm{~mm}$ que possui um fator de absorção na ordem de $10^{6} \mathrm{e}$ absorvem uma boa parte dos nêutrons térmicos.

Com esse conjunto de caixas de parafina cobertas com cádmio o objetivo era conter o feixe de nêutrons que sai do canal de irradiação e se espalha ao percorrer o trilho da mesa de apoio. A figura 26 mostra a mesa de apoio do canal de irradiação antes e depois do arranjo das caixas. 

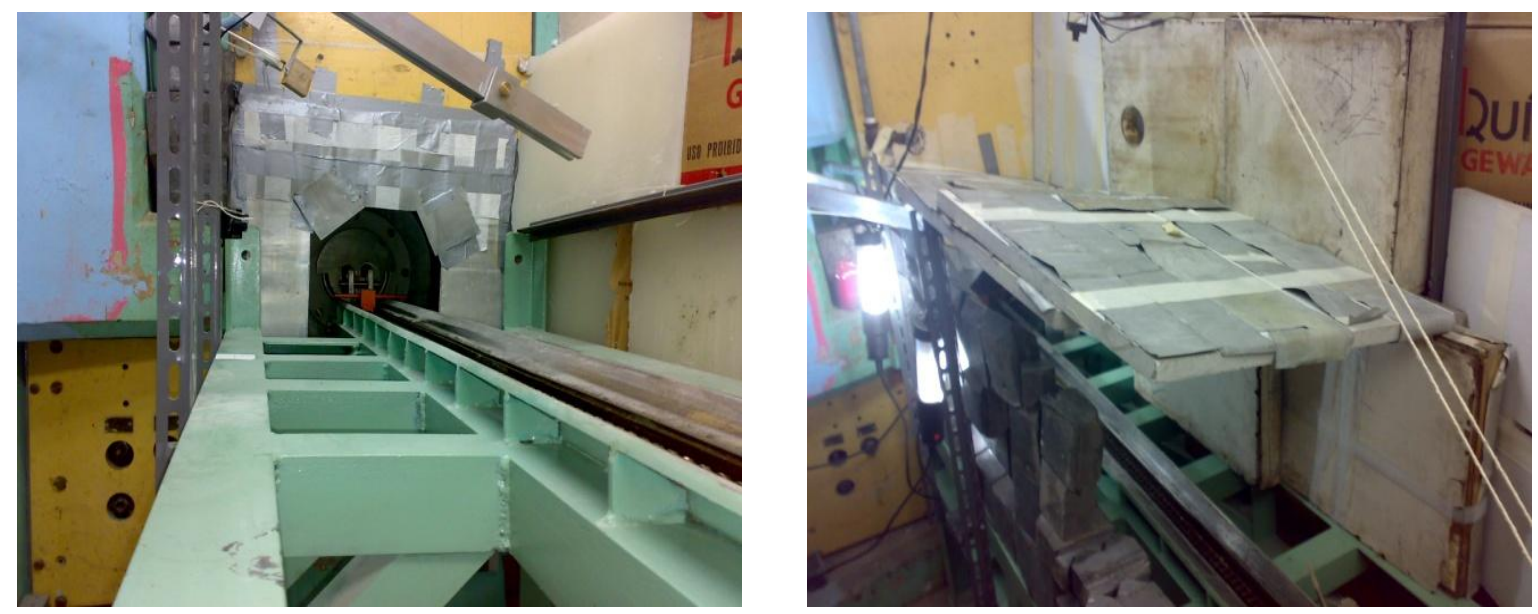

Figura 26 - Mesa de apoio antes e depois da adição da blindagem.

E por último, duas placas de polietileno borado foram posicionadas no lado externo da blindagem externa de frente aos equipamentos do canal de irradiação seis. Estas placas e toda a junção entre blindagem e a parede do reator foram cobertas com $1 \mathrm{~mm}$ de cádmio. A placa de polietileno borado por ser material hidrogenado também atenua a energia dos nêutrons que escapam da blindagem biológica e a presença do ${ }^{10} \mathrm{~B}$ diluído nas placas e as lâminas de cádmio aumentam a absorção de nêutrons térmicos.

A figura 27 mostra a blindagem externa antes e depois de adicionar as placas e as lâminas de cádmio.
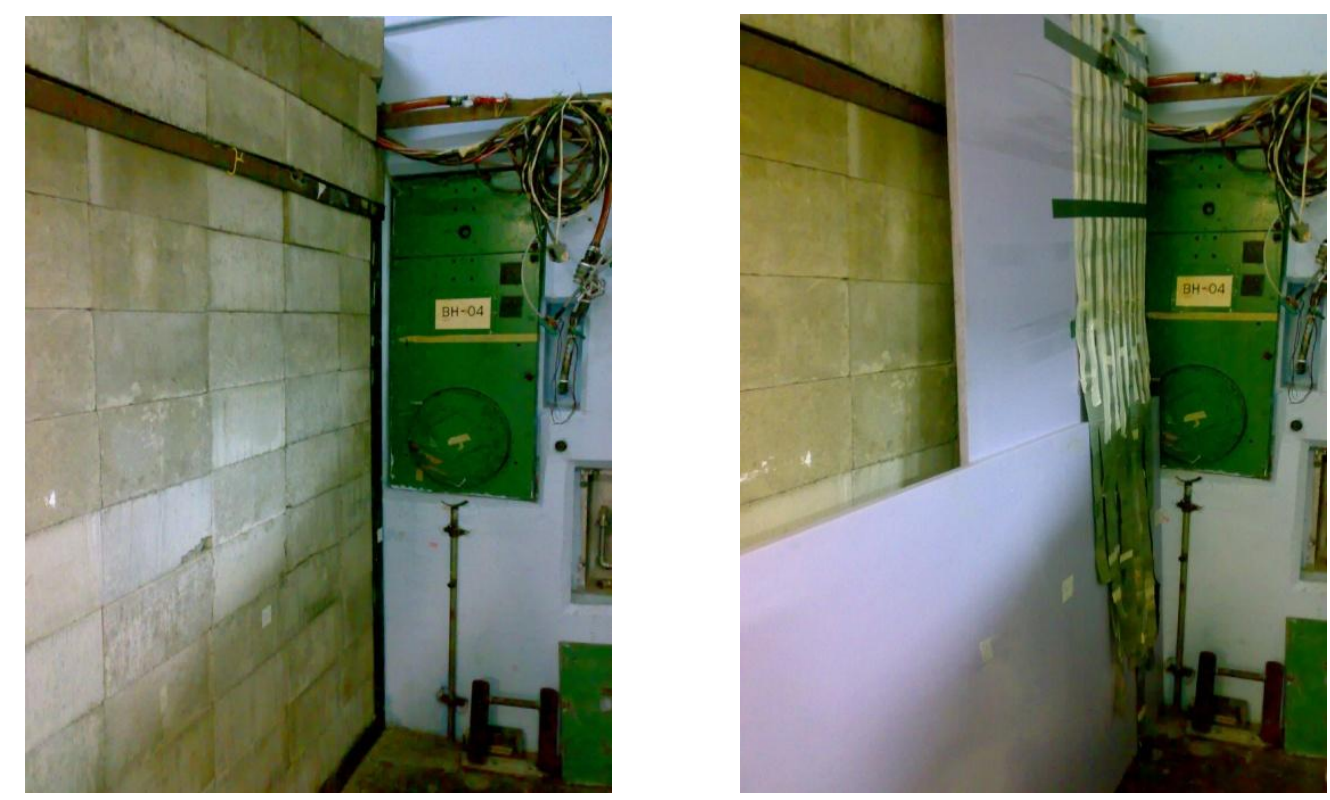

Figura 27 - Blindagem externa antes e depois da adição da blindagem. 
Para se quantificar o efeito de cada blindagem adicionada foram determinados três pontos no lado externo da blindagem biológica na face em frente aos equipamentos do canal de irradiação seis, estes pontos estão mostrados na figura 28 e percorrem a blindagem biológica no lado externo desde a parede do reator até próximo do beam catcher.

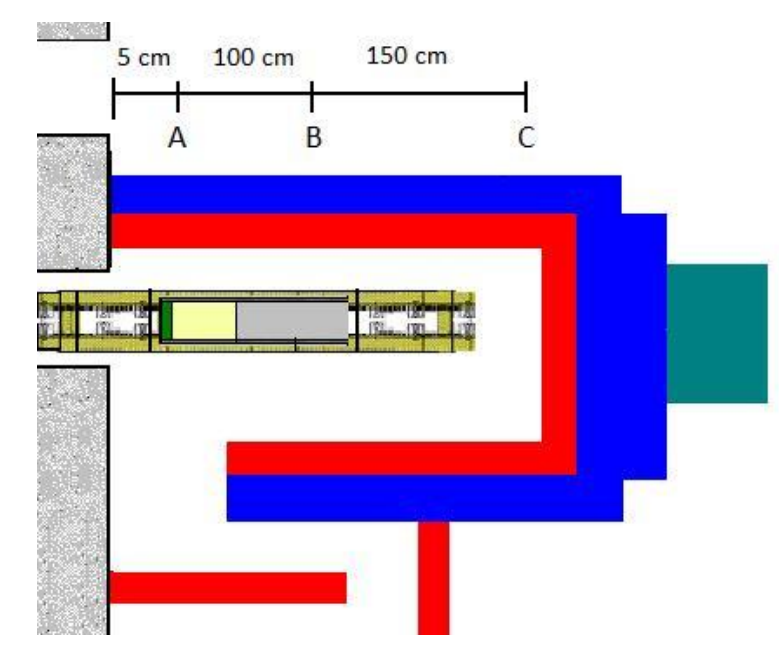

Figura 28 - Pontos para medida dos efeitos das primeiras blindagens adicionadas.

Com o aparelho IdentiFINDER foi quantificado o efeito de cada blindagem adicionada a partir das contagens por segundo (c.p.s) obtidas no detector de ${ }^{3} \mathrm{He}$. A metodologia adotada foi medir as taxas de contagens com a blindagem interna inserida (canal de irradiação fechado) e depois as taxas de contagens com a blindagem interna removida (canal de irradiação aberto). Ao dividir as taxas de contagens com a blindagem interna removida ( ) pelas taxas de contagens com a blindagem interna inserida ( ) obtém-se uma razão que serve de parâmetro para quantificar o efeito de cada blindagem adicionada. Quanto mais próximo de 1 essa razão atingir menor será a interferência causada nos equipamentos do canal de irradiação seis. Após cada blindagem adicionada nesta etapa do trabalho esta razão foi obtida nos pontos da figura 28; a tabela 9 mostra essas razões. 


\begin{tabular}{cccc}
\hline $\begin{array}{c}\text { Pontos da } \\
\text { Blindagem }\end{array}$ & A & B & C \\
\hline Situação inicial & $4,00 \pm 0,60$ & $5,48 \pm 0,82$ & $6,67 \pm 1,00$ \\
Primeira blindagem & $2,70 \pm 0,40$ & $1,50 \pm 0,22$ & $2,00 \pm 0,30$ \\
Segunda blindagem & $2,55 \pm 0,40$ & $1,30 \pm 0,19$ & $1,47 \pm 0,22$ \\
Terceira blindagem & $1,21 \pm 0,18$ & $1,30 \pm 0,19$ & $1,25 \pm 0,18$ \\
\hline
\end{tabular}

O que se nota da tabela 9 é que a melhor redução atingida foi após a inserção da primeira blindagem que foi constituída de uma cortina de cádmio e pequenos blocos de chumbo na saída do canal de irradiação e é justamente por estar nesta saída que houve a melhor redução, o feixe não é tão espalhado dentro do canal de irradiação e a cortina de cádmio consegue absorver uma parte significante dos nêutrons térmicos do feixe.

Mantendo a primeira blindagem, com a segunda blindagem em cima da mesa de apoio atingiu-se uma pequena redução que nos pontos $A$ e $B$ ainda estão dentro das incertezas da primeira redução atingida, acredita-se que essa redução foi pequena porque as caixas de parafina não conseguiram conter o feixe adequadamente devido a frestas entre as posições da caixas.

Porém considerou-se que de fato houve uma pequena redução e que estas incertezas são relativamente altas devido ao fato do IdentiFINDER não conseguir estabilizar em uma taxa de c.p.s constante. Tal fato se deve aos seguintes fatores: o background do próprio salão dos experimentos não é constante, os pontos medidos são muito próximos ao canal de irradiação número quatro (figura 26) que aumenta o background sensivelmente e por último devido ao fato do IdentiFINDER ser um detector portátil sujeito a pequenas variações de posicionamento por parte do operador.

$\mathrm{Na}$ terceira blindagem adicionada nesta primeira etapa percebe-se uma redução significativa para os três pontos e esta redução ocorre principalmente para o ponto $A$ 
porque este ponto está posicionado bem no centro das blindagens adicionadas. Porém foi mais difícil estabilizar o equipamento neste ponto porque as taxas de contagens com a blindagem interna inserida ( ) foram muito pequenas e com bastante flutuação.

Depois das três blindagens adicionadas nesta primeira etapa do trabalho foram determinados quatro pontos ao redor dos equipamentos do canal de irradiação para se verificar se a razão atingiria valores próximos de um, e consequentemente verificar se o problema da interferência em níveis de background já estava resolvido apenas com estas blindagens iniciais; a figura 29 mostra os pontos ao redor dos equipamentos do canal de irradiação seis .

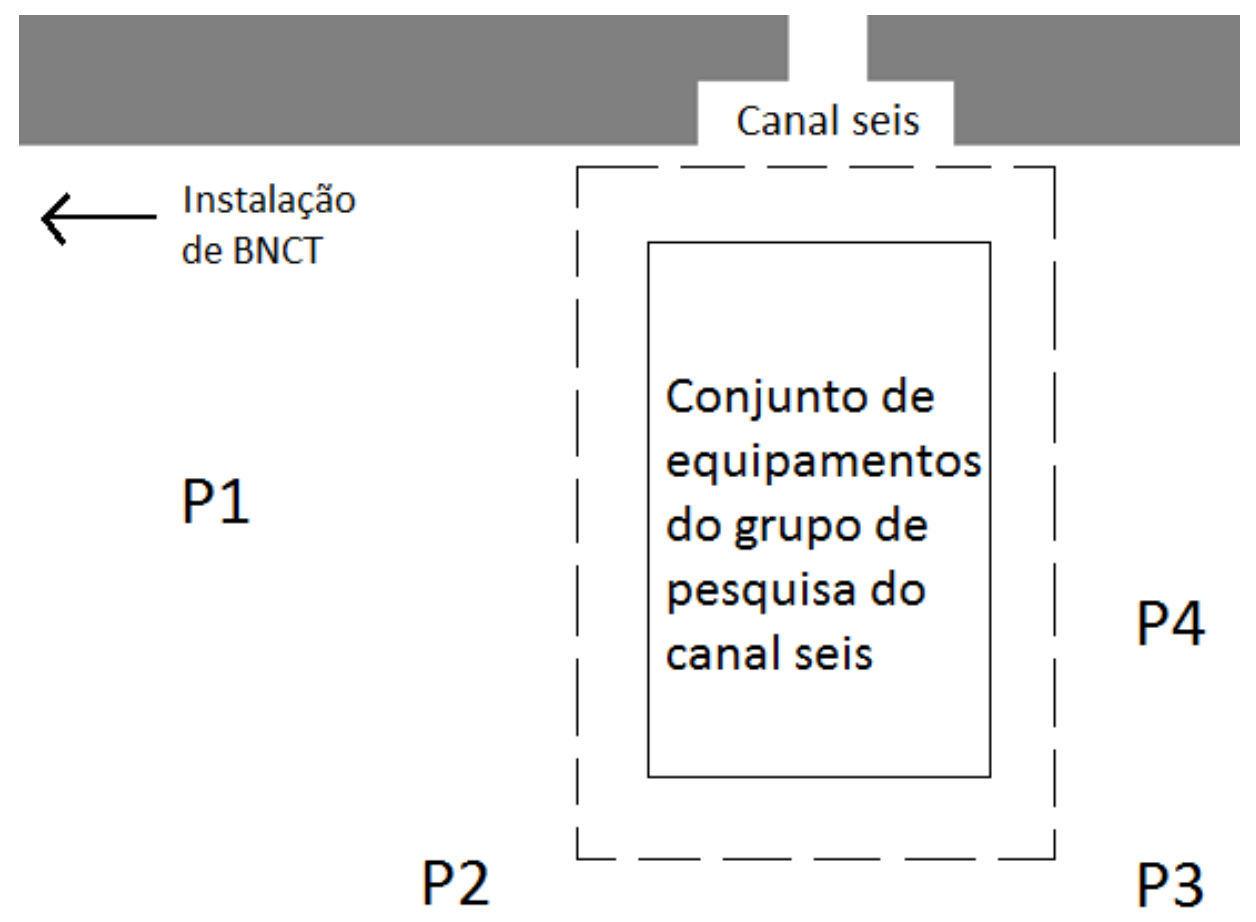

Figura 29 - Pontos ao redor do equipamento do grupo de pesquisa do canal de irradiação seis.

$\mathrm{Na}$ ocasião da realização destas medidas procurou-se determinar um ponto (P1) que estivesse em frente à instalação de BNCT e outros três pontos que contornassem os equipamentos. As razões atingidas nestes pontos são apresentadas na tabela 10. 


\begin{tabular}{ccccc} 
PONTOS & P1 & P2 & P3 & P4 \\
RAZÕES & $1,39 \pm 0,20$ & $1,57 \pm 0,23$ & $1,36 \pm 0,20$ & $1,11 \pm 0,16$ \\
\hline
\end{tabular}

Como é possível observar na tabela não se conseguiu atingir valores próximos de um para os pontos ao redor dos equipamentos, o que se evidencia também é que a interferência em background é sentida ao redor de todo o conjunto de equipamentos. Porém, os valores das c.p.s nestes pontos foram muito inferiores aos obtidos nos pontos da blindagem biológica da instalação para pesquisa em BNCT, mas mesmo assim quando se retirava a blindagem interna as contagens aumentavam em algumas unidades.

Nesta situação além das medidas com o IdentiFINDER foi solicitado ao grupo de pesquisa para verificar se ainda existia a interferência em background e mesmo depois dessas primeiras melhorias adicionadas foi verificado que ao se retirar a blindagem interna na instalação de pesquisas em BNCT ainda existe uma interferência que impossibilita a realização das medidas do grupo de pesquisa do canal de irradiação seis.

Porém esta etapa do trabalho foi fundamental para guiar as simulações com o código MCNP5 para as blindagens definitivas, porque conclui-se que os nêutrons térmicos que provocam a interferência é uma soma dos nêutrons térmicos que escapam da blindagem com os nêutrons termalizados devido a diversos espalhamentos sofridos no salão de experimentos do reator, e estes nêutrons termalizados não são contados nos pontos da blindagem da instalação devido à baixa eficiência do detector em regiões de energia acima da faixa térmica. Portanto as blindagens definitivas necessitam moderar os nêutrons rápidos e absorver os nêutrons térmicos.

\section{2 - Simulações das melhorias definitivas com o MCNP5}

A partir da fonte caracterizada pelo espectro da figura 21 a blindagem biológica da instalação foi simulada com a blindagem interna removida, utilizou-se o tally F4 que determina o fluxo médio em uma célula. E para isso foi definido pequenos volumes de ar 
ao redor da parede de parafina que fica ao lado do canal de irradiação frente aos experimentos do canal seis, na figura 30 é possível observar onde se definiu esses pequenos volumes de ar.

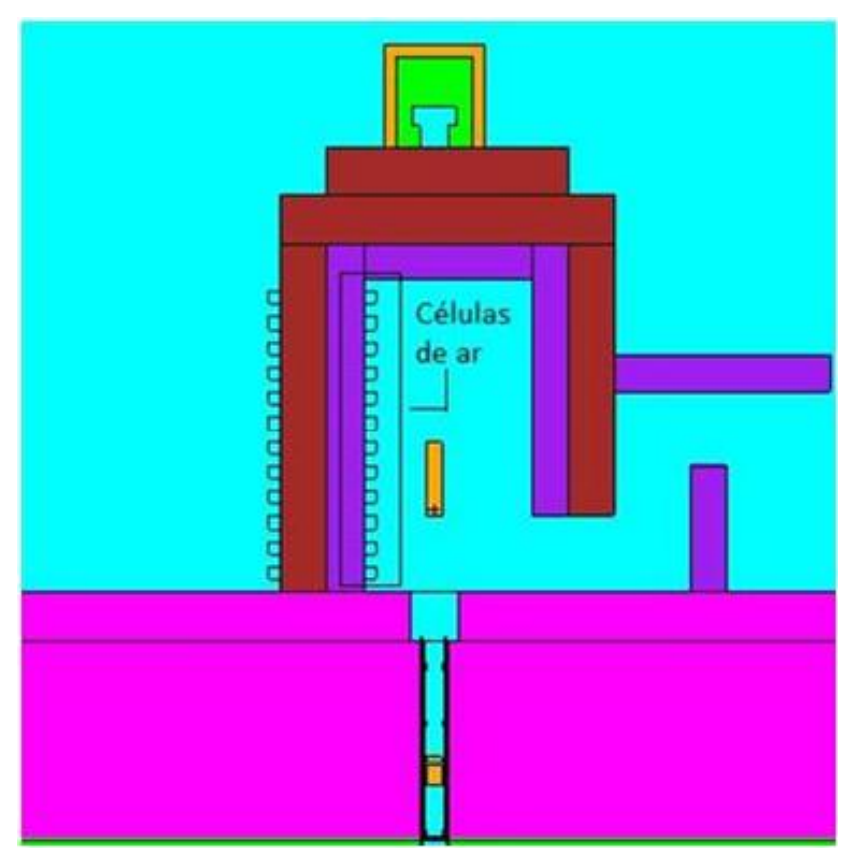

Figura 30 - Plot da modelagem da blindagem biológica onde estão destacadas as regiões de tally.

Esses pequenos volumes de ar estão junto à parede de parafina e percorrem toda extensão da parede, desde a parede do reator até blindagem frontal de parafina. Estes volume de ar estão na forma de chapas de $\operatorname{ar}$ com $1 \mathrm{~cm}$ de espessura e $10 \mathrm{~cm}$ de aresta. Primeiramente simulou-se a blindagem biológica sem a adição de nenhuma melhoria para que fosse possível comparar os efeitos de cada melhoria de blindagem adicionada na modelagem da blindagem biológica. Considerando nêutrons térmicos até $0,5 \mathrm{eV}$, epitérmicos de $0,5 \mathrm{eV}$ a $10 \mathrm{KeV}$ e rápidos para energias maiores que $10 \mathrm{KeV}$, calculou-se como é o comportamento do fluxo de nêutrons nestes três intervalos de energia no interior destas células de ar em torno na blindagem biológica. A figura 31 mostra como se comporta o fluxo de nêutrons. 


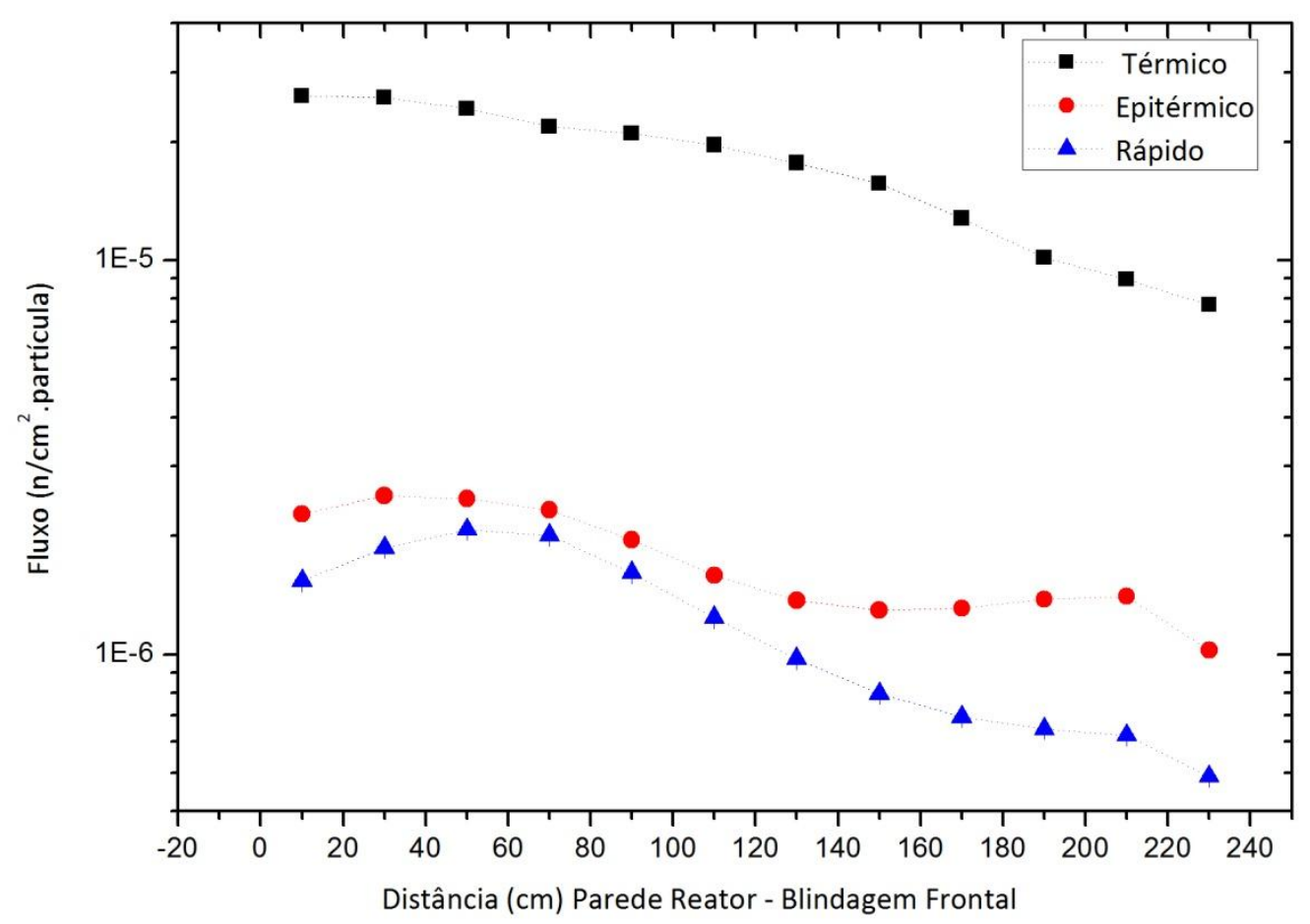

Figura 31 - Comportamento do fluxo de nêutrons ao longo da blindagem biológica no seu lado interno.

A partir desse comportamento é possível observar que existe um alto fluxo de nêutrons térmicos que decresce lentamente à medida que se afasta do canal de irradiação enquanto o fluxo epitérmico e o rápido decrescem mais rapidamente, principalmente a partir da distância de $60 \mathrm{~cm}$ da parede do reator. Isto ocorre porque é nessa posição que está o começo da blindagem interna, quando retirada, e os nêutrons de maior energia espalham mais no chumbo.

Ao se analisar esse comportamento em relação ao espectro da fonte (figura 21) percebe-se que a contribuição dos nêutrons rápidos diminuiu e a contribuição epitérmica fica maior, isto se deve pelo fato da fonte ter sido caracterizada antes do começo do conjunto de filtros e moderadores, portanto o feixe que provêem do canal de irradiação e atinge a blindagem biológica está muito mais espalhado. É possível evidenciar também um pequeno "calombo" no comportamento do fluxo térmico fazendo com que ele não caia tão abruptamente, isto ocorre a partir da distância de $60 \mathrm{~cm}$ (inicio do chumbo) e é a contribuição dos nêutrons do feixe com energias maiores sendo espalhados no chumbo aumentando o fluxo térmico nessa região da parede. No final da blindagem bem junto à blindagem frontal o comportamento do fluxo epitérmico sofre um pequeno aumento, 
isto por que, boa parte dos nêutrons, que estavam na região rápida após sofrerem espalhamentos no chumbo e no restante da blindagem biológica, agora está dentro do intervalo da região epitérmica.

Com esse comportamento referência do fluxo de nêutrons foi simulado uma primeira melhoria definitiva: uma peça de polietileno que fechasse a janela do canal de irradiação da melhor forma possível, permitindo apenas que o suporte de amostras que remove a blindagem interna da instalação fosse retirado. Esta peça de polietileno cobre $10 \mathrm{~cm}$ do canal de irradiação indo até o limite da janela; não se simulou uma peça com espessura maior porque existe uma peça que controla o fim da inserção da blindagem interna no canal de irradiação.

A peça foi simulada como sendo feita de polietileno puro e no fim da peça uma fatia de cádmio foi adicionada com a espessura de $1 \mathrm{~mm}$, o arranjo geométrico dessa peça simulada está mostrado na figura 32.

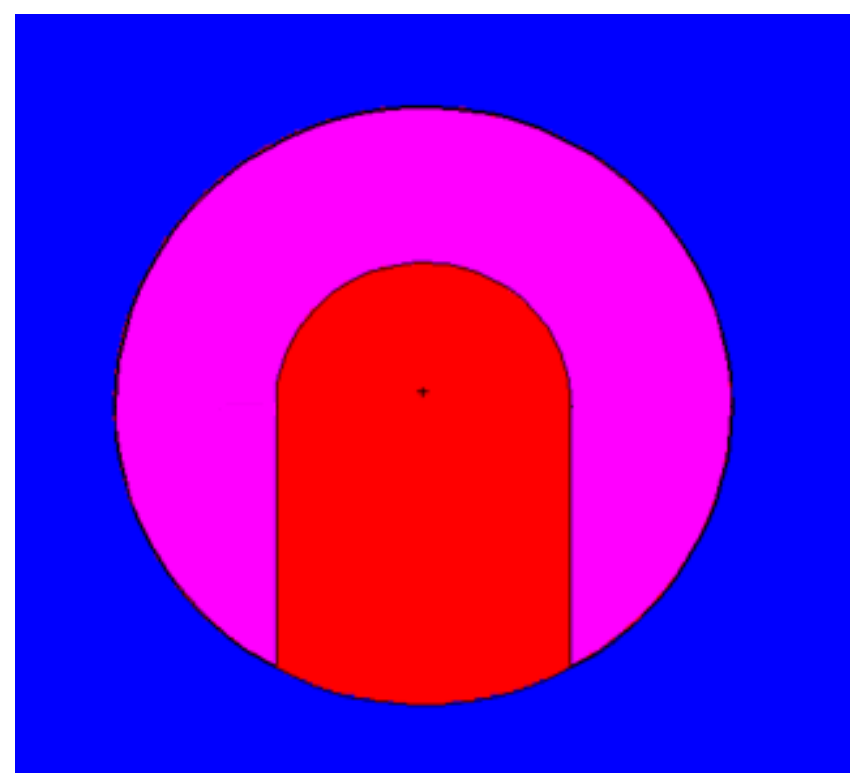

Figura 32 - Arranjo geométrico da primeira melhoria definitiva simulada.

Neste plot da primeira melhoria simulada não é possível visualizar a peça de cádmio de mesmo formato que está cobrindo a peça de polietileno, porém ela foi simulada juntamente com a peça de polietileno. Como na primeira melhoria utilizou-se a peça de polietileno que é um material hidrogenado esperava-se reduzir bastante o fluxo de nêutrons térmicos e moderar uma parte significativa dos nêutrons epitérmicos e rápidos 
até a faixa térmica e com a peça de cádmio de $1 \mathrm{~mm}$ que implica um fator de atenuação de $10^{6}$ para nêutrons térmicos eliminar uma parte significativa dos nêutrons térmicos.

Após a simulação da blindagem biológica, com essa melhoria inclusa, obteve-se comportamento para o fluxo de nêutrons no decorrer da parede de parafina da blindagem biológica indicado na figura 33.

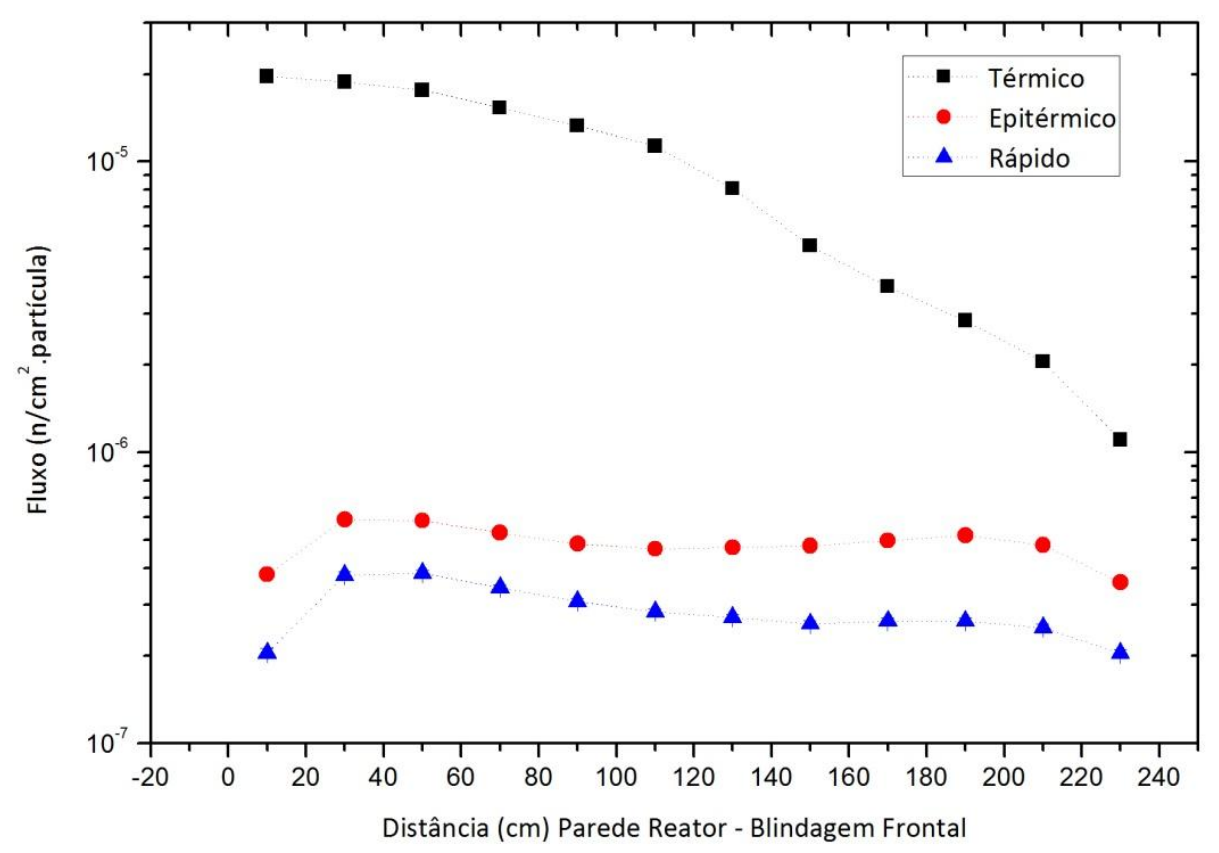

Figura 33 - Comportamento do fluxo de nêutrons ao longo da blindagem biológica no lado interno após a inserção da primeira melhoria na modelagem geométrica.

Como se pode observar na figura 33 o comportamento dos nêutrons térmicos é similar a situação sem nenhuma blindagem adicionada, porém as intensidades são menores, e é evidente que essa inclusão de melhoria conseguiu reduzir significativamente o fluxo de nêutrons acima de 0,5 eV. A figura 34 mostra o comportamento apenas do fluxo térmico para uma melhor visualização. 


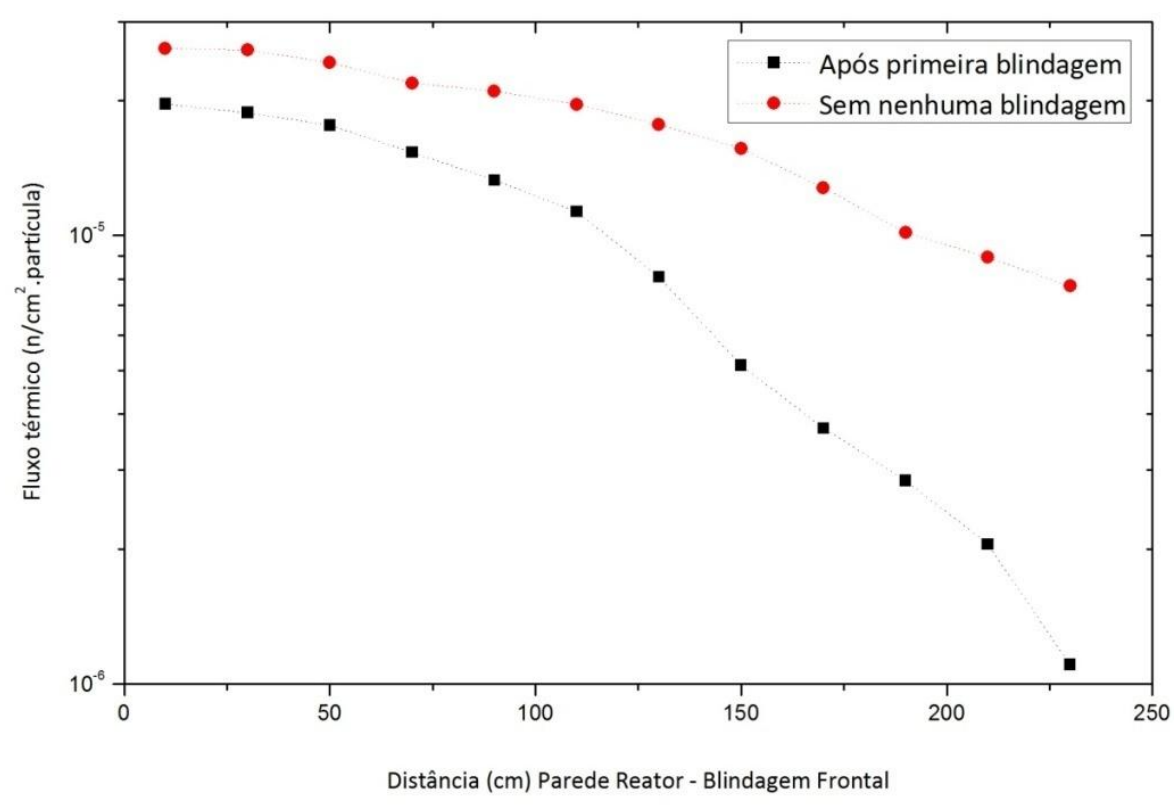

Figura 34 - Comportamento do fluxo térmico após a inserção da primeira melhoria na modelagem geométrica.

O comportamento do fluxo térmico é similar nos dois casos, porém as intensidades são menores após a inserção dessa primeira melhoria na modelagem. Consegue-se atenuar em média o fluxo térmico em $(51,30 \pm 22,35) \%$, existindo posição ao longo da parede de parafina aonde essa atenuação chega em 85\%. A figura 35 mostra a atenuação ocorrida nos pontos ao longo da parede para o fluxo térmico.

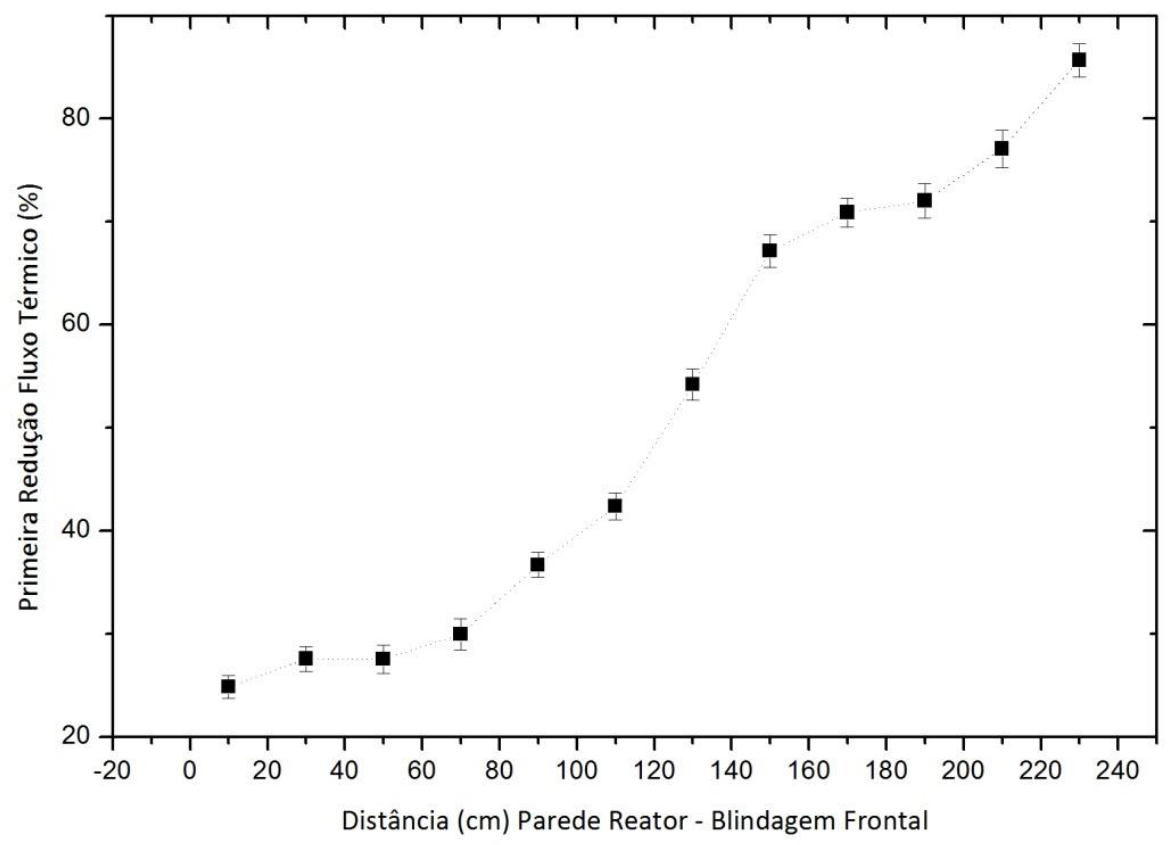

Figura 35 - Atenuação do fluxo térmico ao longo da blindagem biológica em seu lado interno. 
Pode-se perceber que o maior efeito dessa blindagem no fluxo térmico ocorre no final da parede de parafina (pontos acima de 50\% de redução) o que indica que a contribuição de nêutrons sendo termalizados no chumbo e nas paredes de parafina diminui significativamente, ou seja os nêutrons com energia superior a $0,5 \mathrm{eV}$ foram bastante reduzidos logo após a blindagem extra adicionada.

Ao se analisar o comportamento do fluxo epitérmico e rápido separadamente do fluxo térmico consegue-se observar melhor o efeito dessa melhoria. A figura 36 mostra o comportamento do fluxo epitérmico ao longo da blindagem biológica no seu lado interno.

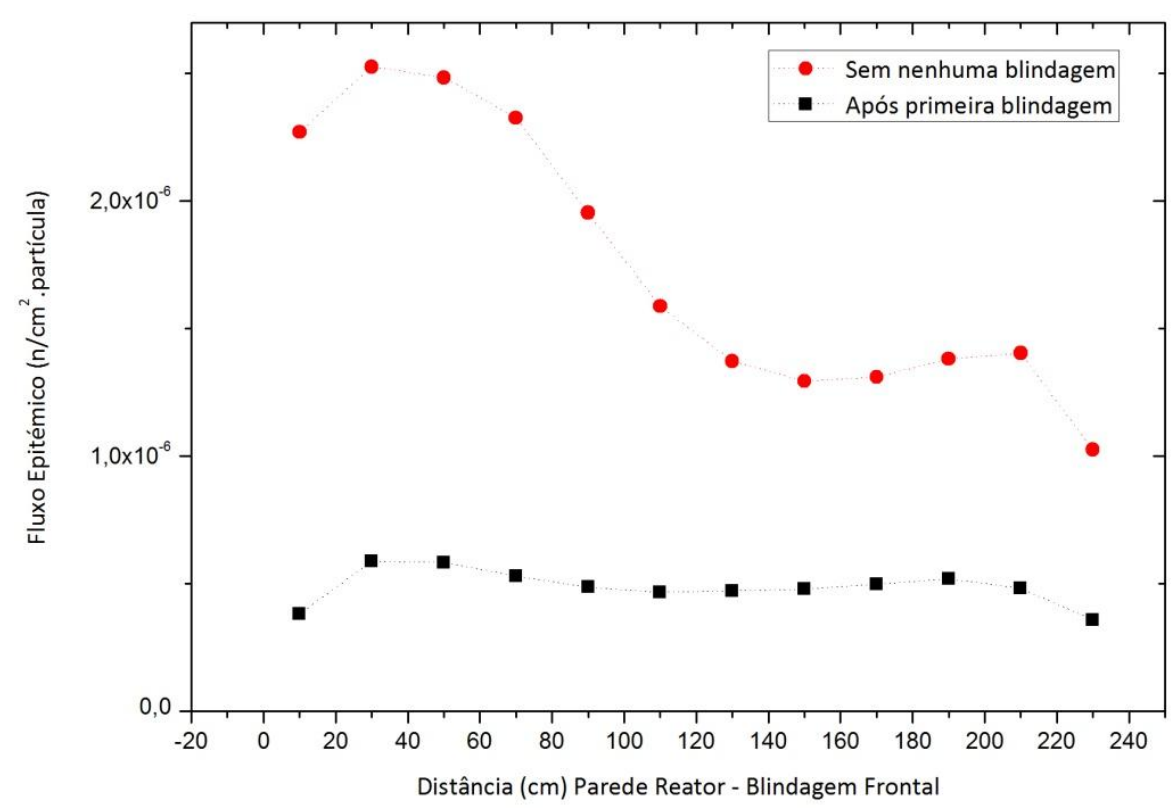

Figura 36 - Comportamento do fluxo epitérmico ao longo da blindagem biológica em seu lado interno.

Como se pode observar o fluxo epitérmico caiu bastante logo nos primeiros centímetros após a blindagem evidenciando que a primeira melhoria incluída na modelagem consegue de fato atenuar significativamente a energia dos nêutrons e o mesmo ocorre com o fluxo rápido, na figura 37 é possível evidenciar o mesmo comportamento para o fluxo rápido. 


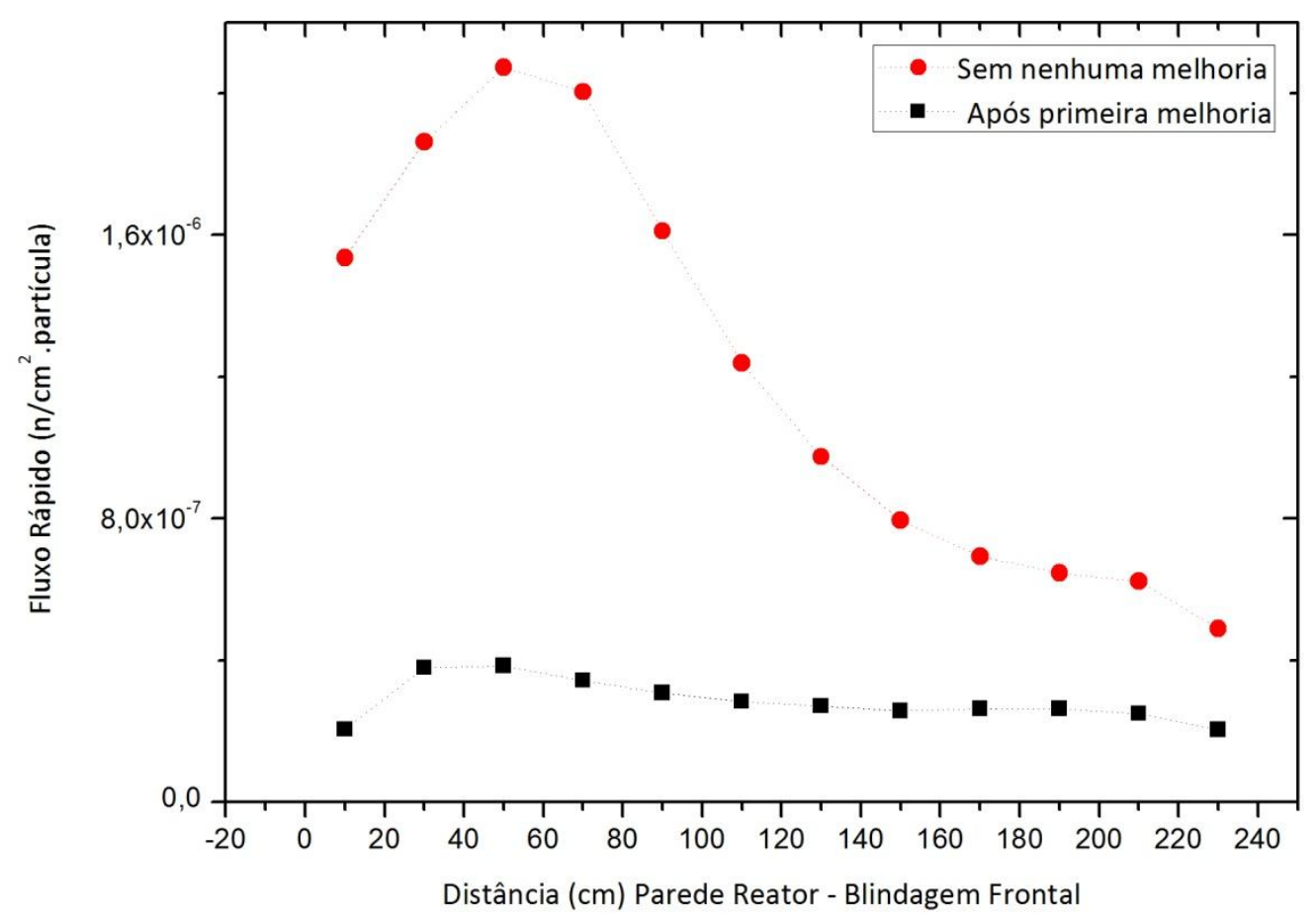

Figura 37 - Comportamento do fluxo rápido ao longo da blindagem biológica no seu lado interno.

No caso do fluxo rápido, o comportamento mostrado na figura 37 apresenta uma queda logo nos primeiros centímetros que é bastante intensa evidenciando que essa primeira melhoria atenua a energia dos nêutrons e a peça de cádmio absorve os nêutrons que conseguem atingir a faixa térmica. Ao se analisar a redução percentual do fluxo epitérmico e do fluxo rápido juntamente com a redução percentual do fluxo térmico fica evidente uma inversão no comportamento. A figura 38 mostra as reduções percentuais para as três faixas de energia. 


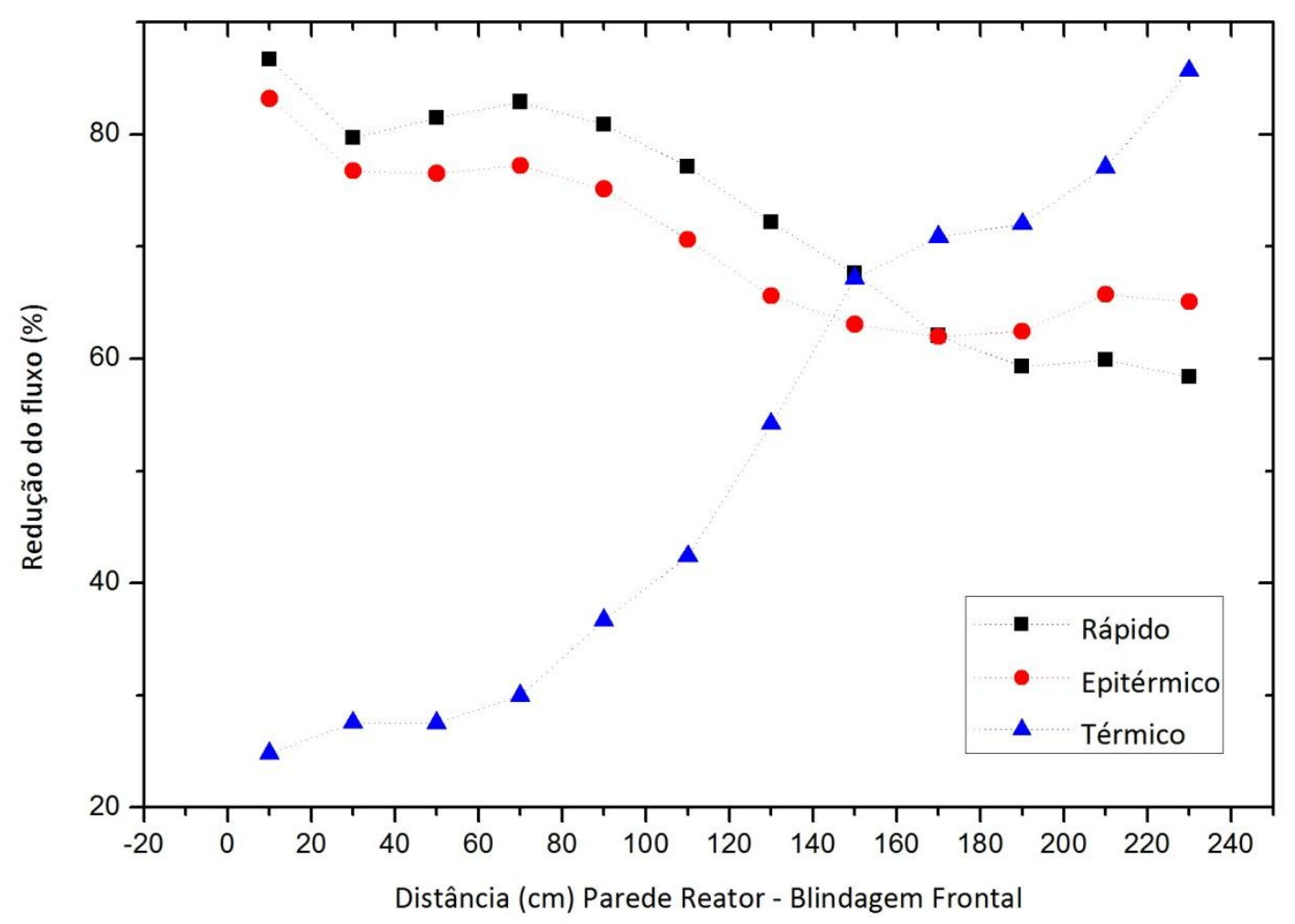

Figura 38 - Reduções percentuais para as três faixas de energia.

Esta inversão no comportamento aponta que a melhoria é muito mais eficiente para nêutrons com energia superior a $0,5 \mathrm{eV}$ nos primeiros centímetros ao longo da blindagem e nos últimos pontos ela é mais eficiente para os nêutrons com energia inferior a 0,5 eV (nêutrons térmicos). A contribuição de nêutrons termalizados ao longo do trajeto fora do canal de irradiação diminui proporcionalmente com a diminuição do fluxo epitérmico e rápido fazendo com que as reduções do fluxo térmico nos últimos pontos sejam muito maiores do que as reduções nos primeiros pontos.

No lado externo da blindagem foram definidas células de ar idênticas as células de ar utilizadas para os cálculos internos, entretanto o tempo de cálculo para se obter os resultados no lado de fora da blindagem é muito maior. Isto é normal em simulações envolvendo blindagens com o código MCNP5, pois poucos nêutrons conseguem atravessar a blindagem e existe uma série de ferramentas estatísticas que o usuário dispõe para realizar o cálculo, estas ferramentas são conhecidas como técnicas de redução de variância.

A que se utilizou neste trabalho foi a técnica de importância para as células que são mais relevantes para o cálculo. Nesta técnica a partícula é multiplicada por dois quando 
passa de uma região de importância 1 para uma região de importância 2, por exemplo, mas seu peso estatístico é divido pela metade. A célula que modela a parafina e a o concreto que fazem parte da blindagem biológica foram divididas em duas e a distribuição das importâncias definidas para cada célula está na figura 39.

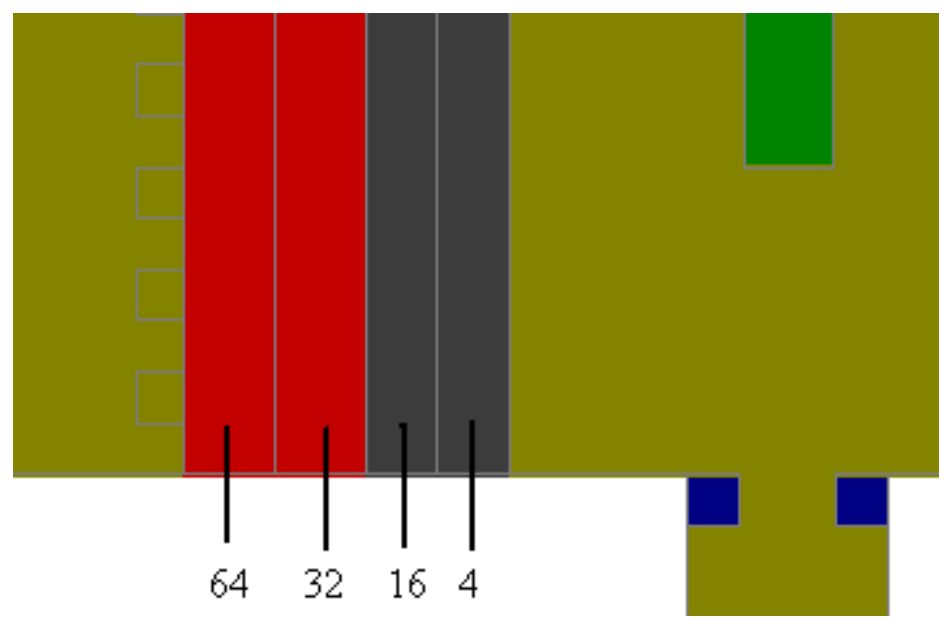

Figura 39 - Distribuição das importâncias para cálculos fora da blindagem biológica.

Com essa técnica de redução de variância consegui-se reduzir significativamente o tempo de processamento para se atingir um resultado com uma incerteza baixa, porém o tempo continuou expressivo, demorando vários dias utilizando o computador descrito na seção 3.4 para se atingir um resultado com incerteza em torno de $5 \%$ para os primeiros pontos em torno da blindagem biológica.

Entretanto, para o cálculo do fluxo epitérmico e rápido essa técnica de redução de variância não foi suficiente para conseguir resultados confiáveis, já que o número de partículas com energia superior a 0,5 eV que conseguem atravessar a blindagem biológica é muito pequeno.

Apenas calculou-se o fluxo térmico ao longo da blindagem biológica no lado externo, entretanto isto não significa que não exista um fluxo de nêutrons com energia acima de $0,5 \mathrm{eV}$, ele existe e é muito pequeno. E neste trabalho não se conseguiu calcular com um resultado confiável porque o tempo de processamento iria se tornar impraticável e ainda se corria o risco de não se conseguir resultados confiáveis. O comportamento do fluxo térmico antes e depois da adição da primeira melhoria na modelagem geométrica simulada é apresentado na figura 40. 


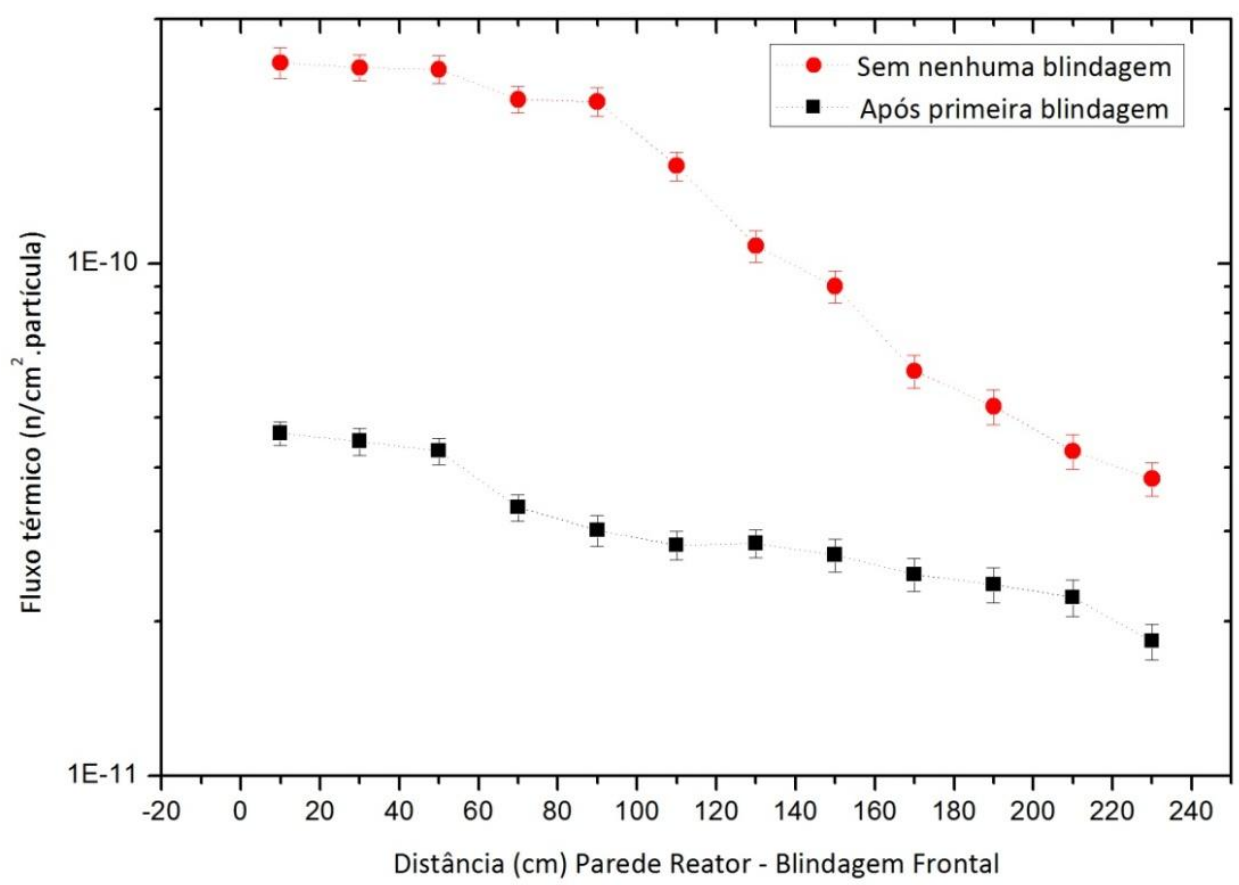

Figura 40 - Comportamento do fluxo térmico ao longo da blindagem biológica no seu lado externo.

Pode-se perceber que o fluxo térmico ao longo da blindagem biológica no lado exterior é reduzido significativamente após a inserção dessa melhoria na modelagem geométrica. Sendo que as maiores reduções acontecem nos primeiros centímetros e à medida que se percorre a blindagem as reduções são menores. Para se melhor analisar o efeito dessa melhoria a redução percentual é apresentado na figura 41.

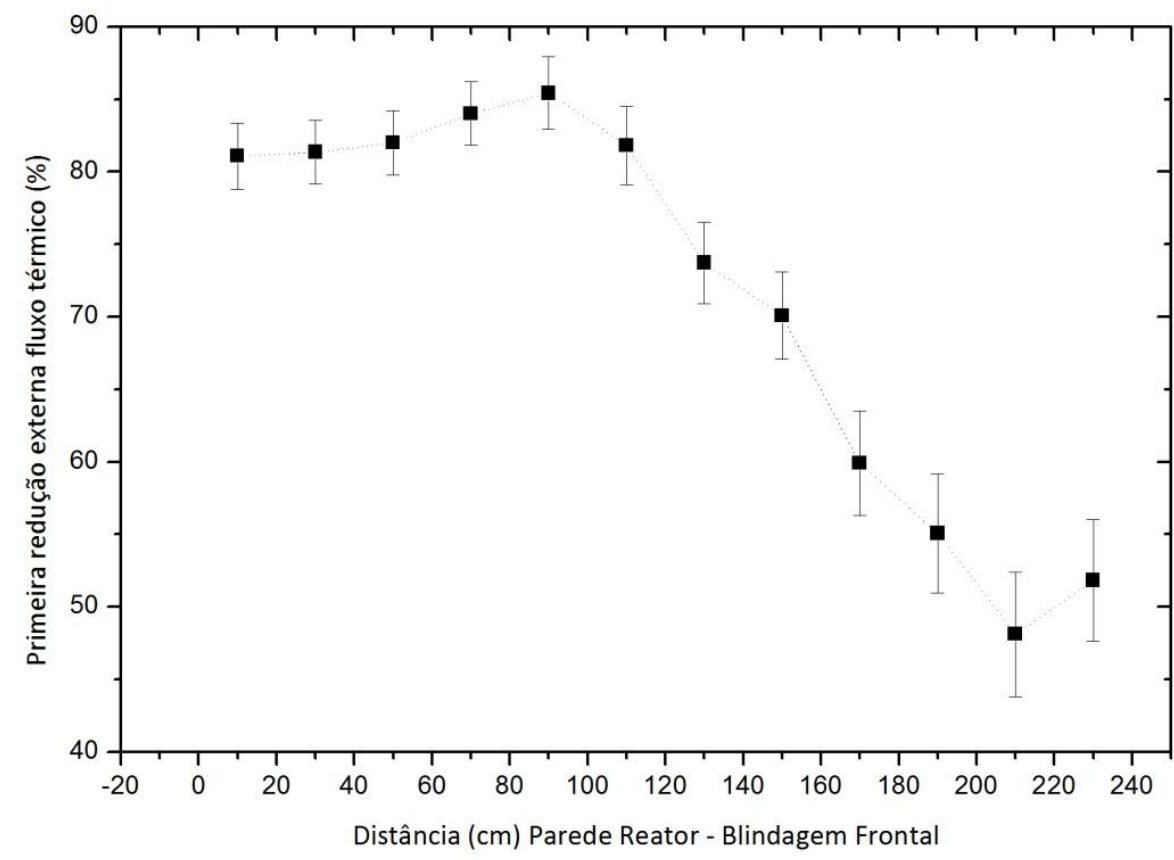

Figura 41 - Redução do fluxo térmico no lado externo. 
Na figura 41 é possível observar que a maior redução é atingida em torno de $1 \mathrm{~m}$ de distância da parede e logo depois essa redução percentual diminui gradativamente até o penúltimo ponto aonde ocorre uma inversão, porém o valor aumenta apenas 3\% (de 48\% a $51 \%$ ), e a redução no fluxo térmico em média no lado exterior é $71,2 \pm 13,8 \%$, e essa redução é considerada alta, ainda mais por se tratar de um nível de fluxo que anteriormente a inserção dessa melhoria na blindagem biológica já correspondia ao background dentro dos limites de radioproteção.

Quando se compara a redução percentual do fluxo térmico interno com a redução percentual do fluxo térmico externo percebe-se que o comportamento dessas reduções não são similares. A figura 42 apresenta as reduções para o fluxo térmico ao longo da blindagem biológica no lado interno e externo.

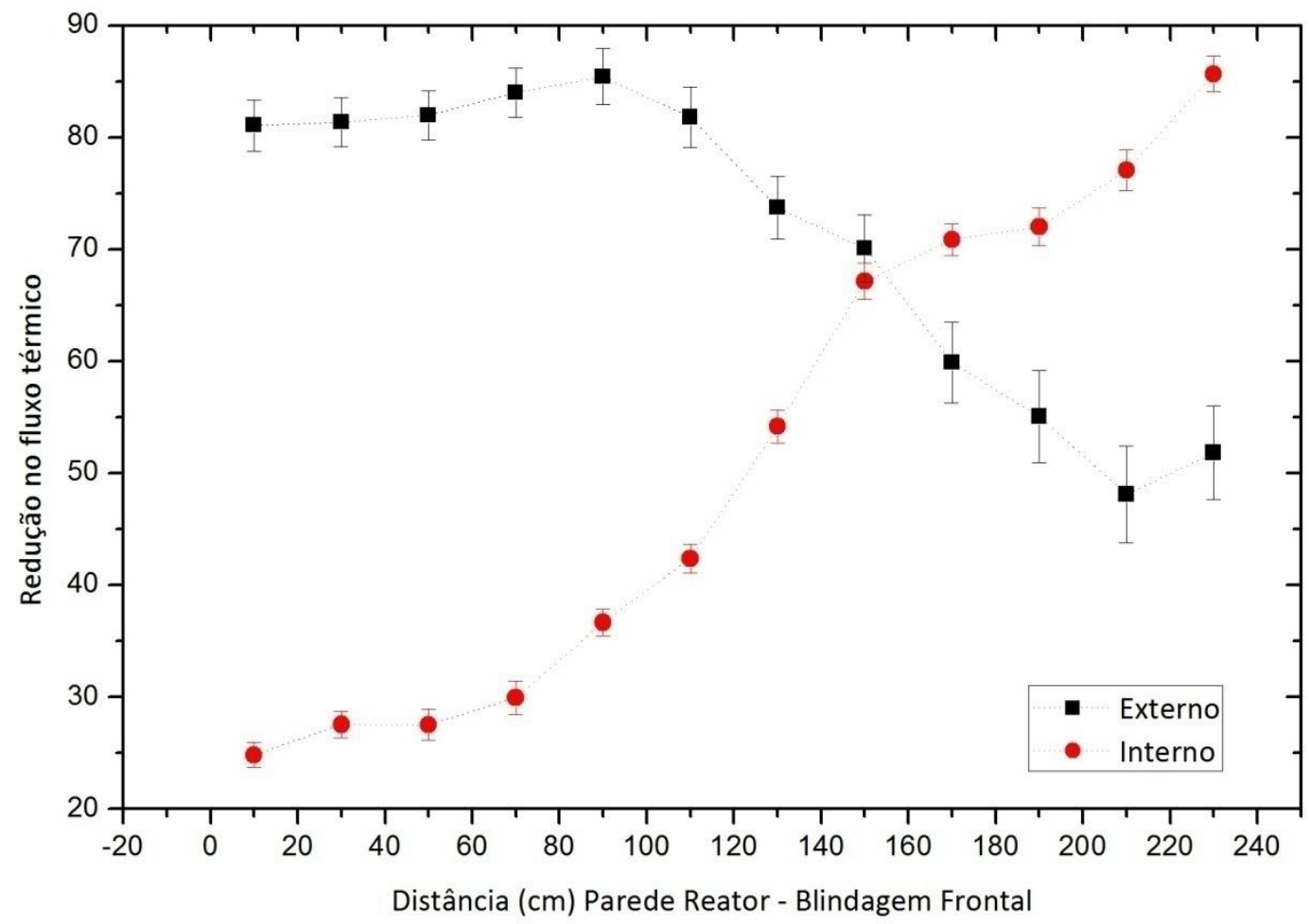

Figura 42 - Redução do fluxo térmico ao longo da blindagem biológica para o lado interno e externo.

O comportamento dessas reduções apresentadas na figura 42 não é similar porque grande parte da fração de nêutrons térmicos no lado externo é devido a fração de nêutrons com energia superior a $0,5 \mathrm{eV}$ que incidem na blindagem biológica e são termalizados. Ou seja, muito dos nêutrons que são considerados térmicos no lado externo antes de atravessarem a blindagem biológica eram considerados epitérmicos ou 
rápidos. Isto levou a conclusão que as melhorias na blindagem no lado interno deveriam exercer um papel moderador intenso, pois os nêutrons epitérmicos e rápidos que atravessa a blindagem biológica tornam-se térmicos no seu lado externo.

A partir dessa conclusão e mantendo a primeira melhoria definitiva na modelagem geométrica da blindagem biológica, modelou-se um túnel que estaria posicionado em cima da mesa de apoio e cobriria os $30 \mathrm{~cm}$ existentes desde a parede do reator até o inicio da posição de inserção/remoção das amostras com o auxílio do conjunto de garras e trilhos (figura 24).

Simularam-se três composições para a construção desse túnel, havia a possibilidade de construir um tanque no formato do túnel que comportaria ácido bórico ou água leve, e também foi simulado o túnel sendo composto de polietileno puro coberto com uma camada de cádmio de $1 \mathrm{~mm}$, a figura 43 mostra o formato da modelagem desse túnel.
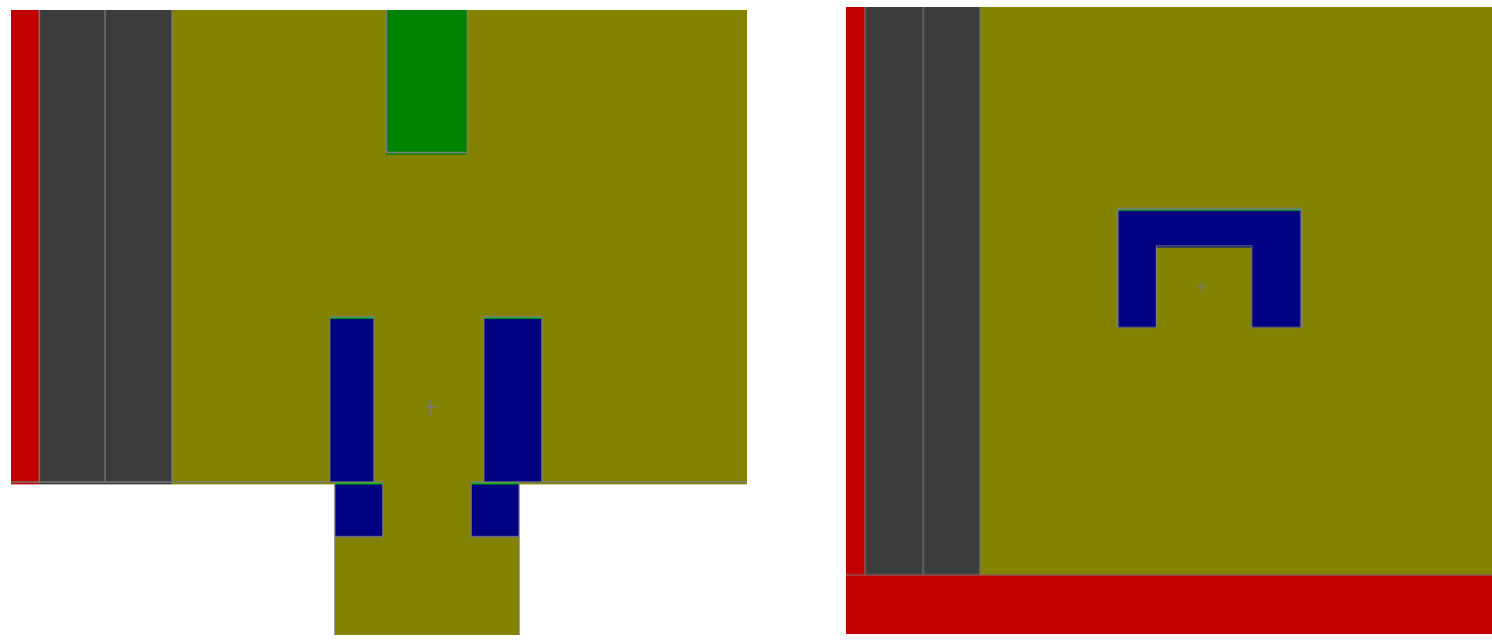

Figura 43 - Arranjos geométricos da modelagem do túnel planejado como segunda melhoria definitiva; visão superior (esquerda) e visão frontal (direita).

Na figura 43, o arranjo geométrico da visão superior apresenta o túnel na versão polietileno puro coberto com cádmio e também a primeira melhoria (figura da esquerda) já inserida na janela do beam hole, na figura da direita é visto o túnel frontalmente, na escala do da figura 43 não é possível visualizar a cobertura de cádmio nessa versão do túnel, porém ela está presente na modelagem e o túnel nas outras versões de composição possui o mesmo formato, porém sem a cobertura de cádmio. A figura 44 
mostra o comportamento do fluxo epitérmico no lado interno da blindagem biológica para as três composições simuladas do túnel.

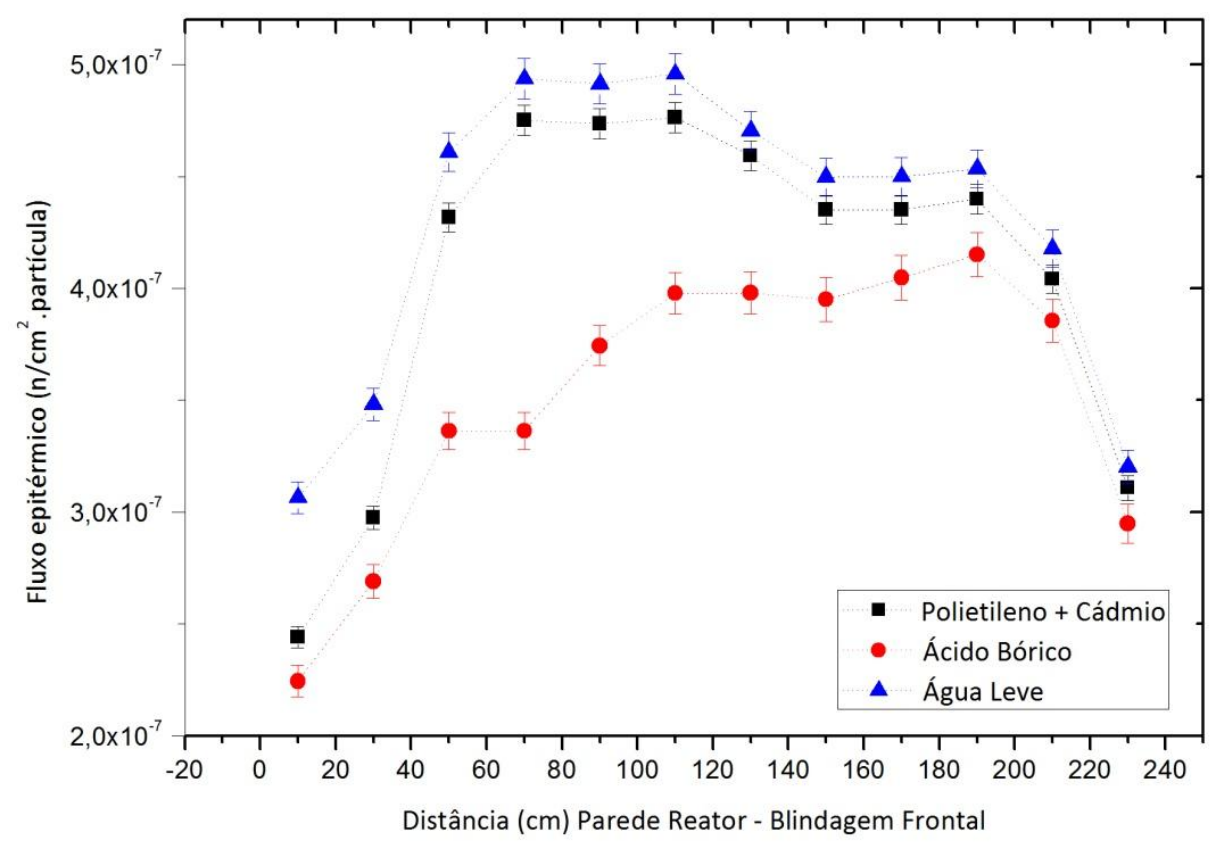

Figura 44 - Comportamento do fluxo epitérmico para as três composições simuladas ao longo da blindagem biológica no seu lado interno.

O fluxo epitérmico tem a maior redução quando se utiliza o ácido bórico $\left(\mathrm{H}_{3} \mathrm{BO}_{3}\right)$ na modelagem do túnel, isto se deve aos seguintes fatos: o ácido possui uma densidade maior do que a densidade da água e do polietileno puro, o hidrogênio presente na sua formulação permite reduzir a energia dos nêutrons e o boro devido sua alta seção de choque de absorção elimina parte dos nêutrons que atingem a região térmica. Entretanto, o comportamento dos nêutrons rápidos também deve ser analisado com cautela, pois estes nêutrons são mais energéticos e são termalizados na blindagem biológica e contribuem para a interferência nos equipamentos do canal 6 . A figura 45 apresenta o comportamento do fluxo rápido para as três composições simuladas. 


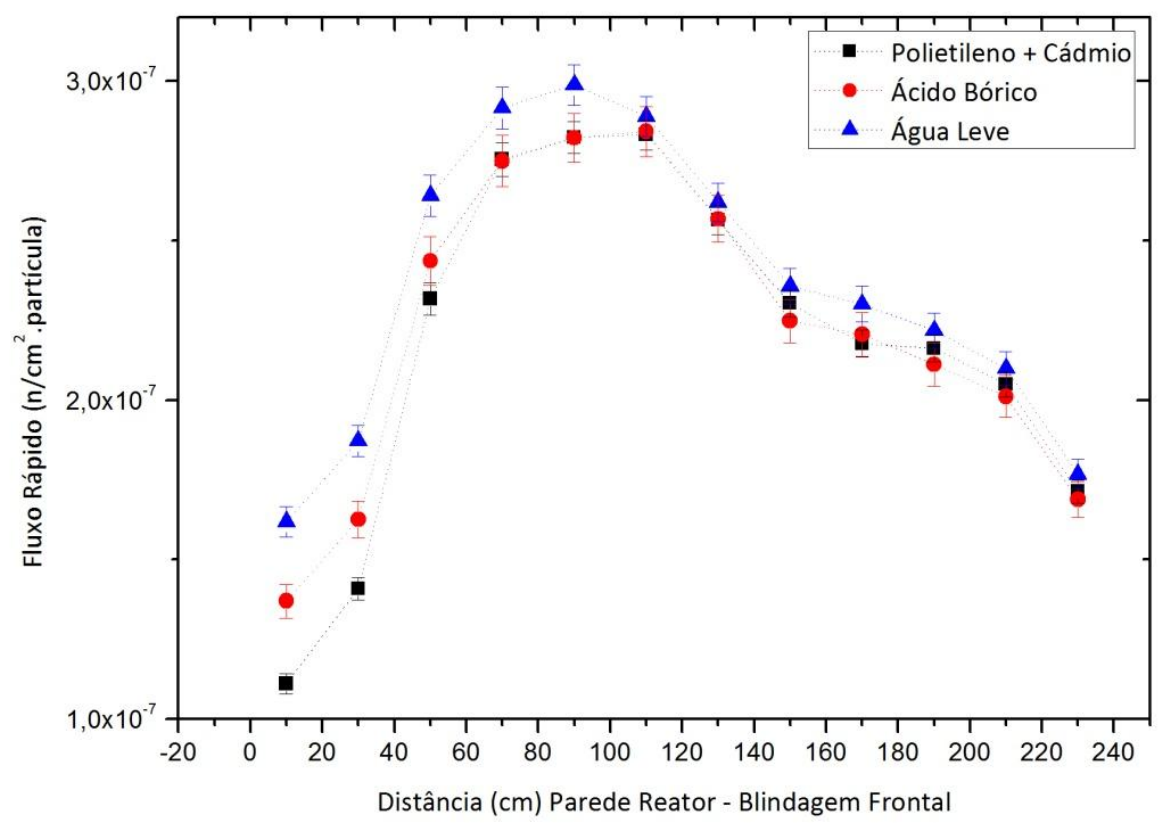

Figura 45 - Comportamento do fluxo rápido para as três composições simuladas ao longo da blindagem biológica no seu lado interno.

O fluxo rápido tem a melhor redução quando se utiliza polietileno puro coberto com cádmio e o seu comportamento a partir dos $70 \mathrm{~cm}$ de distância da parede do reator é semelhante para as três composições simuladas diferenciando-se na região próxima a parede do reator, nesta região o fluxo rápido é menor para o caso do polietileno puro coberto com cádmio, por que além ser exatamente nesta região que está modelado o túnel, com seus $30 \mathrm{~cm}$ de comprimento, o polietileno puro possui mais hidrogênio por unidade de volume do que o ácido bórico e água leve; isto atribui um poder de moderação maior para essa composição.

Para se confeccionar esta melhoria houve certa indecisão na escolha do material, porém escolheu-se o polietileno puro coberto com cádmio, apesar de o ácido bórico ser mais eficiente na redução dos nêutrons epitérmicos por duas razões principais: o ácido bórico em pó precisaria ser muito bem prensado em um recipiente no formato do túnel para atingir a densidade simulada e atingir uma uniformidade seria muito mais difícil, o material do recipiente precisaria ser quimicamente resistente e apesar do ácido bórico ser mais eficiente na região epitérmica o polietileno puro coberto com cádmio é mais eficiente na região rápida, e estes nêutrons têm maior probabilidade de ultrapassar a 
blindagem biológica e emergir com energia térmica porque são originalmente mais energéticos.

Após a inserção do túnel de polietileno puro coberto com cádmio o novo comportamento do fluxo de nêutrons ao longo da blindagem biológica é apresentado na figura 46.

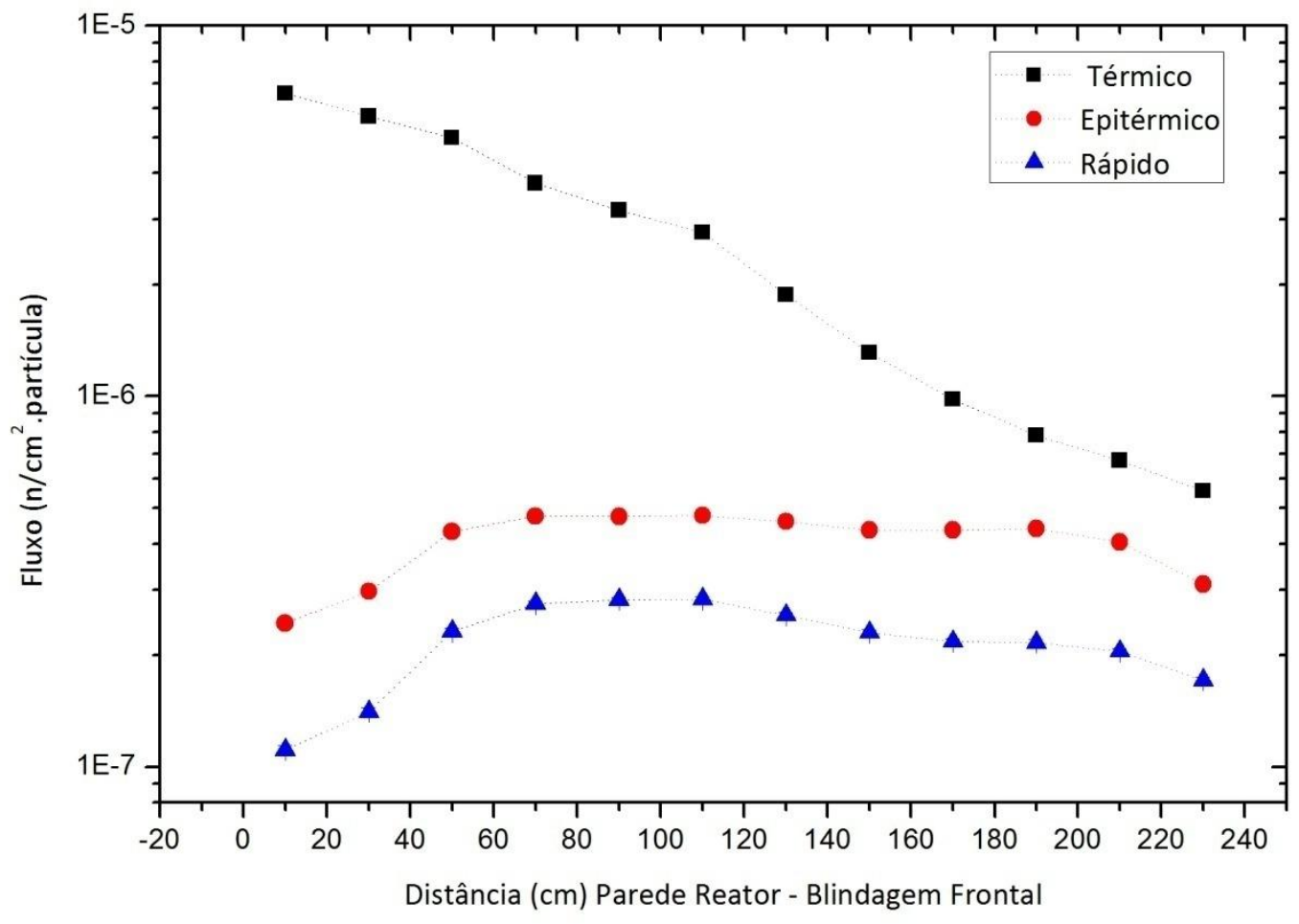

Figura 46 - Comportamento do fluxo de nêutrons depois da inserção da primeira e segunda melhoria definitiva.

O comportamento do fluxo de nêutrons com a inserção do túnel se mantém semelhante aos anteriores (sem melhoria nenhuma ou com a primeira melhoria), mantendo um valor sempre maior para o fluxo térmico, um valor intermediário para o fluxo epitérmico e sempre um valor menor para o fluxo rápido. Porém no fim da blindagem biológica os fluxos térmico, epitérmico e rápido ficam na mesma ordem de grandeza. Não se observa isso nos comportamentos anteriores, e isto ocorre porque o fluxo térmico é reduzido sensivelmente após as duas inserções das melhorias, enquanto o fluxo epitérmico e rápido na inserção da primeira melhoria reduz significativamente, porém na inserção da segunda melhoria definitiva o fluxo é reduzido apenas nos primeiro centímetros. 
Entretanto, uma análise do comportamento de cada fluxo após as inserções é necessário para poder compreender melhor os efeitos de cada melhoria na blindagem biológica, a figura 47 apresenta o comportamento do fluxo térmico.

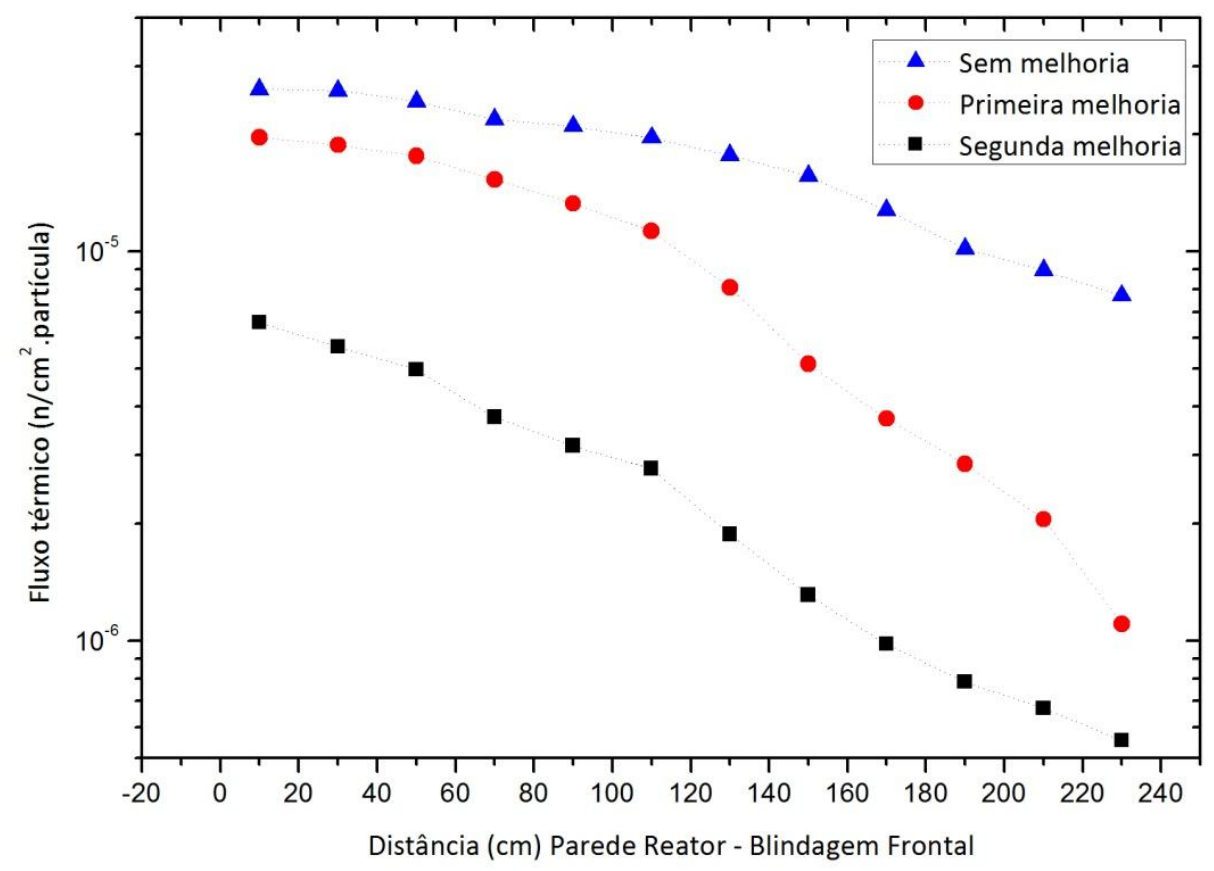

Figura 47-Comportamento do fluxo térmico após as inserções da primeira e segunda melhoria definitiva ao longo da blindagem biológica no seu lado interno.

A primeira melhoria causa uma redução no fluxo térmico que é maior à medida que se afasta da parede do reator, isto porque a inserção da primeira melhoria ocorre dentro do canal de irradiação junto a parede do reator e esta inserção da melhoria atua como um colimador do feixe de nêutrons térmicos, fazendo com que o efeito da primeira melhoria seja mais visível nos pontos mais distantes da parede do reator. Na inserção do túnel de polietileno puro coberto com cádmio como segunda melhoria definitiva a redução no fluxo térmico é muito mais sensível nos primeiros centímetros de distância porque o túnel está fora da parede do reator e não consegue colimar o feixe de maneira eficiente. Para que seja possível analisar melhor os efeitos dessas melhorias inseridas na modelagem geométrica as reduções percentuais após as inserções das melhorias definitivas estão apresentadas na figura 48. 


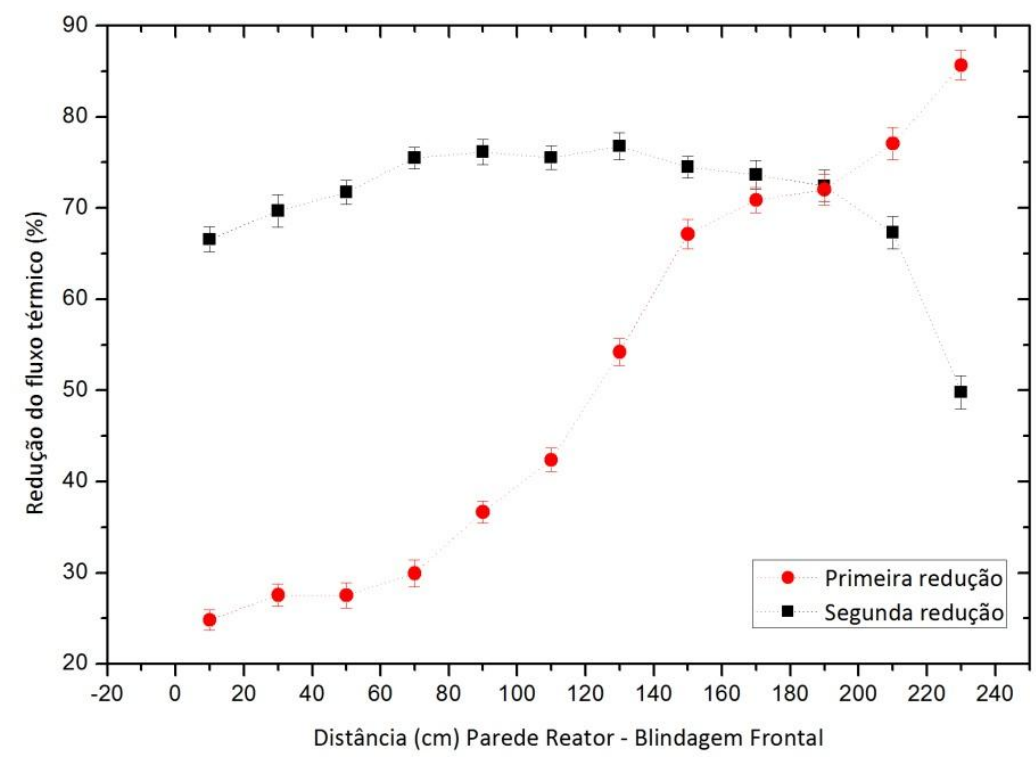

Figura 48 - Reduções percentuais do fluxo térmico ao longo da blindagem biológica no seu lado interno após as inserções das duas melhorias definitivas.

O gráfico da figura 48 mostra que a primeira melhoria é de fato mais eficiente nos centímetros finais enquanto a segunda melhoria é mais eficiente nos primeiros centímetros, após a inserção da primeira melhoria o fluxo térmico obteve uma redução média de $(51,30 \pm 22,35)$ \% e após a segunda inserção consegue se atenuar o fluxo térmico em média em $(70,08 \pm 7,42) \%$ e após as duas inserções a redução média que se obtém no fluxo térmico é $(86,41 \pm 6,39) \%$.

Após a inserção da segunda melhoria definitiva no fluxo epitérmico e rápido as reduções percentuais são muito mais sensíveis nos primeiros centímetros. No gráfico da figura 49 é possível observar o comportamento desses fluxos junto com o comportamento do fluxo térmico. 


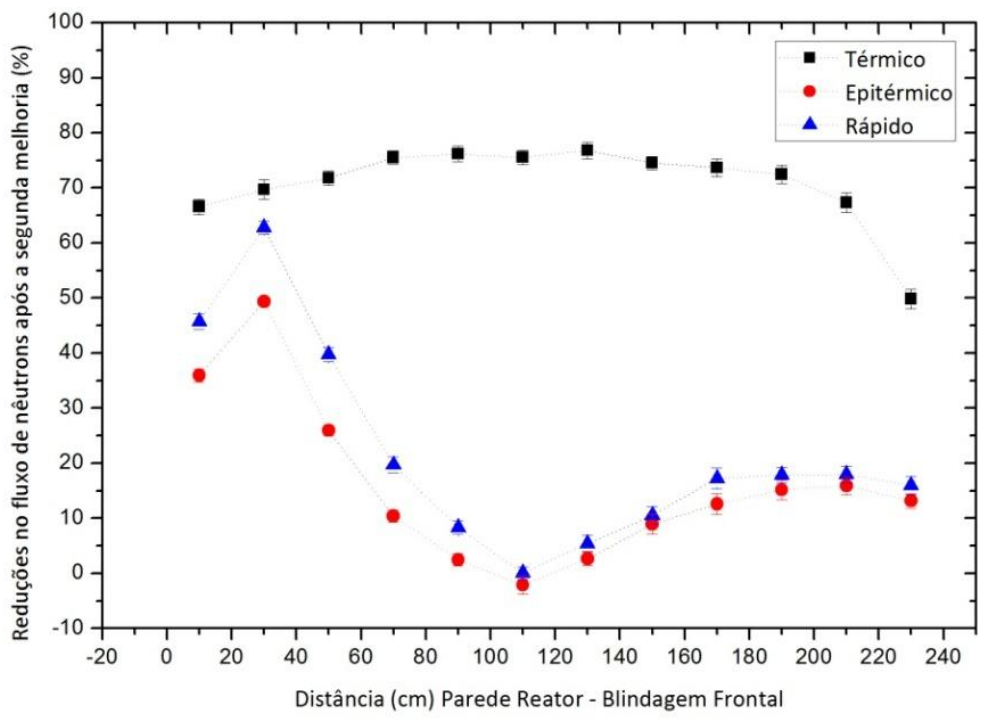

Figura 49 - Redução no fluxo de nêutrons após a inserção da segunda melhoria.

O túnel de polietileno puro coberto com cádmio é bastante eficiente na redução de nêutrons com energia superior a térmica nos primeiros centímetros, justamente onde existe a influência da presença do material hidrogenado do túnel, isto deve ser evidenciado no comportamento do fluxo térmico no lado externo da blindagem biológica. Já que grande parte dos nêutrons térmicos que conseguem atravessar a blindagem origina-se na sua maioria dos nêutrons de maior energia antes de começar a travessia. A figura 50 mostra o comportamento do fluxo térmico no lado externo da blindagem biológica.

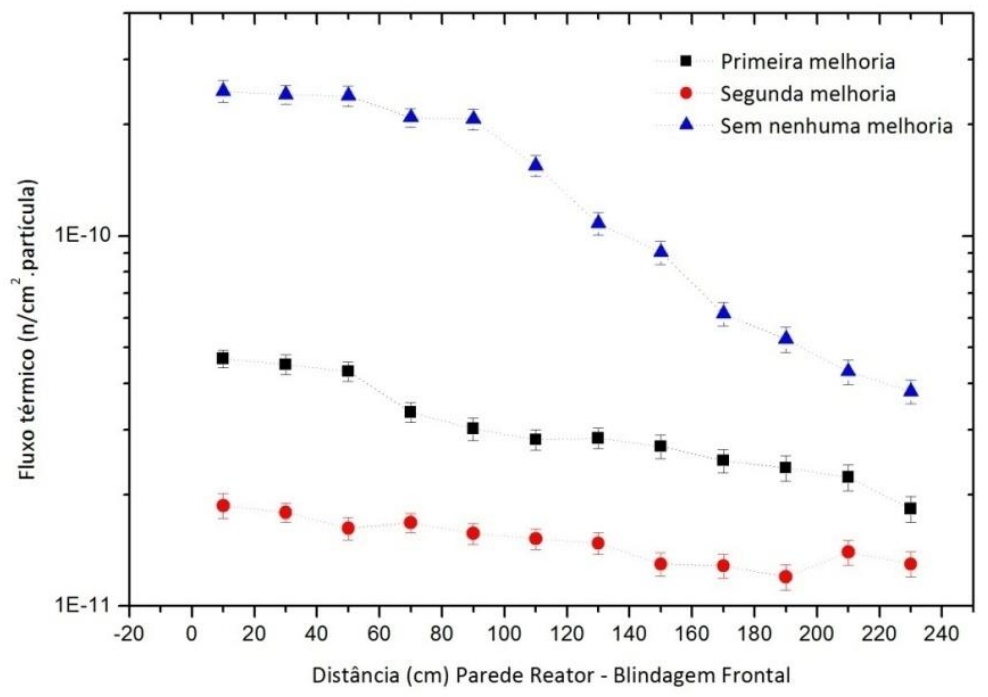

Figura 50 - Fluxo térmico no lado externo da blindagem biológica após as inserções das melhorias definitivas na modelagem geométrica da blindagem biológica. 
Após a inserção da segunda melhoria o fluxo térmico no lado exterior da blindagem biológica foi reduzido de forma mais significativa nos primeiros centímetros, isto é efeito do túnel de polietileno coberto com cádmio que consegue reduzir bastante nesses primeiros centímetros o fluxo epitérmico e rápido. Nos últimos centímetros a redução é constante, porém ainda significativa devida também à presença da segunda melhoria. 0 nêutron ao atravessar a blindagem biológica sofre diversos espalhamentos e não atravessa a blindagem de forma reta, mas é razoável esperar que nos centímetros próximos da posição do túnel este fluxo seja mais atenuado.

A figura 51 mostra a redução percentual causada no fluxo térmico no lado externo devido à presença do túnel de polietileno coberto no lado interno.

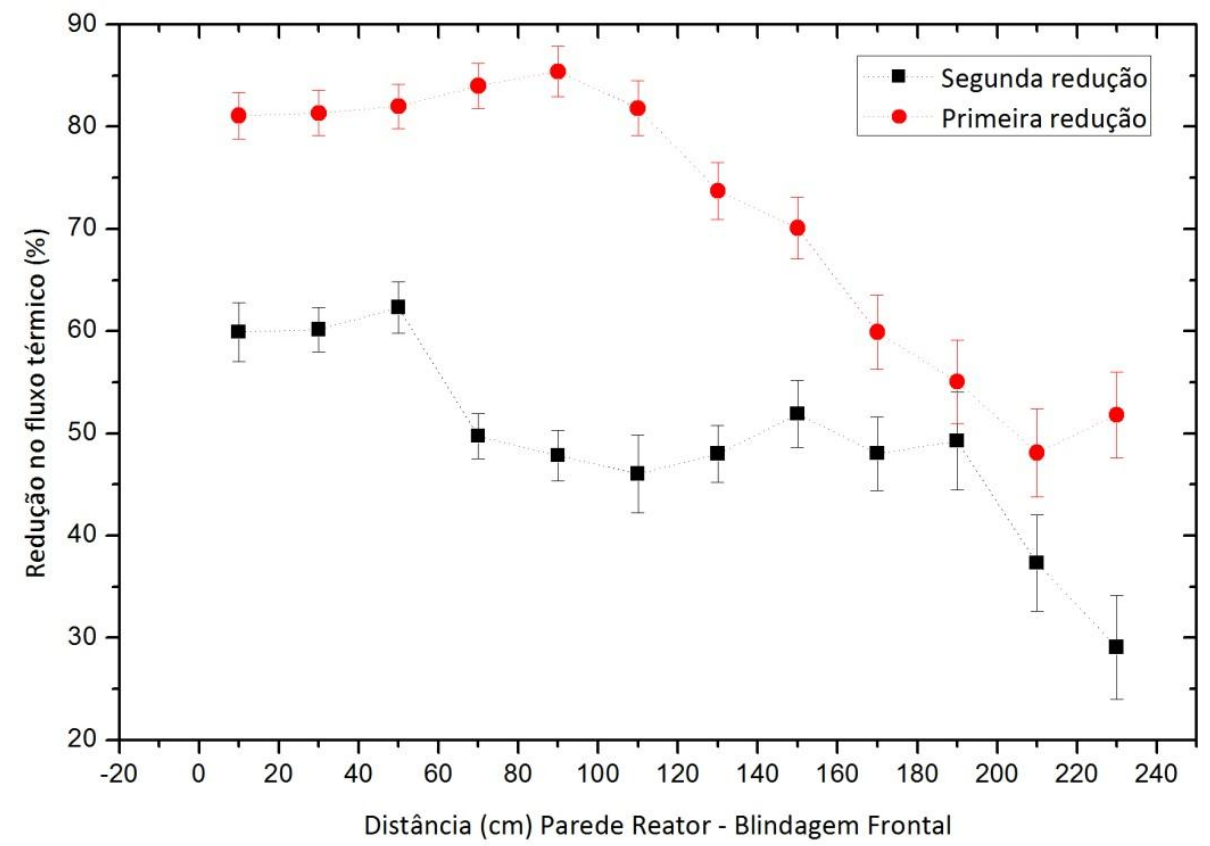

Figura 51 - Reduções percentuais do fluxo térmico ao longo da blindagem biológica no seu lado externo após as inserções das duas melhorias definitivas.

O fluxo térmico no lado externo da blindagem biológica tem sua maior redução na primeira melhoria porque ela consegue reduzir significativamente os nêutrons com energia superior à térmica, na segunda redução devido à inserção do túnel de polietileno coberto com cádmio o fluxo térmico tem a maior redução nos primeiros centímetros e depois ainda continua a reduzir, mas de forma não tão expressiva. Se o túnel fosse mais extenso com certeza essa redução no fluxo seria maior, porém não é possível realizar tal túnel sem comprometer o funcionamento da instalação, ou seja, o sistema de trocar 
amostras com o auxilio do trilho e da garra. Entretanto a redução é considerada boa e com apenas os $30 \mathrm{~cm}$ de túnel que foi simulado alcança se uma redução média total de $(84,52 \pm 9,90) \%$ para o fluxo térmico no lado exterior da blindagem biológica.

A terceira melhoria definitiva simulada foi a placa de polietileno borada adquirida da empresa DirectScientific para implementar a blindagem biológica da instalação, ela possui em sua composição $5 \%$ de Boro entretanto a exata composição da placa é indisponível por se tratar de segredo industrial, a solução encontrada foi utilizar a composição polietileno puro em $95 \%$ e adicionar o restante com a composição de boro natural.

A placa de polietileno borada foi simulada no lado de fora da blindagem biológica junto à parede do reator, as dimensões da placa são $(1 \mathrm{~m} \times 2 \mathrm{~m} \times 2,5 \mathrm{~cm})$ e ela foi posicionada frente aos equipamentos do canal de irradiação. A figura 52 mostra seu posicionamento após a inserção na modelagem geométrica da blindagem biológica.

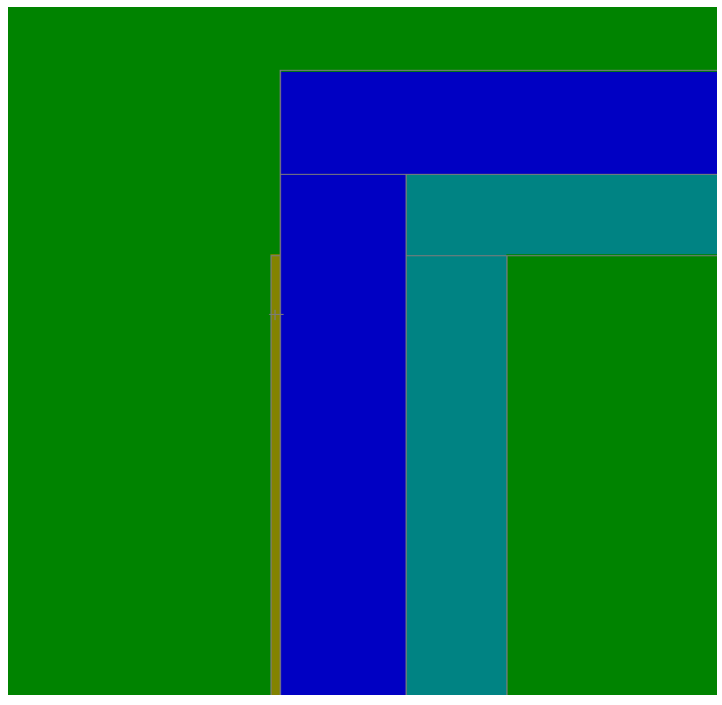

Figura 52 - Esquema frontal da placa de polietileno borada na modelagem geométrica da blindagem biológica no seu lado externo.

O comportamento do fluxo de nêutrons no lado interno não vai se modificar após a inserção dessa placa de polietileno borado justamente porque ela está inserida no lado externo da blindagem biológica. O comportamento do fluxo de nêutrons térmicos após a inserção da placa de nêutrons foi calculado para o lado externo e para isso foi preciso deslocar os volumes de ar aonde se registra o cálculo no código em 2,5 cm (espessura da 
placa). A figura 53 mostra o comportamento do fluxo de nêutrons após a inserção da placa de polietileno borada.

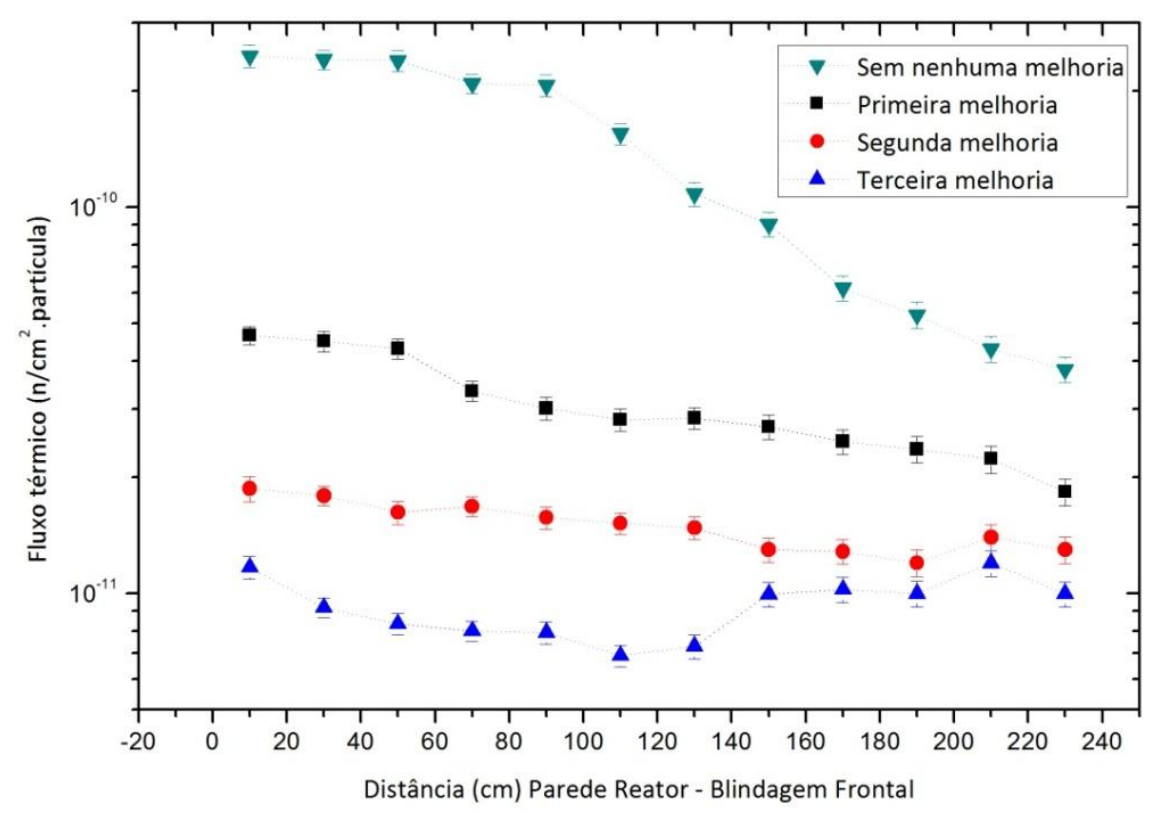

Figura 53 - Comportamento do fluxo de nêutrons térmicos após a inserção da placa de polietileno borada na modelagem da blindagem biológica no seu lado externo.

A inserção da placa de polietileno borada consegue reduzir ainda mais o fluxo de nêutrons térmicos ao longo da blindagem biológica pelo seu lado externo, devido à presença do hidrogênio no polietileno e do ${ }^{10} \mathrm{~B}$ que é um excelente absorvedor de nêutrons térmicos. É evidente que a redução ocorre apenas significativamente na região onde está modelada a placa de polietileno borada, ou seja, até $100 \mathrm{~cm}$ de distância da parede e depois o comportamento é semelhante ao fluxo térmico após a inserção da segunda melhoria, porém um pouco menor devido ao fato de se afastar os volumes de ar, e isso permitiu que o feixe se espalhasse um pouco mais. A figura 54 mostra as reduções percentuais após cada melhoria definitiva para o fluxo de nêutrons térmicos ao longo da blindagem biológica no seu lado externo. 


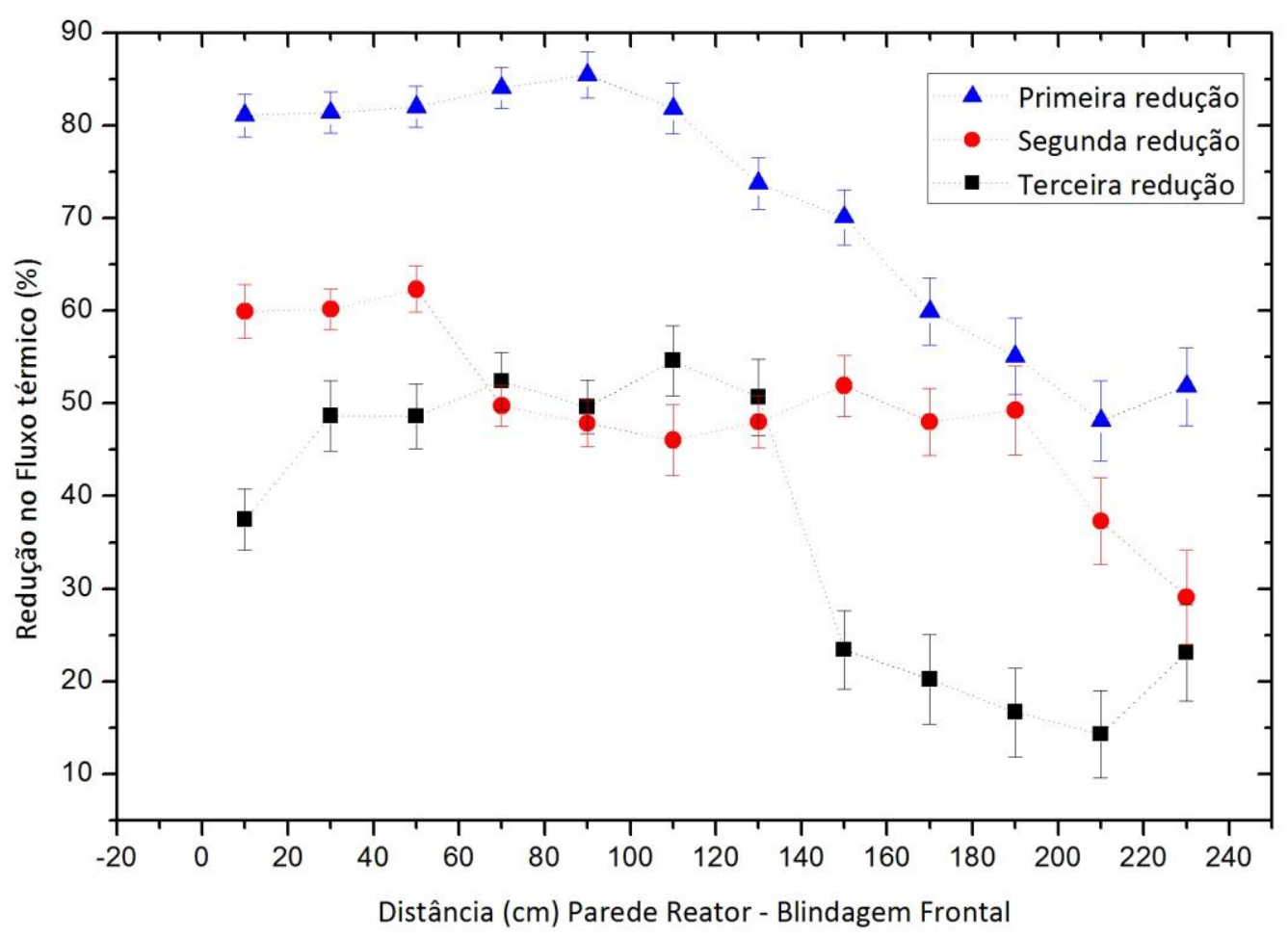

Figura 54 - Reduções percentuais no fluxo térmico após as inserções das melhorias definitivas ao longo da blindagem biológica pelo seu lado externo.

A redução média entre a segunda e a terceira melhoria é $(36,6 \pm 15,8) \%$ sendo que a os maiores valores ocorrem dentro dos 100 primeiro centímetros que é justamente a posição da placa de polietileno borada na modelagem geométrica da blindagem biológica. E o novo valor da redução média total para o fluxo térmico ao longo da blindagem biológica no seu lado exterior é $(89,2 \pm 9,1) \%$.

O conjunto das três melhorias resulta em uma boa redução média no fluxo térmico considerando que este fluxo antes de qualquer inserção de melhoria na blindagem biológica já estava dentro dos níveis de background e de proteção radiológica. A placa de polietileno borada poderia ser utilizada nas melhorias simuladas no lado interno da blindagem biológica, porém como ela é de alto custo e os cortes necessários para a confecção das melhorias iriam "desperdiçar" o material causando retalhos que não poderiam ser empregados em nenhuma outra melhoria, decidiu-se então que esta placa iria ser utilizada no lado de fora para que a placa fosse totalmente utilizada. 


\section{3 - Medidas experimentais utilizando TLD's e detectores de ativação tipo folha.}

Após as simulações das melhorias definitivas e a análise dos resultados que poderiam ser alcançados, utilizou-se o material disponível para confeccionar as melhorias para que fosse possível comparar os resultados calculados com os medidos utilizando dosímetros termoluminescentes e detectores de ativação tipo folha. Os materiais disponíveis para a confecção das melhorias eram:

i. Placas de polietileno puro com espessuras de $2,5 \mathrm{~cm}$ e $1 \mathrm{~cm}$.

ii. Lâminas de cádmio de alta pureza com 0,5 mm de espessura.

iii. 1 Placa de polietileno borada com ( $200 \times 100 \times 2,5) \mathrm{cm}$ de dimensões.

Com o auxílio do serviço de oficina do IPEN as melhorias foram confeccionadas utilizando os materiais descritos acima, para a confecção da primeira melhoria utilizou-se placas de polietileno puro com $2,5 \mathrm{~cm}$ de espessura, utilizando quatro peças para conseguir a espessura de $10 \mathrm{~cm}$ que foi simulada para primeira melhoria. E com lâminas de cádmio foi confeccionada a cobertura de $1 \mathrm{~mm}$ de espessura para finalizar a primeira melhoria. A figura 55 mostra a primeira melhoria confeccionada e instalada no canal de irradiação.

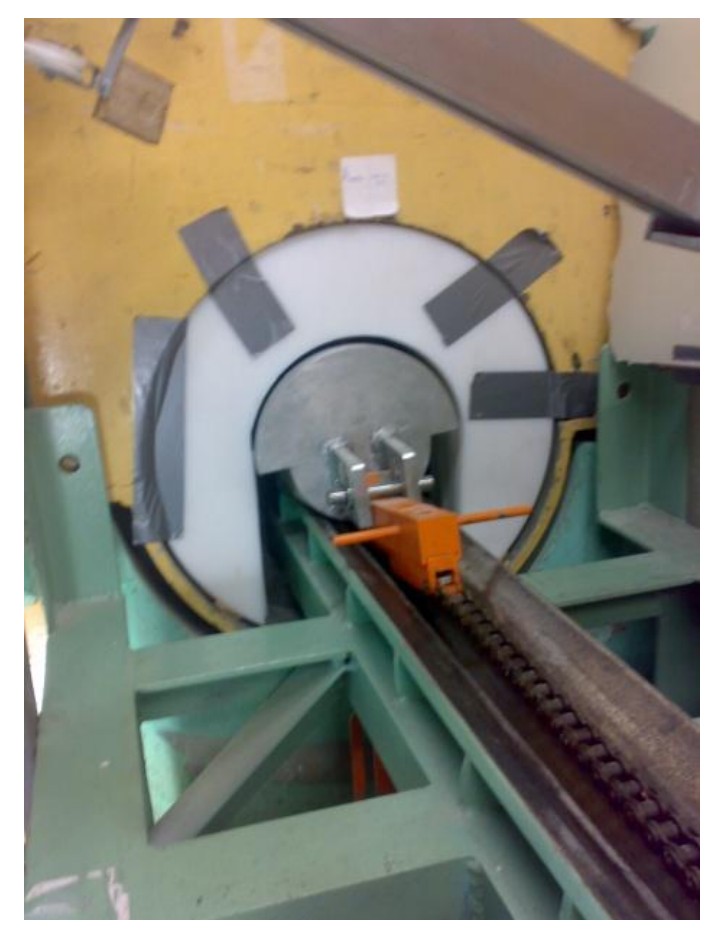

Figura 55 - Primeira melhoria confeccionada instalada no canal de irradiação 3 do IEA-R1. 
Após a confecção dessa melhoria e sua instalação no canal de irradiação, foi confeccionado o túnel de polietileno puro coberto com cádmio, utilizou-se 8 placas de polietileno com 2,5 cm de espessura e 10 placas de polietileno com $1 \mathrm{~cm}$ de espessura para conseguir alcançar os $30 \mathrm{~cm}$ de túnel simulado. A figura 56 mostra o túnel de polietileno puro coberto com cádmio instalado sobre a mesa de apoio da instalação de pesquisa em BNCT.

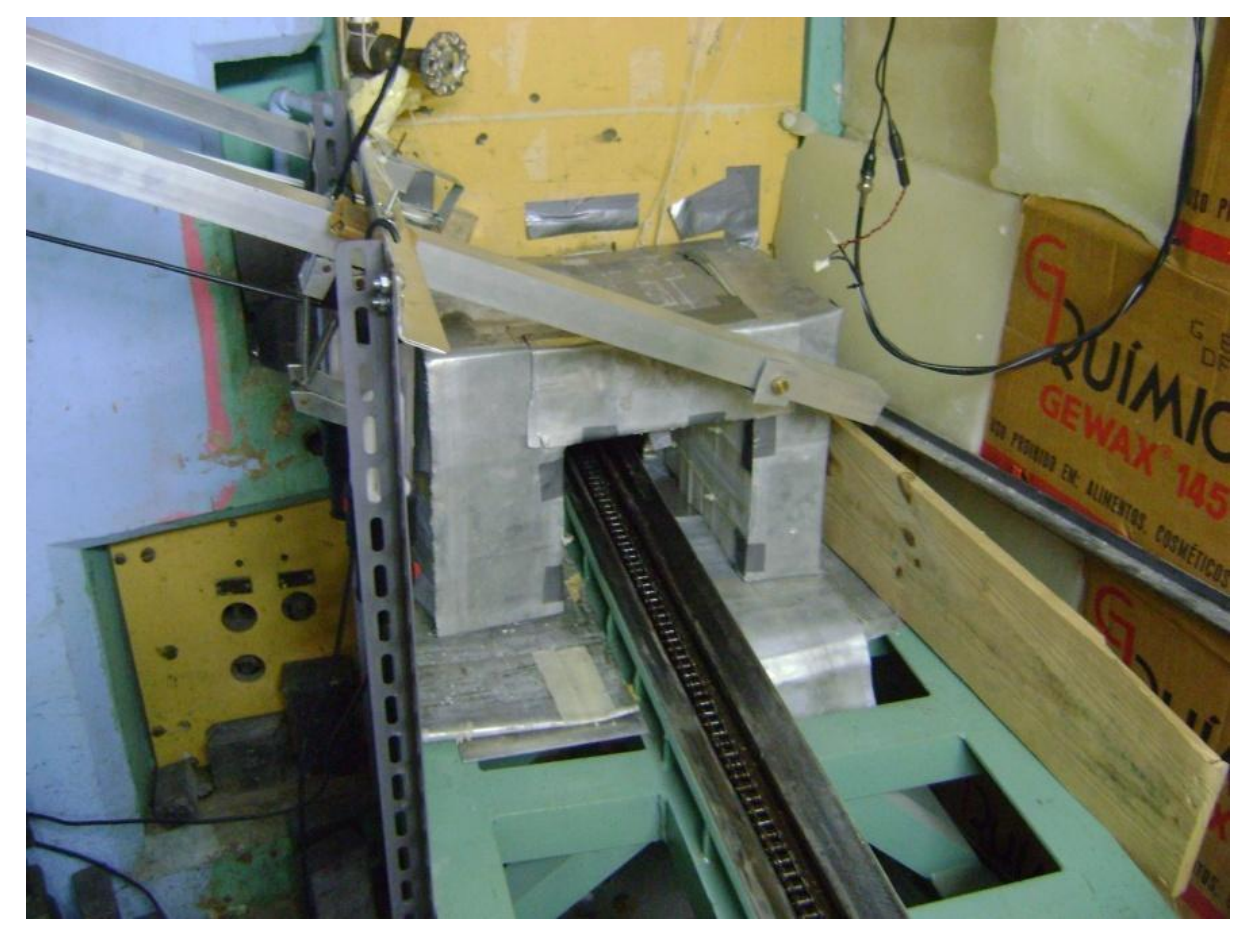

Figura 56 - Túnel de polietileno puro coberto com cádmio instalado sobre a mesa de apoio da instalação de pesquisas em BNCT.

Com a primeira e segunda melhoria instalada na blindagem biológica, a placa de polietileno borada foi posicionada ao lado da blindagem biológica no seu lado externo, porém não foi possível encostar totalmente a placa de polietileno borada na parede do reator devido a uma peça suporte em cima do canal de irradiação 4. A placa ficou afastada da parede em um pouco menos de 5 centímetros modificando um pouco a posição aonde a placa foi simulada, porém os cinco centímetros perto da extensão de 100 $\mathrm{cm}$ da placa de polietileno não devem resultar em um erro relevante na comparação entre o calculado e o medido. A figura 57 mostra a placa de polietileno borada junto à blindagem biológica da instalação de pesquisa em BNCT. 


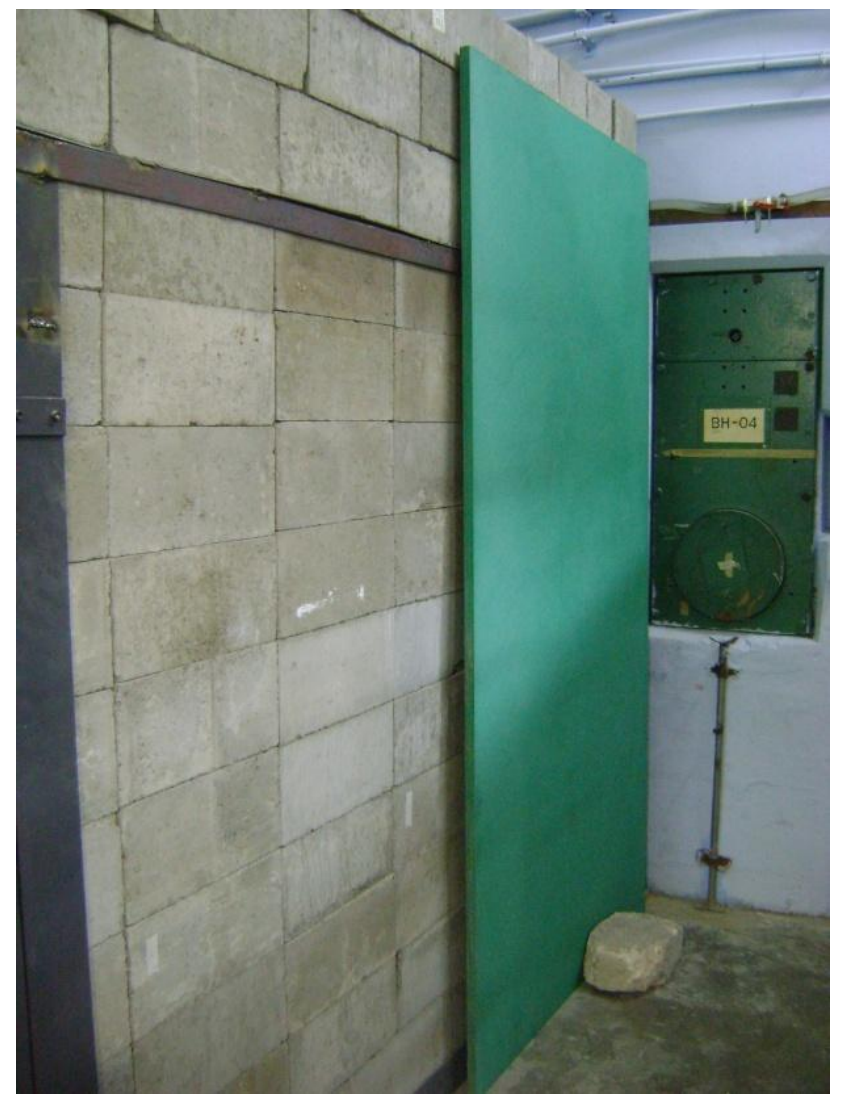

Figura 57-Placa de polietileno borada junto à blindagem biológica da instalação de pesquisa em $B N C T$.

Entre as instalações das melhorias definitivas na blindagem biológica foram realizadas as medidas experimentais com TLD's e as folhas de Au para isto foram marcados pontos no lado interno e externo da blindagem biológica e estes pontos estão apresentados na figura 58, estes pontos estão distantes do chão em 78 centímetros e coincidem com o centro do canal de irradiação. 


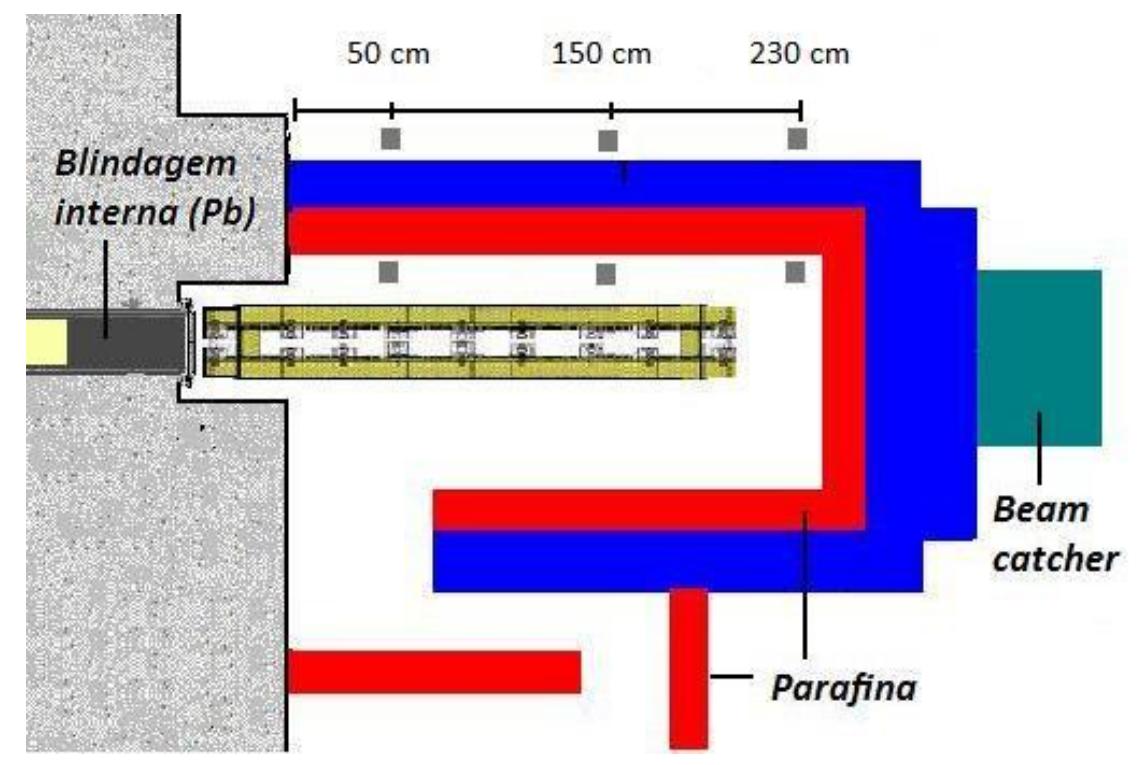

Figura 58 - Pontos para as medidas experimentais utilizando TLD's e folhas de Au.

As medidas experimentais foram realizadas durante 4 horas utilizando a blindagem interna removida e para que fosse possível retirar os kits internos que seguravam os TLD's e as folhas de Au foi realizado um sistema de cordas para que se retirar os kits sem a necessidade de entrar na instalação. Isto é necessário devido à alta dose que se toma quando se entra na instalação com a blindagem interna removida.

Cada kit era composto com os seguintes TLD's: 2 TLD's 600; 2 TLD's 700 e 2 TLD's 400. Apenas o kit interno na posição $50 \mathrm{~cm}$ possuía folhas de Au porque somente nesta posição foi possível ativar folhas suficientemente para realizar a espectrometria gama. No lado externo não se consegue ativar as folhas suficientemente mesmo com o a blindagem interna removida durante os três dias de operação do reator IEA-R1 e por esta razão não se colocou folhas de Au nos kits externos.

Após a instalação de cada melhoria definitiva foram feitas as leituras dos TLD's dos kits e utilizando a equação 3.4 (para os pares TLD's 600 e 700), no lado interno foi calculado o comportamento da carga obtida na leitura dos TLD's devido a nêutrons térmicos após a instalação de cada melhoria definitiva na blindagem biológica. A figura 59 mostra este comportamento. 


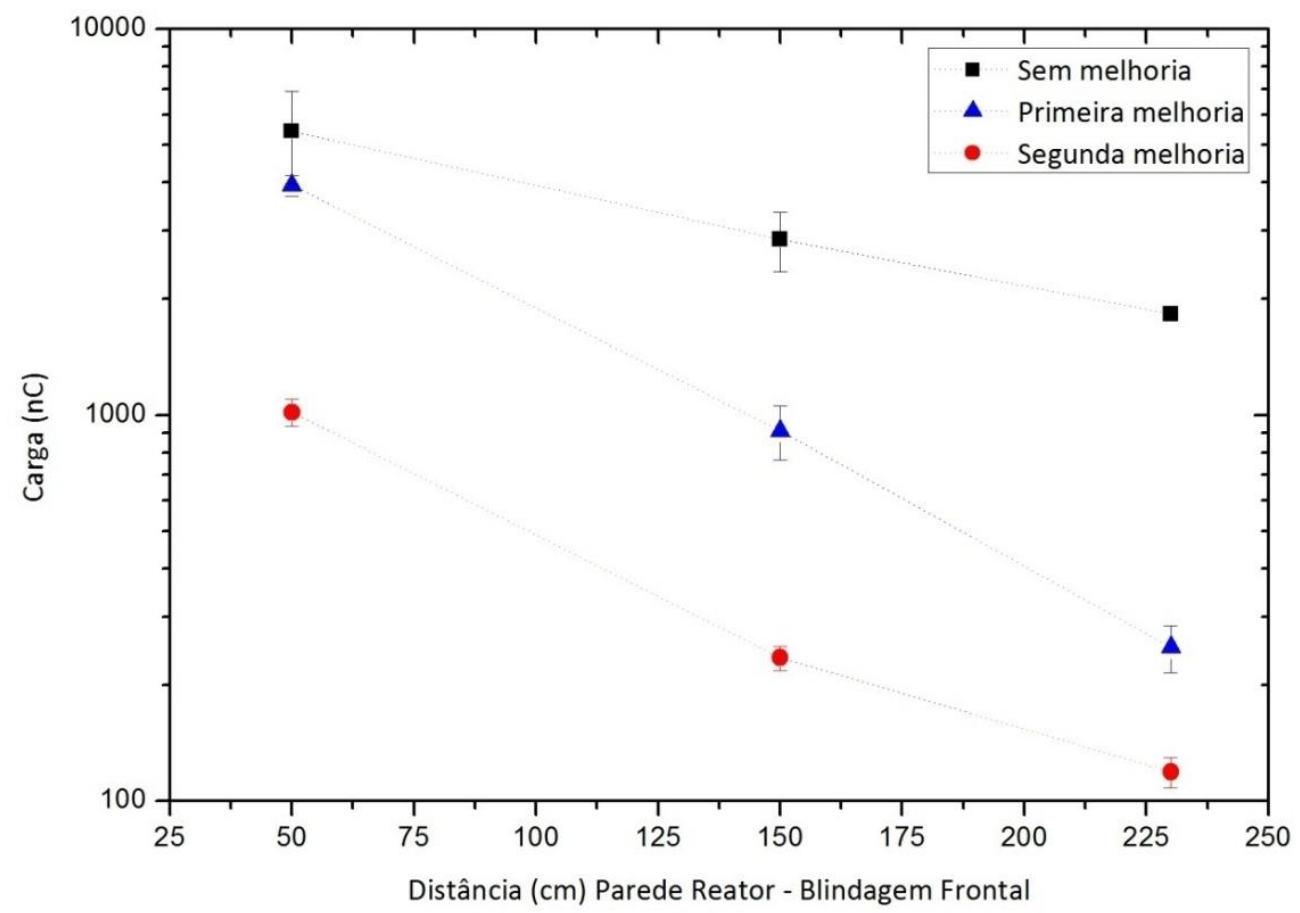

Figura 59 - Comportamento da carga (nC) devido a nêutrons térmicos ao longo da blindagem biológica no seu lado interno.

Estes valores de cargas são os obtidos na leitura dos TLD's 600 depois da correção (equação 3.4) para obter apenas a resposta que é devido a nêutrons térmicos. Esta grandeza é diretamente proporcional ao fluxo de nêutrons térmicos e foi comparada com o cálculo do fluxo térmico obtido via o código MCNP5. A tabela 11 mostra essas comparações entre o calculado e o medido para as reduções percentuais dos três pontos em questão.

Tabela 11 - Comparação entre os valores calculados e medidos para as reduções percentuais do fluxo de nêutrons térmicos nos três pontos em questão.

$\begin{array}{cccc}\text { Distância } & \text { Zero Melhoria > Primeira } & \text { Primeira Melhoria > } & \text { Redução Total } \\ (\mathrm{cm}) & \text { Melhoria } & \text { Segunda Melhoria } & \end{array}$

\begin{tabular}{ccccccc} 
& Calculado (\%) & Medido (\%) & Calculado (\%) & Medido (\%) & Calculado (\%) & Medido (\%) \\
$\mathbf{5 0}$ & $\mathbf{2 6 , 6 \pm 0 , 8}$ & $27,5 \pm 5,2$ & $73,5 \pm 1,0$ & $77,1 \pm 2,3$ & $79,5 \pm 0,7$ & $83,3 \pm 3,6$ \\
$\mathbf{1 5 0}$ & $67,2 \pm 1,0$ & $69,1 \pm 4,6$ & $74,5 \pm 0,9$ & $77,1 \pm 2,8$ & $91,6 \pm 0,9$ & $95,7 \pm 2,3$ \\
$\mathbf{2 3 0}$ & $85,7 \pm 1,0$ & $88,2 \pm 3,7$ & $50,1 \pm 1,0$ & $53,4 \pm 3,6$ & $92,8 \pm 1,0$ & $96,4 \pm 1,9$ \\
\hline
\end{tabular}


Os valores das reduções calculadas no fluxo térmico estão razoavelmente próximos das reduções observadas na carga das leituras do TLD 600 após a utilização da equação 3.4, porém as incertezas dos valores medidos são sempre maiores. Isto porque no cálculo todas as incertezas estão em torno de $1 \%$ e nas medidas experimentais elas são muito superiores e chegam próximo dos $10 \%$. Esta incerteza alta no valor experimental pode ser atribuída ao fato de que para cada ponto utilizou-se apenas dois TLD's de cada tipo, e o resultado atribuído para cada um destes pontos foi a média das duas leituras obtidas e a incerteza atribuída foi o desvio padrão entre essas duas leituras.

Para o ponto que dista $50 \mathrm{~cm}$ da parede do reator foi medido experimentalmente o valor do fluxo de nêutrons térmico e epitérmicos, a tabela 12 mostra os valores destes fluxos após a instalação das duas primeiras melhorias definitivas no lado interno.

Tabela 12 - Valores medidos para o fluxo de nêutrons térmico e epitérmico na posição que dista $50 \mathrm{~cm}$ da parede do reator.

\begin{tabular}{|c|c|c|c|c|c|}
\hline \multicolumn{2}{|c|}{ Zero Melhoria } & \multicolumn{2}{|c|}{ Primeira Melhoria } & \multicolumn{2}{|c|}{ Segunda Melhoria } \\
\hline \multicolumn{2}{|c|}{$\left(\mathrm{n} / \mathrm{cm}^{2} . \mathrm{s}\right)$} & \multicolumn{2}{|c|}{$\left(\mathrm{n} / \mathrm{cm}^{2} . \mathrm{s}\right)$} & \multicolumn{2}{|c|}{$\left(\mathrm{n} / \mathrm{cm}^{2} . \mathrm{s}\right)$} \\
\hline$(3,00 \pm 0,11) \cdot 10^{6}$ & $(1,80 \pm 0,09) \cdot 10^{5}$ & $(2,16 \pm 0,09) \cdot 10^{6}$ & $(3,42 \pm 0,26) \cdot 10^{4}$ & $(4,55 \pm 0,04) \cdot 10^{5}$ & $(2,18 \pm 0,17) \cdot 10^{4}$ \\
\hline
\end{tabular}

Estes valores de fluxo foram medidos utilizando as equações da seção 2.5 deste trabalho e as folhas foram submetidas à espectrometria gama no mesmo dia em que foram irradiadas para evitar perda de estatística devido à queda na atividade da folha. Após as medidas destas folhas estes valores foram comparados com os obtidos no cálculo via o código MCNP5 e a tabela 13 mostra as reduções percentuais para cada etapa envolvida. 
Tabela 13 - Reduções percentuais no fluxo térmico e epitérmico na posição que dista $50 \mathrm{~cm}$ da parede do reator.

\section{ZERO MELHORIA > PRIMEIRA MELHORIA}

\begin{tabular}{cccc}
$\begin{array}{c}\text { Calculado (\%) } \\
26,6 \pm 0,8\end{array}$ & $\begin{array}{c}\text { Medido (\%) } \\
28,0 \pm 0,1\end{array}$ & $\begin{array}{c}\text { Calculado (\%) } \\
76,5 \pm 0,7\end{array}$ & $\begin{array}{c}\text { Medido (\%) } \\
81,0 \pm 0,3\end{array}$ \\
\hline & PRIMEIRA MELHORIA > SEGUNDA MELHORIA & \\
Calculado (\%) & Medido (\%) & Calculado (\%) & Medido (\%) \\
$73,5 \pm 1,0$ & $78,9 \pm 0,1$ & $25,9 \pm 1,0$ & $36,25 \pm 0,3$ \\
\hline \multicolumn{4}{c}{ REDUÇÃo TOTAL } \\
\hline \\
Calculado (\%) & Medido (\%) & Calculado (\%) & Medido (\%) \\
$79,5 \pm 0,7$ & $84,8 \pm 0,1$ & $82,6 \pm 0,9$ & $87,8 \pm 0,2$ \\
\hline
\end{tabular}

De forma geral os resultados experimentais para o lado de dentro da blindagem biológica mostraram que os efeitos das blindagens e suas respectivas reduções foram maiores que as calculadas com o auxilio do código MCNP5, porém os cálculos na maioria dos casos mostraram-se coerentes com as medidas, considerando as respectivas incertezas. Existe um caso apenas onde o valor calculado se mostra incompatível com o medido: a segunda redução causada no fluxo epitérmico devido à instalação da segunda melhoria.

Este resultado pode ser atribuído a diversos fatores envolvidos no cálculo, o principal é o fato que a construção da fonte para a realização das simulações envolveu uma série de simplificações que vão desde a escolha do uso do espectro de fissão até a fonte caracterizada junto à parede da piscina (figura 22), estas simplificações impossibilitam uma dosimetria absoluta e os resultados experimentais mostram que sua aplicação deve ser cuidadosa até em medidas relativas, pois na maioria dos casos o cálculo sobreestimou os valores medidos.

Existem também alguns outros fatores de geometria na modelagem que podem ajudar a justificar estes resultados, um deles é o fato que a construção da blindagem 
biológica da instalação não é paralela ao canal de irradiação, existe uma pequena inclinação entre o canal de irradiação e a blindagem biológica devido ao fato da parede do reator ser cilíndrica (figura 1) que não foi levada em conta, isto para facilitar a construção da geometria no código MCNP5.

Outros fatores de geometria podem ser discutidos tais como a instalação das melhorias, na inserção da primeira melhoria na modelagem geométrica não foi considerada nenhuma fresta entre as peças de polietileno e o canal de irradiação e durante a instalação das peças foi observado que por mais que o desenho das peças tenha sido feito com o auxílio das plantas de construção do canal de irradiação estas frestas foram observadas, utilizaram-se pequenos pedaços finos de isopor para sustentar as placas e cobrir as frestas.

Já na confecção da segunda melhoria utilizou-se um total de 18 placas para alcançar os 30 centímetros que foram simulados e nessa simulação o túnel foi modelado como uma peça só, e por mais que se prendessem bem as 18 placas com o auxilio de braçadeiras com sistema de travamento (insulok) não é possível garantir que não existe lacunas de ar entre as placas.

Outro detalhe que não foi levado em conta na simulação é a mesa de apoio, ela não é peça única e é praticamente uma armação de aço (na figura 25 é possível visualizar a mesa de apoio), escolheu-se não modelar a mesa de apoio nas simulações porque se pensou que a mesa justamente por não ser uma peça contínua ela não interferiria significativamente nos resultados, entretanto os resultados experimentais mostram que há a necessidade refinamentos na modelagem geométrica e na fonte utilizada.

Após as leituras dos TLD's externos observou-se que o funcionamento do par TLD 600 e 700 não é aconselhável para campos mistos aonde a contribuição de gama é muito pequena, pois os TLD's 700 não conseguiram gerar uma curva TL que conseguisse se sobrepor ao background da leitora de TLD's. A equação 3.4 foi utilizada entretanto apenas com o fator de selecionamento e os resultados das leituras do TLD's 600 para os três pontos externos estão apresentados na figura 60 . 


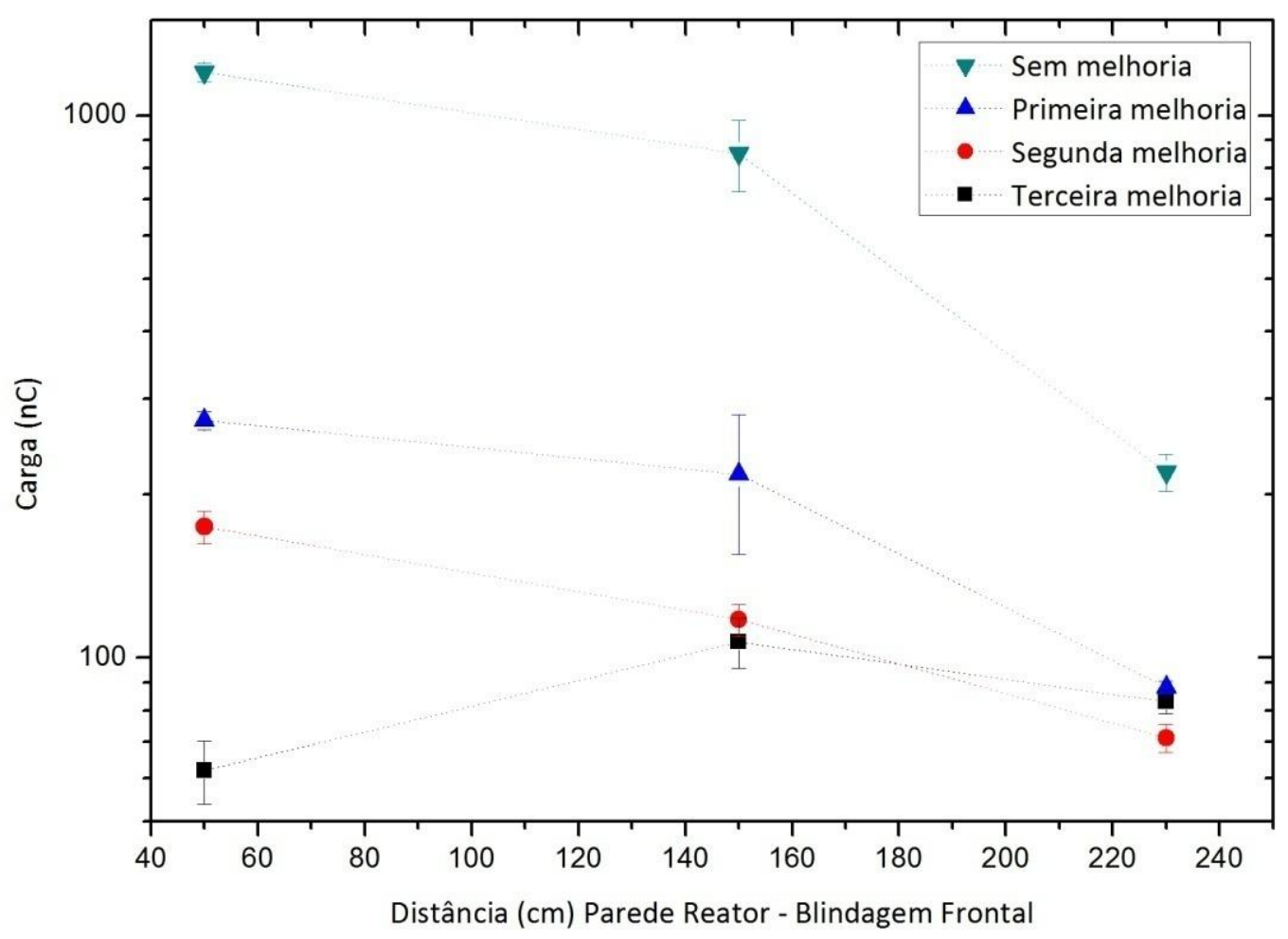

Figura 60 - Resposta dos TLD's 600 nos três pontos externos da blindagem biológica após cada melhoria instalada.

Estes TLD's foram lidos com a tensão da fotomultiplicadora ajustada em $1150 \mathrm{~V}$, esta tensão é a máxima que a leitora utilizada consegue alcançar, porém os TLD's que fizeram parte das ultimas medidas estiveram com suas curvas TL's próximas dos pontos de ruído de fundo evidenciando que estas medidas no lado exterior seriam mais bem executadas com um tempo maior de irradiação.

As cargas dos TLD's 600 são proporcionais ao fluxo térmico e as reduções percentuais observadas nas cargas dos TLD's 600 foram comparadas com as reduções percentuais do fluxo térmico calculadas com o auxílio do código MCNP5, estas comparações estão apresentadas na tabela 14. 
Tabela 14 - Reduções percentuais no lado externo da blindagem biológica.

\begin{tabular}{|c|c|c|}
\hline \multicolumn{3}{|c|}{ ZERO MELHORIA PARA PRIMEIRA MELHORIA } \\
\hline Posição & CALCULADO (\%) & MEDIDO (\%) \\
\hline 50 & $81,9 \pm 6,8$ & $77,1 \pm 3,5$ \\
\hline 150 & $70,1 \pm 6,6$ & $74,3 \pm 13,2$ \\
\hline 230 & $51,8 \pm 5,1$ & $59,8 \pm 5,6$ \\
\hline \multicolumn{3}{|c|}{ PRIMEIRA MELHORIA PARA SEGUNDA MELHORIA } \\
\hline Posição & CALCULADO (\%) & MEDIDO (\%) \\
\hline 50 & $62,1 \pm 5,3$ & $36,3 \pm 4,1$ \\
\hline 150 & $51,8 \pm 6,1$ & $45,98 \pm 6,43$ \\
\hline 230 & $29,0 \pm 5,5$ & $19,3 \pm 3,6$ \\
\hline \multicolumn{3}{|c|}{ SEGUNDA MELHORIA PARA TERCEIRA MELHORIA } \\
\hline Posição & CALCULADO (\%) & MEDIDO (\%) \\
\hline 50 & $48,5 \pm 5,2$ & $64,4 \pm 4,5$ \\
\hline 150 & $23,4 \pm 3,4$ & $9,0 \pm 9,8$ \\
\hline 230 & $23,0 \pm 4,0$ & $-16,5 \pm 3,3$ \\
\hline \multicolumn{3}{|c|}{ REDUÇÃO TOTAL } \\
\hline Posição & CALCULADO (\%) & MEDIDO (\%) \\
\hline 50 & $96,5 \pm 7,3$ & $94,8 \pm 7,2$ \\
\hline 150 & $88,9 \pm 6,9$ & $87,4 \pm 8,3$ \\
\hline 230 & $73,7 \pm 8,4$ & $62,2 \pm 6,7$ \\
\hline
\end{tabular}

As medidas dos TLD's 600 no lado externo da blindagem para a primeira melhoria se mostraram coerentes com os resultados do cálculo com o código MCNP5, porém para a segunda melhoria os resultados dos cálculos superestimaram em muito os valores das reduções. Isto é uma conseqüência direta da discrepância observada na medida do fluxo epitérmico no lado interno e esta discrepância provavelmente ocorre no fluxo rápido, e são estes dois fluxos contribuem muito para o fluxo térmico no lado externo da blindagem biológica.

Para a terceira melhoria o valor medido é maior que o valor calculado para a redução no primeiro ponto (posição $50 \mathrm{~cm}$ ), isto pode ser atribuído ao fato que não é 
disponível a composição exata da placa de polietileno borada, o que se fez foi modelar a placa sendo $95 \%$ polietileno puro e o restante de boro natural, entretanto esta não é a real composição da placa e, além disso, a densidade da placa de polietileno borada foi considerada a mesma que a da placa de polietileno puro, pois o fabricante também não fornece essa informação. Uma alternativa para se simular essa placa de polietileno borada é analisar em um dos laboratórios do IPEN a exata composição.

Para a redução total os valores calculados estão mais coerentes com os valores medidos isto por que ocorre uma compensação entre os efeitos das melhorias adicionadas, isto é, uma acaba sobreestimando e outra superestimando o valor medido e na redução total os dois valores convergem. Na ultima posição essa concordância não é tão evidente, isto deve ocorrer por que para a terceira melhoria a redução neste ponto é inexistente, ela tem um valor negativo, ou seja, as medidas dos TLD's acusaram um valor maior do que as medidas após a segunda melhoria. Isto ocorre porque em uma medida com o TLD 600 em campos aonde o fluxo de nêutrons térmicos é pequeno a variação da resposta do TLD 600 tende a aumentar.

De forma geral, medidas e cálculos quando se trata de problemas de blindagem com atenuação drástica, é difícil de obter resultados confiáveis. O código MCNP5 é uma poderosa e consagrada ferramenta de cálculo, mas o código necessita de partículas para fornecer um resultado confiável e em problemas de blindagem o que se procura é justamente aniquilar as partículas.

Entretanto, existem técnicas de redução de variância que driblam este problema, porém seu uso deve ser cauteloso e o próprio manual do código afirma que às vezes utilizar técnicas de redução de variância se trata mais de uma arte do que uma técnica em si. Neste trabalho a técnica utilizada é a mais comum e simples, porém utilizando-a consegue-se alcançar incertezas da ordem de $8 \%$ em média sendo que para os primeiros pontos esta incerteza é em torno de $6 \%$ porém à medida que se afasta as incertezas chegam a valores próximos de $11 \%$ e ainda assim os resultados para o cálculo do fluxo térmico utilizaram um tempo bastante expressivo de processamento, da ordem de 3 semanas a 4 semanas.

As medidas experimentais apresentadas neste trabalho podem ser complementadas com o auxílio de folhas de ativação para fluxo rápido e outros tipos de dosímetros podem ser implementados para realizar uma dosimetria de nêutrons que 
cubra todo o espectro energético dos nêutrons que atravessam a blindagem biológica. Já o cálculo com o auxilio do código MCNP5 apresenta as limitações já explicadas anteriormente e um refinamento da modelagem da fonte e algumas correções na geometria da simulação são necessárias.

Mas, é razoável afirmar que os valores alcançados com o cálculo são coerentes com os valores medidos dentro das limitações já discutidas e que os valores medidos experimentalmente, de forma geral, geram reduções maiores do que as previstas com o auxílio do código. Isto levando em conta a natureza do problema que este trabalho se propõe a resolver é uma boa característica, pois quanto mais se reduz a interferência nos equipamentos do canal seis mais próximos de alcançar o objetivo se está, porém é um nítido sinal de um erro sistemático que ocorre na parte de cálculo.

Reduzir a interferência o máximo possível é o principal objetivo deste trabalho e após a adição destas melhorias na blindagem biológica observou uma redução media na carga dos TLD's 600 de $(81,50 \pm 17,06) \%$, esta redução na carga do TLD 600 é diretamente proporcional ao fluxo térmico e é nesta região de energia que estão os nêutrons que causam a interferência em níveis de background nos equipamentos do canal seis.

Entretanto, apenas com essas melhorias não é possível chegar à conclusão que não existe mais a interferência em background, e a medida experimental que responderia esse questionamento não depende apenas do grupo que utiliza o canal de irradiação três do reator IEA-R1 para realizar pesquisas envolvendo BNCT. 


\section{5 - CONCLUSÕES e SUGESTÕES DE ATIVIDADES FUTURAS}

A instalação de pesquisa em BNCT possui uma blindagem biológica que atende as normas de radioproteção, porém quando se remove sua blindagem interna para utilizar o canal, tal como realizar trocas de amostras a serem irradiadas, o nível de background no salão de experimentos do reator IEA-R1 aumenta. Essa pequena variação no background, apesar de não ser prejudicial em termos de proteção radiológica, interfere nas medidas do grupo de pesquisa em difração de nêutrons que utiliza o canal de irradiação seis do reator IEA-R1.

Para que fosse possível que esses dois grupos de pesquisa utilizassem o reator IEAR1 ao mesmo tempo, um conjunto de melhorias iniciais foi planejado para tentar eliminar a interferência de nêutrons térmicos o mais rápido possível. Para isto utilizaram-se blindagens para nêutrons já existentes em de um laboratório do CEN/IPEN e do CRPQ/IPEN, e utilizando o detector para nêutrons térmicos Identfinder disponibilizado pelo serviço de radioproteção do IEA-R1. Esta etapa do trabalho foi fundamental para se quantificar a sensibilidade dos equipamentos do grupo de pesquisa do canal de irradiação seis e também para guiar as futuras atividades posteriores deste trabalho mesmo não tendo sido alcançada a situação de não interferência na utilização simultânea dos dois grupos de pesquisas do reator IEA-R1.

Após esses estudos iniciais, foi planejada uma série de melhorias na blindagem biológica da instalação para BNCT utilizando o código de transporte de radiação MCNP5; essas melhorias foram avaliadas realizando experimentos envolvendo detectores de ativação e dosímetros termoluminescentes.

Com auxilio do código MCNP5 simulou-se um conjunto de melhorias na blindagem biológica, obtendo-se nos cálculos uma redução média o fluxo de nêutrons térmicos em $(89,02 \pm 9,17) \%$ no lado exterior da blindagem biológica. Este conjunto de melhorias foi então confeccionado de acordo com as simulações e verificou-se experimentalmente, utilizando dosímetros termoluminescentes uma redução média de $(81,50 \pm 17,06) \%$ na dose devido a nêutrons térmicos. 
A convergência destes resultados mostra que a metodologia adotada para o cálculo é razoavelmente boa e adequada dentro dos seus limites já discutidos, porém há a necessidade de se refinar mais a fonte empregada na simulação e corrigir pequenos detalhes de geometria, isto juntamente com novas medidas de fluxo rápido utilizando diferentes tipos de folhas de ativação pode ajudar a melhorar ainda mais a convergência entre os resultados calculados com o código e os resultados medidos experimentalmente.

As reduções nos fluxos epitérmico e rápido calculadas dentro da blindagem com o MCNP5 foram significativas evidenciando que mais melhorias podem conseguir diminuir ainda mais o background quando se remove a blindagem interna da instalação de pesquisas em BNCT. Entretanto, apenas essas reduções podem ser insuficientes para solucionar o problema de interferência, visto que o detector que sente essa variação de background no canal de irradiação seis é extremamente sensível, tanto que o grupo de que realiza pesquisa envolvendo neutrongrafia também interfere quando realiza medidas.

Existe a possibilidade de se cobrir com cádmio o lado da blindagem biológica que fica em frente aos equipamentos do canal de irradiação seis. O cádmio necessário para essa cobertura foi adquirido e fez parte do planejamento de melhorias a serem confeccionadas, porém como já discutido na seção 3.5 deste trabalho não foi possível laminar o material.

Além de todo trabalho envolvendo melhorias na blindagem foi realizado em conjunto com o grupo de pesquisa em BNCT a implementação de uma metodologia de dosimetria de nêutrons térmicos utilizando o par de dosímetros termoluminescentes TLD 600 e 700.

Novas melhorias podem ser realizadas na blindagem biológica visando diminuir ainda mais a interferência nos equipamentos do canal de irradiação seis, a seguir algumas sugestões de melhorias são apresentadas.

I. Injeção de $\mathrm{H}_{2} \mathrm{O}$ no canal de irradiação durante a remoção da blindagem interna da instalação de pesquisa em BNCT.

II. Cobertura de cádmio ( $1 \mathrm{~mm}$ de espessura) em parte da blindagem biológica.

III. Estender o túnel já construído até o final da mesa de apoio. 
IV. Construção de uma parede extra de concreto barita junto ao lado da blindagem biológica em frente aos equipamentos do canal de irradiação seis.

V. Cobrir a fresta entre a blindagem biológica e a parede do reator com uma blindagem tipo argamassa contendo material hidrogenado e $5 \%$ de boro na sua composição.

Todas essas sugestões de melhorias podem ser realizadas sem prejudicar a funcionalidade da instalação de pesquisas em BNCT. Essas novas melhorias juntamente com um refinamento da metodologia de cálculo e com novos detectores na parte experimental podem solucionar o problema de interferência em nível de background que acontece toda vez que se retira a blindagem interna para se utilizar a instalação de pesquisas em BNCT. 


\section{REFERÊNCIAS BIBLIOGRÁFICAS}

Abdel-Haleem, A., Zohny, E., \& Zaghloul, R. A., The use of neutron attenuation in borated materials as an indicator of their boron content. Radiation Phys. Chem. , 233-235, (1994).

Attix, F. H., Introduction to radiological physics and radiation dosimetry. Weinheim: WILEY-VCH Verlag GmbH \& Co. KGaA, (2004).

Beckurtz, K., \& Wirtz, K., Neutron physics. Nova York: Springer . (1964).

Bittelli, U., Medida e cálculo da distribuição espacial e energética de nêutrons no núcleo do reator IEA-R1. São Paulo : Dissertação de Mestrado, (1988).

Boneca Medical Company. (s.d.). Boneca. Acesso em 17 de Novembro de 2010, disponível em Boneca: www.boneca.fi

Bortolussi, S., Altieri, S., Protti, N., Stella. S, Ballarini, F., Bruschi, P., et al. (2010). 10B measurement by alpha spectrometry and $10 \mathrm{~B}$ imaging by neutron autoradiography as a contribution to the understanding of BNCT radiobiology in oral cancer and liver metastases animal models. Proceedings of 14th international congress on neutron capture therapy (pp. 59 - 62). Buenos Aires: Comisión Nacional de Energía Atómica.

Briesmeister, J. F. (2001). MCNP - A general Monte Carlo N-Particle transport code, version 5. Los Alamos National Laboratory Report.

Campos, L. L. (1998). Termoluminescência de materiais e sua aplicação em dosimetria da radiação. Cerâmica , ISSN 0366-6913.

Campos, T. P. (2000). Considerações Sobre a Terapia de Captura de Nêutrons pelo Boro. Revista Brasileira de Cancerologia , 283-92, vol. 46.

Campos, T., \& Andrade, L. (2000). Viabilidade da braquiterapia via Cf-252 para tratamento de tumores de glandulas salivares. $V$ Encontro Nacional de Aplicaçõe Nucleares .

Carrillo, R. E., Uribe, R. M., Woodruff, G. L., \& Stoebe, T. G. (1987). Lithium fluoride (tld 700) response to a mixed thermal neutron and gamma field. Radiation Protection Dosimetry, $55-57$.

Casswell, R. S., J.J., C., \& Randolph, M. L. (1980). Kerma factors for neutron energies below 30 MeV. Rad. Res. 83, 217.

Coderre, J., \& Morris, G. (1999). The Radiation Biology of Boron Neutron Capture Therapy. Radiation Research , 151: 1-10. 
Coelho, P., Ferreira, D. J., Zahn, G., Rogero, J. R., Maiorino, J., Damy, M. d., et al. (1996). Estudos para a implantação de uma instalação para NCT no reator IEA-R1 do IPENCNEN/SP. V ENAN .

Comissão Nacional de Energia Nuclear. (1988). Direstrizes básicas de proteção radiológica. CNEN NE 3.01.

Delgado, J. L. A., On the use of Lif TLD 600 in neutron gamma mixed fields. Radiation Protection Dosimetry Advance Access (2007), vol. 125, 237 - 330.

El-Khatib, A., Fawzy, M. A., \& Abou Taleb, W. (1996). Attenuation of D+T neutrons in borated low density polyethylene. Material Letters , 59-63.

Evans, R. D. (1968). Radiation Dosimetry II. Nova York: Academic Press.

Fairchild, R. G. (1989). Clinical aspects of neutron capture therapy. Nova York: Plenum Press.

Flores, F. F., Coelho, P., Muniz, R., Souza, G., Arruda-Neto, J., \& Maria, D. (2010). Antitumor potential induction and free radicals production in melanoma cells by boron neutron capture therapy. International Congress on Neutron Therapy Capture Therapy (pp. 137-140). Buenos Aires: Comisión Nacional de Energía Atómica.

Fujii, T., Tanaka, H., Maruhashi, A., Ono, K., \& Sakurai, Y. (2010). Study on optimization of multi ionization-chamber system for BNCT. Proceedings of 14th International Congress on Neutron Capture Therapy (pp. 177-180). Buenos Aires: Comisión Nacional de Energía Atómica.

H.Soloway, A., Barth, R. F., Gahbauer, R. A., Blue, T. E., \& Goodman, J. H. (1997). The rationale and requirements for the development of boron neutron capture therapy of brain tumors. Journal of Neuro- Oncology 33 , pp. 9-18.

Hatanaka, H. (1986). Clinical Experience of Boron Neutron Capture Therapy of Brain Tumors. Japan: Nishimura Niigata.

INCA. (10 de Novembro de 2010). O que é câncer ? - INCA. Acesso em 10 de Novembro de 2010, disponível em Instituto Nacional de Câncer: www.inca.gov.br

International Atomic Energy Agency. (2001). Current status of neutron capture therapy. Vienna.

International Comission on Radiation Units and Measurements. (1971). Radiation quantities and units, Report 19. Bethesda.

Junior, V. C. (2008). Caracterização do campo de nêutrons na instalação para estudo em $B N C T$ no reator IEA-R1 (dissertação mestrado). São Paulo: IPEN. 
Kase, K. R., Jarngard, B. E., \& Attix, F. H. (1987). The dosimetry of ionizing radiation, vol I. Orlando: Academic Press.

Knoll, G. F. (1979). Radiation Detection and Measurement. Nova York: John Wiley \& Sons.

Korea Atomic Energy Research Institute. (s.d.). Table of nuclides. Acesso em 13 de 07 de 2010, disponível em http://atom.kaeri.re.kr/

Lamarsh, J. R. (1972). Introduction to Nuclear Reactor Theory. California: Addison-Wesley Publishing Company.

Locker, G. L. (1936). Biological Effects and Therapeutic Possibillities of Neutrons. A M J Roentgenol , 1-13.

Martinez, C. G. \& Mould, R. (1990). Brachytherapy HDR and LDR, proceedings brachytherapy meeting remote afterloading. (Thesis) . Michigan, E.U.A.

Ministério da Saúde . (2009). Estimativa 2010 : Incidência de Câncer no Brasil. Rio de Janeiro, RJ.

Moss, R., Izawa, O. A., Brugger, R., Constantine, G., Harling, O., Liu, H. B., et al. (1997). The requirements and development of boron neutons beams for neutron capture therapy of brain cancer. Journal of Neuro-Oncology 33 , pp. 27-40.

Muniz, R. O. (2010). Desenvolvimento de um simulador antropomórfico para simulação e medidas de dose e fluxo de nêutrons na instalação para estudos em BNCT. (dissertação de mestrado). São Paulo: Instituto de Pesquisas Energéticas e Nucleares.

Muniz, R. O., Coelho, P. R. P., Silva, G. S., Siqueira, P T. D., \& Souza, G. S. (2010). Neutron flux and gama dose profile measurements and calculation along a phantom in the BNCT facility of IEA-R1 reactor. International Congress on Neutron Capture Therapy (pp. 387390). Buenos Aires: Comisión Nacional de Energía Atómica.

Oak Ridge National Laboratory. (1975). DOT 3.5 Two Dimensional Discrete ordinates Radiation Transport code. New Mexico: Radiation Shielding Information Center.

Piesch, E., Burgkhardt, B., \& Sayed, A. M. (1978). Activation and damage effects in tld 600 after neutron irradiation. Nuclear instruments and methods , 179-184.

Segre, E. (1980). Dos Raios X aos Quarks. Brasilia, Distrito Federal: Editora Universidade de Brasília.

Silva, G. S., Coelho, P. R. P., \& Siqueira, P. T. D. (2002); Shielding design for a research facility in the IEA-R1 reactor. PHYSOR. Seoul.

Slatkin, D. N. (1991). A history of Boron neutron capture therapy of brain tumors. Brain, pp. 1609-1629. 
Sweet, W. H. (1997). Early history of development of boron neutron capture therapy of brain tumors. Journal of Neuro - Oncology 33 , pp. 19 -26.

Tauhata, L., Salati, I. P., Prinzio, R. D., \& Prinzio, A. D. (2003). Radioproteção e Dosimetria: Fundametos. Rio de Janeiro: Comissão Nacional de Energia Nuclear.

ThermoScientific. (2011). Acesso em 10 de Janeiro de 2011, disponível em http://www.thermoscientific.com/wps/portal/ts/products/catalog?navigationld=L10422 \&categoryld=81902\&pageNum $=2$

Triolo, A., Brai, M., Marrale, M., Gennaro, G., \& Bartolotta, A. (2007). Study of the glow curves of tld exposed to thermal neutrons. Radiation Protection Dosimetry .

Ujeno, Y. (1992). Clinical experience of BNCT for brain and skins tumor at Kyoto University reactor, in Progress in Neutron Capture Therapy. Nova York: Plenum Press.

Yoshimura, E. M. (2009). Física das Radiações: interação da radiação com a matéria. Revista Brasileira de Física Médica , 57-67.

Zamenhof, R., Solares, G., \& Kiger III, W. S. (1997). Clinical Treatment planning of subjects undergoing boron neutron capture therapy. Advances in Neutron Capture Therapy, Vol II. 


\section{ANEXO A - Selecionamento TLD 600}

Dosímetros termoluminescentes podem apresentar grande dispersão em suas respostas $\mathrm{TL}$, isso pode ocorrer devido a diversos fatores tais como diferenças entre lotes de fabricação, diferença de densidade de dopante entre um e outro TLD e diferenças entre os procedimentos de rotina no uso do TLD. Para que a resposta de um dosímetro termoluminescente seja a mais reprodutível possível é necessário que ele apresente mesma resposta termoluminescente quando exposto diversas vezes a mesmo campo uniforme de radiação.

O grupo de pesquisas em BNCT realizou um procedimento de selecionamento aonde um lote de 99 TLD's 600 disponíveis foram utilizados em diversas irradiações utilizando o esquema experimental com a fonte de AmBe para que suas respostas fossem comparadas em cada radiação e assim selecionar os que apresentaram maior reprodutibilidade da resposta TL.

Os TLD's foram posicionados em suportes de acrílico totalizando 11 suportes de acrílico eqüidistantes ao redor do anel de parafina sendo que cada continha 9 TLD's em uma matriz de $3 \times 3$. Os TLD's foram expostos a irradiações de $17 \mathrm{~h}$ por 6 vezes. 0 gráfico abaixo mostra os 12 TLD's selecionados depois de todo o procedimento de selecionamento

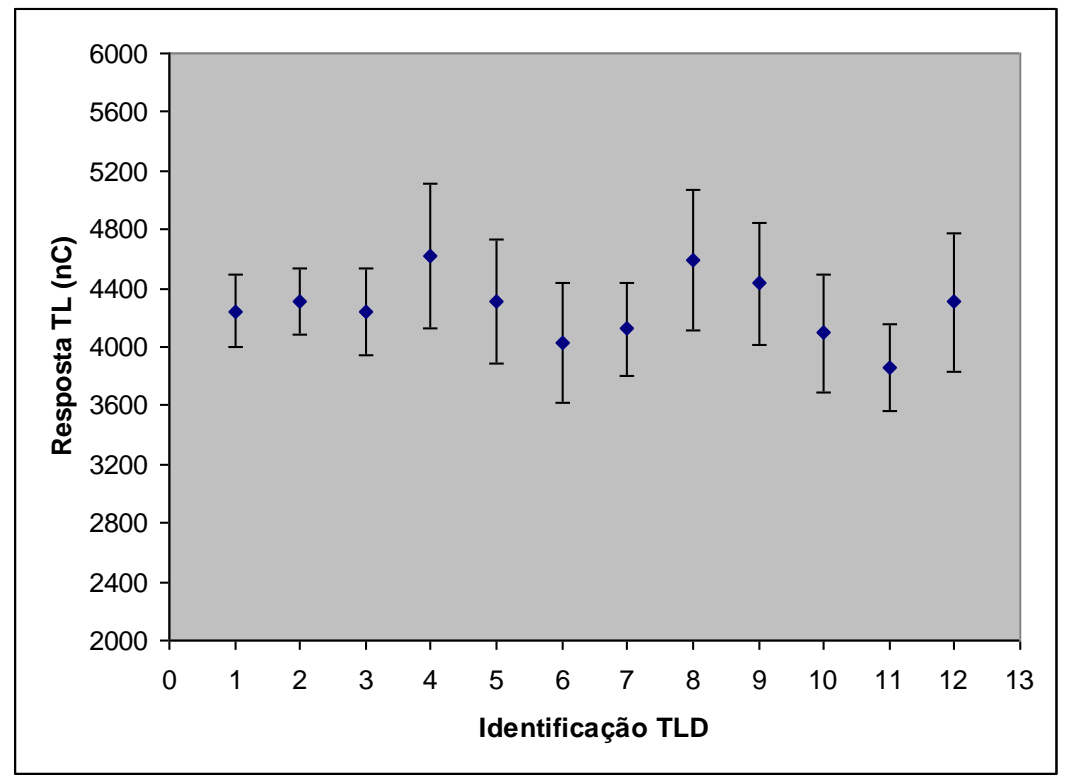

Figura A1- 12 TLD's 600 selecionados na fonte de AmBe 
Apesar de existirem TLD's com incerteza em torno de 10\% esse selecionamento é válido porque o campo de irradiação (uso na instalação de pesquisas para BNCT) presente nos diversos experimentos na qual estes TLD's serão utilizados possui uma taxa de dose devido a nêutrons térmicos muito maior do que o que se consegue com o esquema experimental do selecionamento. E é de se esperar que problemas com incertezas diminuam à medida que se aumenta o volume de dados.

E em posições de medidas experimentais que se situarem depois de blindagem, aonde a dose pode chegar perto da dose alcançada pelo arranjo experimental do selecionamento (baixas taxas de dose), uma diferença de até 10\% entre um TLD 600 e outro pode ser tolerada.

O que se percebeu também é que os TLD's possuíam um comportamento característico devido a sua posição na matriz em que eram posicionados no suporte de acrílico. A figura A2 mostra um gráfico de um suporte que mostra essa diferença de respostas entre as linhas.

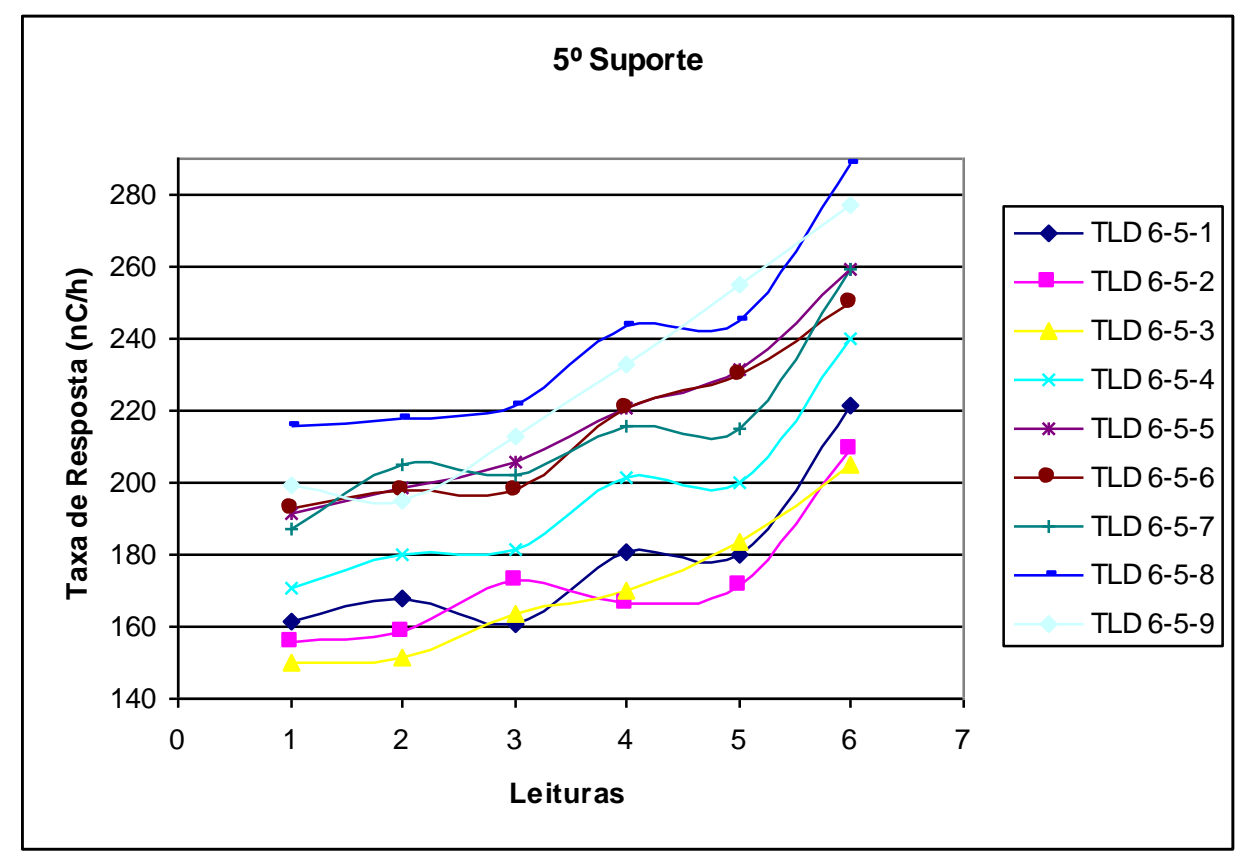

Figura A2: Taxas de Resposta ( $n C / h)$ para cada TLD do 5o suporte de acrílico; A numeração do TLD é $X-Y-Z$, aonde $X$ é o tipo de TLD (6 para 600) e Y é o suporte em que ele está (5o suporte no gráfico acima) e $Z$ é sua posição preenchendo a matriz $3 \times 3$ (1 a 3 corresponde a primeira à linha e assim por diante) 
Percebe-se que os TLD's que preenchiam a primeira linha possuem uma taxa de resposta inferior aos demais isso acontecia porque eles ficavam no limite superior do anel de parafina, com menos parafina entre os TLD's e a fonte. Os TLD's da segunda linha obtiveram uma resposta maior do que os da primeira linha e menores do que os TLD's da terceira linha.

Um desenho simples da geometria da irradiação está na figura $A 3$, na qual pode se perceber a diferença de quantidade de parafina existente entre as linhas da matriz de posicionamento dos TLD's no suporte de acrílico.

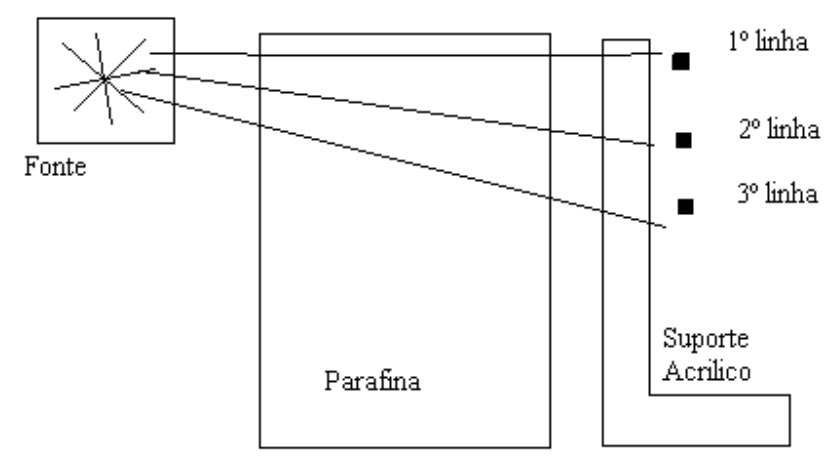

Figura A3 - Desenho da geometria das irradiações feitas no procedimento de selecionamento dos $T L D$ 's 600

O comportamento crescente a cada irradiação das taxas de resposta foi observado para todos os suportes. Esse comportamento foi alvo de investigação porque todos os parâmetros da irradiação (tempo de duração, posição dos suportes e posição do anel de parafina) foram bem controlados.

O que se imaginou foi que deveriam existir interferências das outras fontes existentes no galpão, e de fato, foi descoberto que outros usuários das fontes do galpão tinham deixado por algum intervalo de tempo uma fonte aberta sem blindagem ao redor do arranjo experimental. Como esse foi um comportamento observado em todos TLD's (sem exceção de nenhum) e não havia mais tempo no cronograma para refazer medidas, o selecionamento prosseguiu.

A partir da resposta média dos 12 TLD's 600 foi calculado uma média e a resposta média de cada TLD foi dividido por essa média, o que se encontrou foi um fator individual para cada TLD. A tabela 1 mostra estes fatores individuais e suas incertezas. 
Tabela 1: Fatores individuais para cada um dos 12 TLD's 600 selecinados

\begin{tabular}{|c|c|c|}
\hline TLD & Fator Individual & $\boldsymbol{\sigma}$ Fator \\
\hline 1 & 1,00 & 0,06 \\
\hline 2 & 0,98 & 0,06 \\
\hline 3 & 1,00 & 0,07 \\
\hline 4 & 0,91 & 0,10 \\
\hline 5 & 0,98 & 0,10 \\
\hline 6 & 1,05 & 0,11 \\
\hline 7 & 1,03 & 0,08 \\
\hline 8 & 0,92 & 0,10 \\
\hline 9 & 0,95 & 0,09 \\
\hline 10 & 1,03 & 0,10 \\
\hline 11 & 1,10 & 0,09 \\
\hline 12 & 0,98 & 0,11 \\
\hline
\end{tabular}

Com esses fatores individuais foi calculado um fator de selecionamento que é a média ponderada com a incerteza dos fatores individuais de cada TLD. O valor desse fator é $0,994 \pm 0,024$ e o uso dele é justificado pelo fato de que em um procedimento experimental qualquer na instalação pode se perder a numeração dos TLD's por equivoco ou por algum acidente. 


\section{ANEXO B - Reações $(n, \gamma)$ ao redor da blindagem biológica}

Após cada inserção de melhoria na blindagem também foi requisitado do código MCNP5 que fosse calculado nos pontos externos da blindagem biológica a dose de raios gama devido às interações dos nêutrons com os diversos materiais presentes na simulação. A figura B1 mostra o comportamento da dose gama devido às interações dos nêutrons antes e depois do conjunto de melhorias.

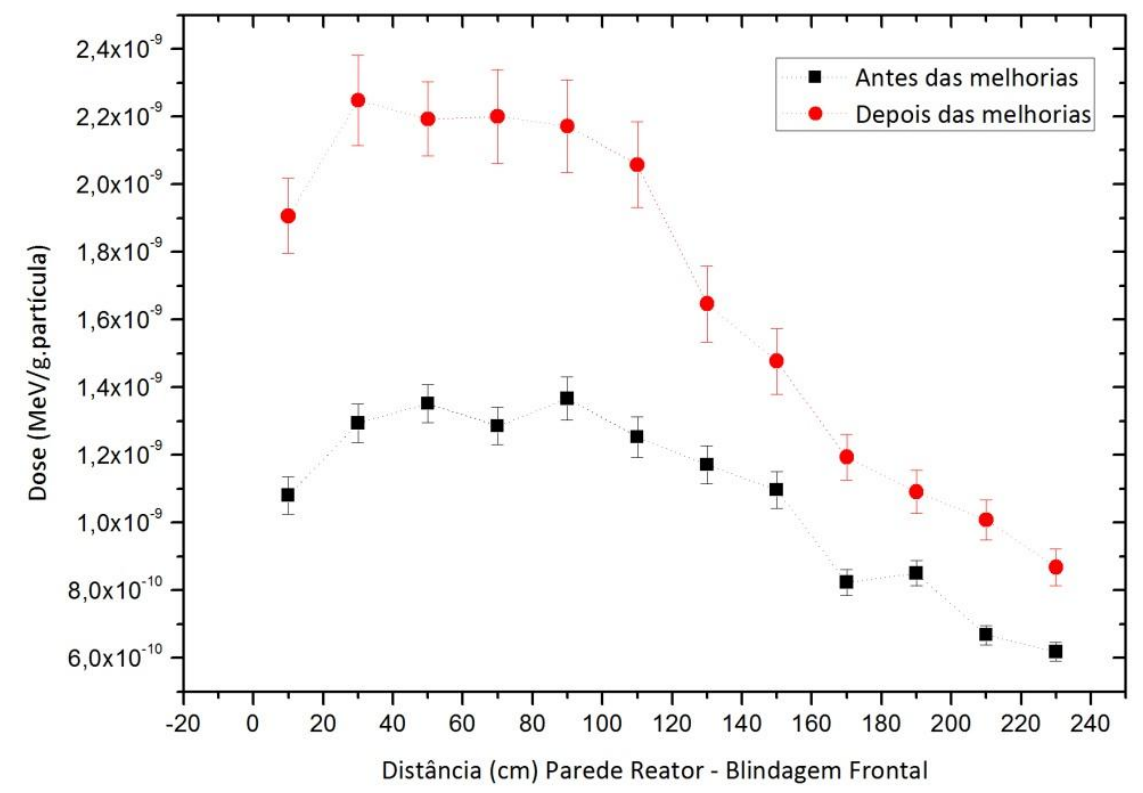

Figura B1 - Comportamento da dose devido aos n'gamas ao longo da blindagem biológica.

A dose devido aos n'gamas não aumentou significativamente de modo geral, entretanto nos primeiros 100 centímetros (posição da placa de polietileno borada) isto ocorre provavelmente devido à reação de captura do nêutron no boro que em 93,7\% das reações é acompanhada de um gama de $478 \mathrm{KeV}$.

A partir do meio até os últimos centímetros esse valor de dose pode ser considerado igual isto porque os n'gamas gerados nas melhorias internas já estão bem longe destes pontos e com bastante material atenuador da própria blindagem biológica. $\mathrm{E}$ esses gamas são apenas das interações dos nêutrons gerados pela fonte utilizada nas simulações, porém isto não é o que se observa, pois existe também um feixe de gamas que vem dos decaimentos dos produtos de fissão que não é levado em conta nessas simulações. 
O dosímetro utilizado para quantificar a dose devido aos raios gamas pelo grupo de pesquisa em BNCT é o TLD 400 e a figura B2 mostra o valor das cargas lidas nas leituras dos TLD's 400 antes e depois do conjunto de melhorias.

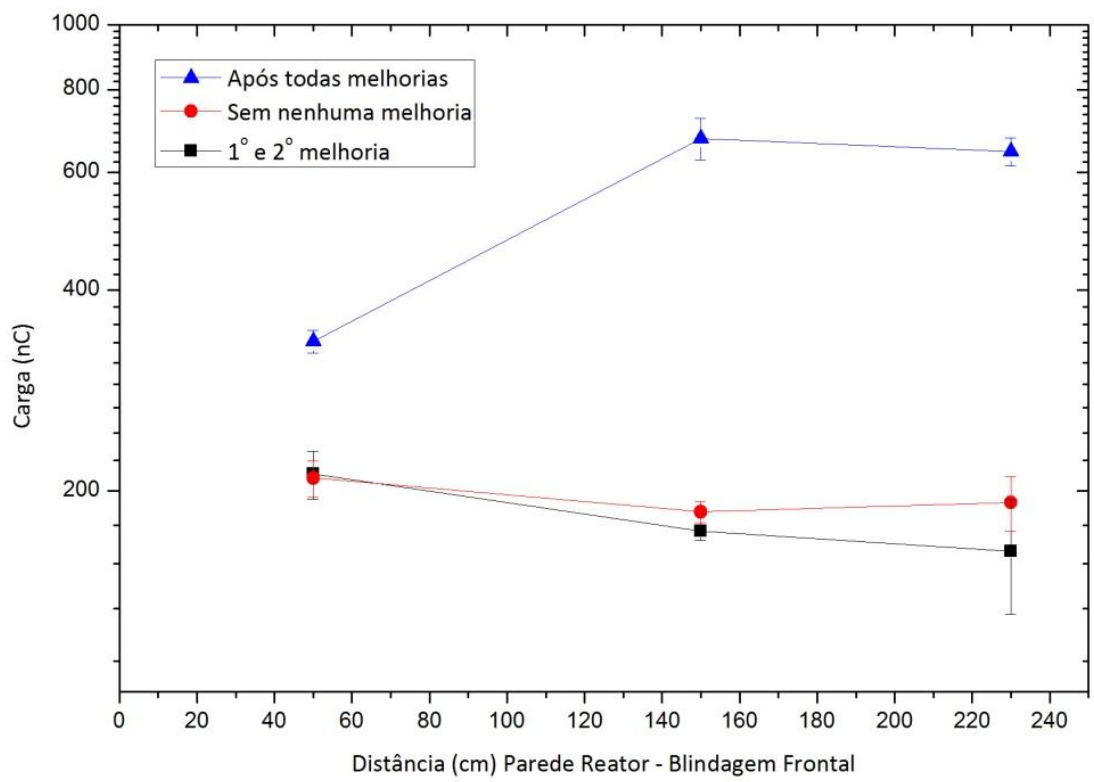

Figura B2 - Valores das leituras dos TLD's 400 no lado externo da blindagem biológica.

É evidente que o comportamento das leituras dos TLD’s 400 após a instalação da placa de polietileno borada é totalmente fora do que se esperava. Sem existir nenhuma razão explicita para tal fato. $\mathrm{O}$ que se fez foi investigar logo no dia seguinte com a ajuda da equipe de radioproteção do IEA-R1 o que poderia estar acontecendo, e foi evidenciado que o background daquela região estava fora do normal. Foi então informado ao grupo de pesquisa que o canal de irradiação quatro poderia estar aumentando significativamente o background daquela região, razão pela qual essa região entre o canal de irradiação três e seis é constantemente isolada pela equipe de radioproteção do IEAR1. A partir de uma análise breve do gráfico da figura B2 é possível afirmar que de fato o nível de dose devido à radiação gama ao redor da blindagem biológica não aumenta a ponto de ultrapassar os limites de radioproteção. 


\section{LISTA DE FIGURAS}

Figura 1: Desenho esquemático do IEA-R1 e seus canais de irradiação

Figura 2 - Interações predominantes em função da energia do fóton incidente e do número atômico do material (Tauhata, Salati, Prinzio, \& Prinzio, 2003)

Figura 3 - Esquema simplificado do efeito Compton .

Figura 4 - Esquema simplificado do efeito fotoelétrico.

Figura 5 - Esquema simplificado da produção de pares

Figura 6 - Esquema do espalhamento elástico entre um nêutron de massa M1 e um núcleo atômico de massa M2 no sistema de laboratório (a), no sistema de centro de massa (b) e de volta ao sistema de laboratório (c); figura obtida da apostila do curso TNR-5764 - Fundamentos de Tecnologia Nuclear - Reatores 28

Figura 7 - Comportamento da atividade da folha de Au ao longo do processo (Bittelii, 1988)...... 32

Figura 8 - Processo de termoluminescência em um TLD (Tauhata, Salati, Prinzio, \& Prinzio, 2003)

Figura 9 - Curva TL para um dosimerto termolumincescente genérico (Campos L. L., 1998) ......... 36

Figura 10 - Esquema simplificado da instalação para pesquisa em BNCT no Reator IEA-R1... 40

Figura 11 - Esquema da blindagem biológica; em vermelho está representado a parafina, em azul está representado o concreto, em preto está representado o chumbo e em verde está representado o beam catcher.

Figura 12 - Foto da blindagem externa e o beam catcher no centro.

Figura 13 - Seções de choque totais para o ${ }^{6} \mathrm{Li}$ (vermelho) e para o ${ }^{7} \mathrm{Li}$ (verde) (Korea Atomic

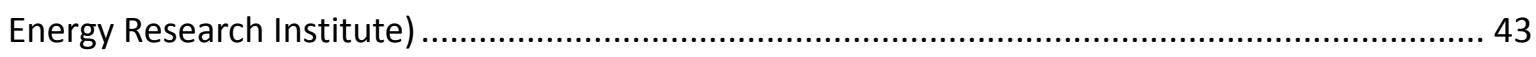

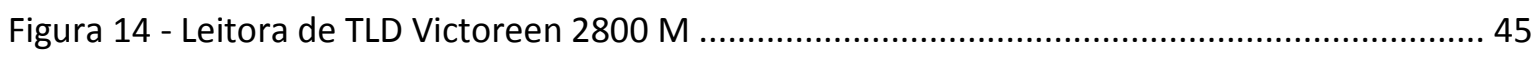

Figura 15 - Esquema simplificado de uma fotomultiplicadora .................................................... 46

Figura 16 - Curva TL para os TLD's 400 (direita) e TLD's 600 e 700 (esquerda) (Muniz R. O., 2010) 47

Figura 17 - Eletrônica associada (direita) e o detector HPGe (esquerda)..... 48

Figura 18 - Modelagem da blindagem biológica; plot superior (direita) e plot lateral (esquerda) . 50

Figura 19 - Plot da modelagem da face do núcleo e do canal de irradiação 52

Figura 20 - Plot axial do canal de irradiação 53

Figura 21 - Espectro energético do fluxo junto à face interna (piscina) da parede do reator IEA-R1 
Figura 22 - Célula de ar aonde se caracterizou uma fonte a partir do espectro da figura 21 54

Figura 23 - Curva de seção de choque de absorção total para o cádmio (Korea Atomic Energy Research Institute)

Figura 24 - Trilho para colocar amostras na cesta de irradiação e uma das câmeras da instalação 57

Figura 25 - Janela do canal de irradiação antes e depois 59

Figura 26 - Mesa de apoio antes e depois 59

Figura 27 - Blindagem externa antes e depois 60

Figura 28 - Pontos para medida dos efeitos das primeiras blindagens adicionadas 60

Figura 29 - Pontos ao redor do equipamento do grupo de pesquisa do canal de irradiação seis... 62 Figura 30 - Plot da modelagem da blindagem biológica aonde está destacado as regiões de tally 64 Figura 31 - Comportamento do fluxo de nêutrons ao longo da blindagem biológica no seu lado interno

Figura 32 - Plot da primeira melhoria definitiva simulada 66

Figura 33 - Comportamento do fluxo de nêutrons ao longo da blindagem biológica no lado interno após a inserção da primeira melhoria na modelagem geometrica.

Figura 34 - Comportamento do fluxo térmico após a inserção da primeira melhoria na modelagem geométrica.

Figura 35 - Atenuação do fluxo térmico ao longo da blindagem biológica em seu lado interno .... 68

Figura 36 - Comportamento do fluxo epitérmico ao longo da blindagem biológica em seu lado interno

Figura 37 - Comportamento do fluxo rápido ao longo da blindagem biologica no seu lado interno 69

Figura 38 - Reduções percentuais para as três faixas de energia. 70

Figura 39 - Distribuição das importâncias para cálculos fora da blindagem biológica 71

Figura 40 - Comportamento do fluxo térmico ao longo da blindagem biológica no seu lado externo.

Figura 41 - Redução do fluxo térmico no lado externo. 72

Figura 42 - Redução do fluxo térmico ao longo da blindagem biológica para o lado interno e externo......

Figura 43 - Arranjos geométricos da modelagem do túnel planejado como segunda melhoria definitiva; visão superior (esquerda) e visão frontal (direita). 
Figura 44 - Comportamento do fluxo epitérmico para as três composições simuladas ao longo da blindagem biológica no seu lado interno. .86

Figura 45 - Comportamento do fluxo rápido para as três composições simuladas ao longo da blindagem biológica no seu lado interno.

Figura 46 - Comportamento do fluxo de nêutrons depois da inserção da primeira e segunda melhoria definitiva.

Figura 47 - Comportamento do fluxo térmico após as inserções da primeira e segunda melhoria definitiva ao longo da blindagem biológica no seu lado interno.

Figura 48 - Reduções percentuais do fluxo térmico ao longo da blindagem biológica no seu lado interno após as inserções das duas melhorias definitivas

Figura 49 - Redução no fluxo de nêutrons após a inserção da segunda melhoria..... 91

Figura 50 - Fluxo térmico no lado externo da blindagem biológica após as inserções das melhorias definitivas na modelagem geométrica da blindagem biológica.

Figura 51 - Reduções percentuais do fluxo térmico ao longo da blindagem biológica no seu lado externo após as inserções das duas melhorias definitivas.

Figura 52 - Esquema frontal da placa de polietileno borada na modelagem geométrica da blindagem biológica no seu lado externo.

Figura 53 - Comportamento do fluxo de nêutrons térmicos após a inserção da placa de polietileno borada na modelagem da blindagem biológica no seu lado externo. .94

Figura 54 - Reduções percentuais no fluxo térmico após as inserções das melhorias definitivas ao longo da blindagem biológica pelo seu lado externo

Figura 55 - Primeira melhoria confeccionada instalada no canal de irradiação 3 do IEA-R1. .96

Figura 56 - Túnel de polietileno puro coberto com cádmio instalado sobre a mesa de apoio da instalação de pesquisas em BNCT.

Figura 57 - Placa de polietileno borada junto à blindagem biológica da instalação de pesquisa em BNCT. 98 
Figura 58 - Pontos para as medidas experimentais utilizando TLD's e folhas de Au. .99

Figura 59 - Comportamento da carga $(\mathrm{nC})$ devido a nêutrons térmicos ao longo da blindagem biológica no seu lado interno .100

Figura 60 - Resposta dos TLD's 600 nos três pontos externos da blindagem biológica após cada melhoria instalada. 104

Figura A1- 12 TLD's 600 selecionados na fonte de AmBe. 115

Figura A2: Taxas de Resposta ( $\mathrm{nC} / \mathrm{h}$ ) para cada TLD do 5o suporte de acrílico; A numeração do TLD é $X-Y-Z$, aonde $X$ é o tipo de TLD (6 para 600) e Y é o suporte em que ele está (50 suporte no gráfico acima) e $Z$ é sua posição preenchendo a matriz $3 \times 3$ (1 a 3 corresponde a primeira à linha e assim por diante). 116

Figura A3 - Desenho da geometria das irradiações feitas no procedimento de selecionamento dos TLD's 600

Figura B1 - Comportamento da dose devido aos n'gamas ao longo da blindagem biológica.......119

Figura B2 - Valores das leituras dos TLD's 400 no lado externo da blindagem biológica 120 


\section{LISTA DE TABELAS}

Tabela 1: Limites de dose anuais (mSv) (Comissão Nacional de Energia Nuclear, 1988) ................ 20

Tabela 2: Valores de fluxo e dose na posição de irradiação (Muniz R.O., 2010) ............................... 41

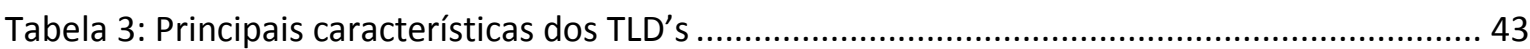

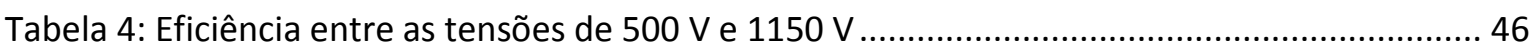

Tabela 5: Parâmetros de leitura utilizados na Victoreen $2800 \mathrm{M}$....................................................... 47

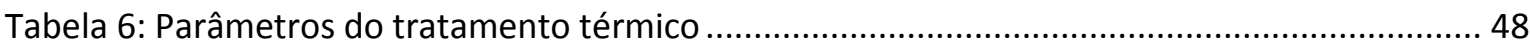

Tabela 7: Composições e seções de choque dos materiais utilizados na modelagem da blindagem

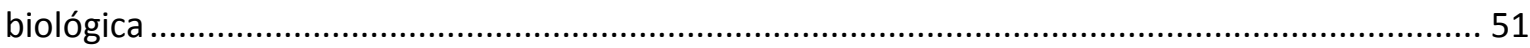

Tabela 8: Composições, seções de choque e cores identificadores do plot ..................................... 52

Tabela 9: Razões $C r / C_{i}$ para os três pontos definidos na blindagem biológica ................................... 61

Tabela 10: Razões $C r / C_{i}$ para os pontos ao redor dos equipamentos do canal seis ......................... 63 